\title{
Aufklärung aktueller tierzüchterischer \\ und verbraucherrelevanter Fragestellungen durch \\ molekulargenetische Strategien
}

\author{
Dissertation \\ zur Erlangung des Doktorgrades \\ der Fakultät für Agrarwissenschaften \\ der Georg-August-Universität Göttingen
}

vorgelegt von

Claudia Floren

geboren in Warburg

Göttingen, Juli 2014 
D7

1. Referent: Prof. Dr. Dr. Bertram Brenig

2. Korreferent: Prof. Dr. Hermann H. Swalve

Tag der mündlichen Prüfung: 18. Juli 2014 
"Everything will be okay in the end. If it's not okay, it's not the end."

(John Lennon) 


\section{Peer-reviewed Publikationen}

Die vorliegende Arbeit basiert auf den hier angegebenen Publikationen und Kongressbeiträgen:

B. Brenig, J. Beck, C. Floren, K. Bornemann-Kolatzki, I. Wiedemann, S. Hennecke, H. Swalve and E. Schütz (2013): Molecular genetics of coat colour variations in White Galloway and White Park cattle. Animal Genetics, 44 (4), 450-453. DOI: 10.1111/age.12029.

H. Swalve*, C. Floren*, M. Wensch-Dorendorf, K. Schöpke, R. Pijl, K. Wimmers and B. Brenig (2014): A study based on records taken at time of hoof trimming reveals a strong association between the IQ motif-containing GTPase-activiating protein 1 (IQGAP1) gene and sole hemorrhage in Holstein cattle. Journal of Dairy Science, 97 (1), 507-519. DOI: 10.3168/jds.2013-6997.

* Both authors contributed equally to the work.

C. Floren, I. Wiedemann, B. Brenig, E. Schütz, J. Beck (2014): Species identification and quantification in meat and meat products using Droplet Digital PCR (ddPCR). Food Chemistry (eingereicht im Februar 2014). 


\section{Kongressbeiträge}

C. Floren, E. Schütz and B. Brenig (2008): Syndactyly in a German Holstein cow - a case report (Poster 2038). XXXI Conference of the International Society for Animal Genetics (ISAG), Amsterdam, 20.-24.07.2008.

C. Floren, E. Schütz und B. Brenig (2008): Molekulargenetische Analyse des bovinen LRP4-Gens bei einer an Syndaktylie erkrankten Holstein-Kuh (Vortrag B13). DGfZ/GfTTagung, Bonn, 17.-18.09.2008.

C. Floren, J. Beck, K. Bornemann-Kolatzki, I. Wiedemann, H. Swalve, S. Hennecke, E. Schütz und B. Brenig (2012): Molekulargenetik der Farbvererbung bei White Galloway (Vortrag A07). DGfZ/GfT-Tagung, Halle/Saale, 12.-13.09.2012.

HH Swalve, C. Floren, M. Wensch-Dorendorf, K. Schöpke, R. Pijl, K. Wimmers and B. Brenig (2013): A designed field study based on records collected at time of hoof trimming reveals a strong association between an individual gene and laminitis in dairy cattle (Vortrag). 17th International Symposium and 9th International Conference on Lameness in Ruminants, Bristol, 11.-14.08.2013.

C. Floren, I. Wiedemann, J. Beck, B. Brenig und E. Schütz (2013): Quantitative Speziesbestimmung mittels droplet digitaler PCR (ddPCR) (Vortrag D6). DGfZ/GfT-Tagung, Göttingen, 04.-05.09.2013. 


\section{Inhaltsverzeichnis}

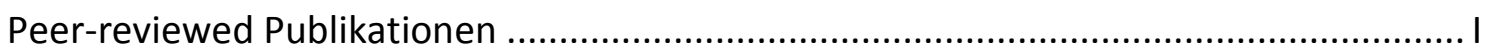

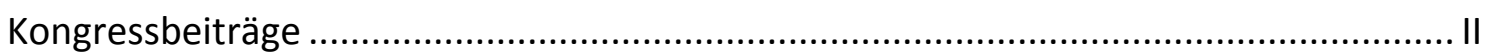

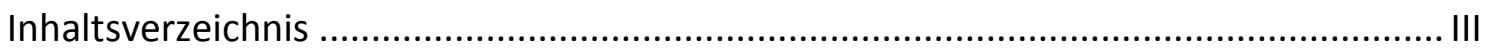

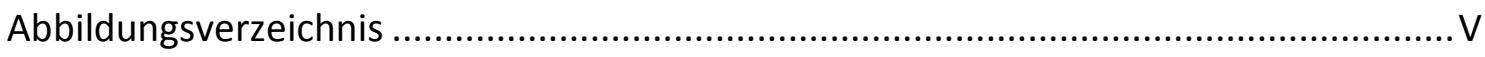

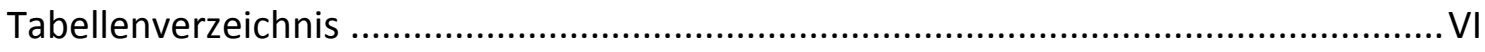

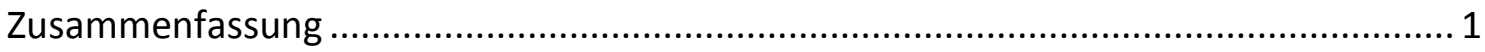

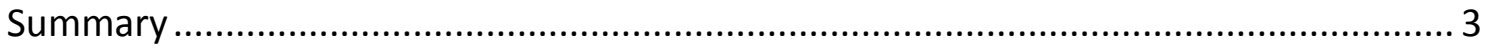

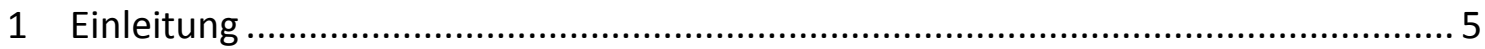

2 Genetische Grundlagen der Klauenrehe und Sohlenhämorrhagien beim Rind ......... 8

2.1 Bedeutung und Verbreitung von Lahmheiten bei Milchkühen ........................... 8

2.2 Krankheitsbild, Ursachen und Entstehung der Klauenrehe bzw.

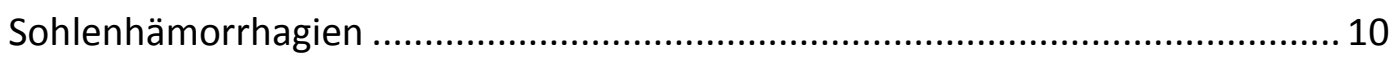

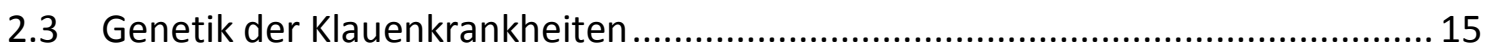

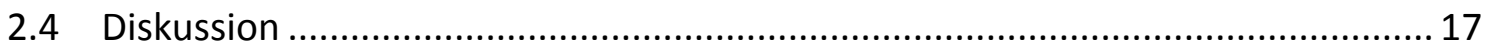

3 Farbvererbung bei White Galloway und White Park ........................................... 25

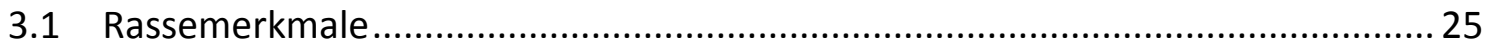

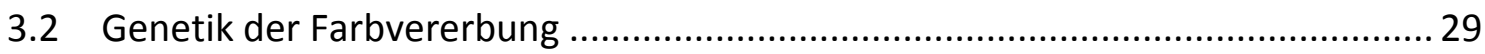

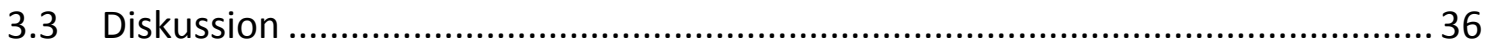

4 Speziesbestimmung in Fleisch und Fleischprodukten ........................................ 41

4.1 Rechtliche Grundlagen und Verfehlungen der Fleischdeklaration....................... 41

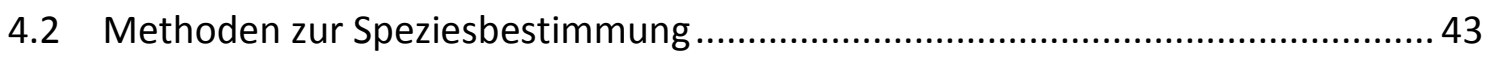

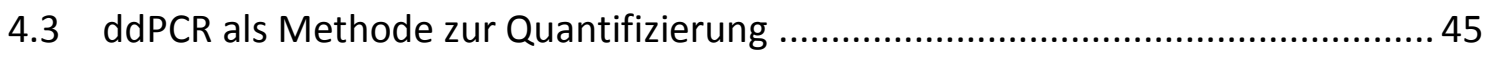

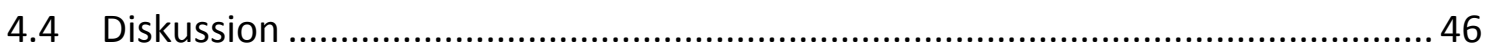


5 Literaturverzeichnis 49

A study based on records taken at time of hoof trimming reveals a strong association between the IQGAP1 gene and sole hemorrhage in Holstein cattle 73

Molecular genetics of coat colour variations in White Galloway and White Park cattle

Species identification and quantification in meat and meat products using Droplet Digital PCR (ddPCR) 125 


\section{Abbildungsverzeichnis}

Abbildung 1: Trend für die Abgangsgründe Unfruchtbarkeit, Eutererkrankheiten und Klauen/Gliedmaßenkrankheiten der letzten 40 Jahre von MLP-Kühen in Deutschland (ADR, 1972-2012).

Abbildung 2: Darstellung der sichtbaren Klauenveränderungen, wie Einblutungen (A) und gelbliches Horn (B) bei subklinischer Klauenrehe (Top Agrar Fachbuch, 2003)

Abbildung 3: White Galloway zeigen vier verschiedene Farbphänotypen: (A) sehr gut markiert, wsg (B) übermarkiert, wsü (C) sehr schwach markiert, wss (D) völlig schwarz, wsch (Mit freundlicher Genehmigung der White Galloway Züchter)

Abbildung 4: White Park zeigen vier verschiedene Farbphänotypen, ähnlich denen der White Galloway: (A) sehr gut markiert, wsg (B) übermarkiert, wsü (C) sehr schwach markiert, wss (D) schwarz, wsch (Mit freundlicher Genehmigung der White Park Züchter). 28

Abbildung 5: Modell zur Entstehung des Cs29 Allels durch Translokation eines zirkulären, das KIT Gen beinhaltenden, 480 kb großen DNA-Segments (modifiziert nach Durkin et al., 2012).

Abbildung 6: Erste Kälber ( $A$ : wsü, $B+C$ : wsg) aus den Anpaarungsversuchen (wss $x$ wsch) im Rahmen des "White Galloway Stars"-Projektes (Mit freundlicher Genehmigung der White Galloway Züchter). 39 


\section{Tabellenverzeichnis}

Tabelle 1: Zusammenstellung einiger Studien aus der Literatur zu geschätzten Heritabilitäten für Laminitis und Sohlenhämorrhagien bei Holstein Friesian Kühen. 15

Tabelle 2: Auswertung der Datenbank des „White Galloway Stars”-Projektes gemäß den Anpaarungen der Elterntiere und deren Nachkommen mit Farbzeichnungen ( $\mathrm{n}=656$ Nachkommen).... 


\section{Zusammenfassung}

Klauenerkrankungen sind die dritthäufigste Abgangsursache bei Milchkühen und $90 \%$ aller Lahmheiten gehen auf verschiedene Erkrankungen der Klauen zurück. Im Rahmen des FUGATO-plus Forschungsprojektes GENE-FL wurden die genetischen Grundlagen der Fundamentstabilität beim Rind, Schwein, Pferd und Schaf untersucht. Für die Untersuchungen beim Rind wurde Probenmaterial von insgesamt 1.962 erstlaktierenden Kühen der Rasse Holstein Friesian gesammelt. Diese stammten von sieben großen Herden aus Mecklenburg-Vorpommern mit vergleichbarem Haltungssystem und TMRFütterung. Der Klauenstatus der Tiere wurde zum Zeitpunkt des Klauenschnitts erfasst. Als Grundlage der molekularbiologischen Untersuchungen wurden anhand von in silico Analysen positionell-funktionelle Kandidatengene mit den assoziierten biochemischen Reaktionswegen für Fundamentmerkmale beim Rind und anderen landwirtschaftlichen Nutztierspezies ausgewählt. Aus den mehr als 1.000 ermittelten Kandidatengenen wurde ein individuell gefertigter SNP-Chip (384 SNP; ein SNP/Gen) erstellt. Mit dem SNP-Chip wurden 1.183 der phänotypisierten Tiere untersucht. Die Schwellenwertmodell-Analyse ergab eine signifikante Assoziation des im IQGAP1 (BTA21) befindlichen intronischen SNP (rs29017173, A/G) mit dem Merkmal Sohlenhämorrhagien. Des Weiteren konnte dieser SNP mit Fundamentmerkmalen der klassischen linearen Exterieurbeurteilung an zusätzlichem Datenmaterial von 2.394 Besamungsbullen der Rasse Holstein Friesian assoziiert werden.

Bei den robusten Fleischrindern White Galloway werden im Bezug auf die Fellfarbe der Tiere vier Phänotypen unterschieden. Neben den drei weißen Fellfarbschlägen, die unterteilt werden in sehr gut markiert (wsg), übermarkiert (wsü) und untermarkiert (wss), gibt es den vollkommen schwarzen Fellfarbtyp (wsch). Als bevorzugte Fellzeichnungen gelten wsg und wsü, während die unerwünschten Zeichnungen wss und wsch sind. Auch bei gezielten Anpaarungen der phänotypisch bevorzugten Tiere kommen die nicht preferierten Farbphänotypen vermehrt vor. Zur Aufklärung des genetischen Hintergrunds der verschiedenen Farbvarianten wurden zunächst vier für die Fellfarbe relevante Gene, mast/stem cell growth factor receptor (KIT, BTA6), KIT ligand (KITLG, BTA5), melanocortin 1 receptor (MC1R, BTA18) und Tyrosinase (TYR, BTA29) verglei- 
chend sequenziert und auf kausale kodierende Sequenzvarianten untersucht. In den potentiellen Kandidatengenen konnten keine Polymorphismen detektiert werden, die die unterschiedlichen Fellzeichnungsvarianten erklären und somit wurde eine Beteiligung dieser Gene ausgeschlossen. Eine kürzlich beim Rind beschriebene KIT Gen Duplikation und Insertion auf BTA29 bzw. Re-Insertion auf BTA6 wurde deshalb mittels Fluoreszenz-in-situ-Hybridisierung (FISH), Whole genome sequencing und Polymerasekettenreaktion (PCR)-basierter Genotypisierung der Insertionsbruchpunkte an 178 White Galloway und 64 White Park Tieren untersucht. In allen Fällen konnten die FellfarbPhänotypen auf die Duplikation und Insertion des KIT Gens auf BTA29 zurückgeführt werden.

Lebensmittelskandale werden in regelmäßigen Abständen aus mehreren Ländern berichtet. Im Jahr 2013 wurden Fertigprodukte mit undeklarierten Pferdefleischbeimischungen entdeckt. Eine genaue Quantifizierung der zugesetzten undeklarierten Menge war bisher nicht verlässlich möglich. Mit der droplet digitalen PCR (ddPCR) wurden im Rahmen dieser Arbeit Testsysteme zum Nachweis entwickelt. Als Zielgene wurden das mitochondriale CYTB und das chromosomale F2 verwendet. Für die Etablierung des Verfahrens wurden als Gewebe zunächst Muskel, Fett, Sehne und Leber verwendet. Während sich in diesen Geweben die Anzahl der mtDNA-Kopien pro Zelle etwa um den Faktor 5 unterschied, war der Gehalt nukleärer DNA nahezu konstant. Ausgehend von den Spezies Rind, Schwein und Pferd wurden verschiedene DNA- und Fleischmischungen hergestellt, wobei der prozentuale Anteil der beigemischten Spezies zwischen $50 \%$ bis 0,001 \% variierte. Mit dem F2-basierten Testsystem wurde eine zuverlässige Quantifizierung (LOQ) bzw. Detektion (LOD) von Beimengungen von nur 0,01 \% bzw. 0,001 \% erreicht. 


\section{Summary}

Claw diseases and disorders are the third leading reason for dairy cows leaving the herds and $90 \%$ of lameness cases are due to various claw diseases. As part of the FUGATO-plus GENE-FL project, the genetic causes of a pre-disposition for ailments of the feet and leg system in cattle, pigs, horses, and sheep were examined. For the investigations in cattle, samples from a total of 1.962 first-lactation Holstein Friesian cows were collected from seven high-producing commercial dairy herds from Mecklenburg-Western Pomerania with similar loose-housing systems and TMR feeding. The disorder status of the claws was recorded at time of trimming. As the basis of molecular biological investigations, positional and functional candidate genes with their associated biochemical pathways were determined by in silico analyses for conformation traits in cattle and other livestock species. A custom-made SNP-chip was developed from more than 1.000 ascertained candidate genes (384 SNP; 1 SNP/Gen). In total 1.183 cows were analyzed with this SNP-chip. A mixed threshold model analysis revealed a significant association between an intronic SNP (rs29017173, A/G) in IQGAP1 (BTA21) and sole hemorrhage status. This SNP also showed a significant association with breeding values for feet and leg conformation traits in a cohort of 2.394 A.I. bulls (Holstein Friesian).

The beef cattle breed White Galloway exhibits four different coat colour phenotypes, well-marked (wsg), strongly marked (wsü), mismarked (wss), and fully black (wsch). The preferred phenotypes are well-marked and strongly marked. Mating of wellmarked or strongly marked animals resulted in a certain percentage of mismarked or fully black animals. To elucidate the genetic background of the coat colour variations in White Galloway cattle, the four coat colour relevant genes mast/stem cell growth factor receptor $(K I T)$, KIT ligand $(K I T L G)$, melanocortin 1 receptor $(M C 1 R)$ and tyrosinase (TYR) were sequenced and analysed for causal coding sequence variants. No polymorphisms were detected in the potentially candidate genes, which explain the different coat colour variations. Due to these results, the genes were excluded as candidate genes. A recently described KIT gene duplication and aberrant insertion on BTA29 and/or re-insertion on BTA6 were analysed by Fluorescence in situ hybridisation (FISH), whole- 
genome sequencing, and PCR-based genotyping of the insertion break points in 178 White Galloway and 64 White Park cattle. In all cases, the coat colour variations of the two breeds can be explained by the recently described duplication and aberrant insertion of the KIT gene on chromosome 29.

Food scandals have been reported from several countries repeatedly. In 2013, undeclared horsemeat was detected in convenience products. A precise quantification of the added undeclared species could not be determined reliably until now. As part of this study a method based on droplet digital PCR (ddPCR) was developed. The mitochondrial CYTB gene and the nuclear F2 gene were used as targets. For the initial establishment of the method muscle, fat, tendon, and liver samples were used. While the number of mtDNA copies per cell differed up to 5 fold in these tissues, the nuclear DNA content was almost constant. Using various DNA- and meat mixtures of cattle, pig, and horse ( $50 \%$ to $0.001 \%$ ) specificity and sensitivity of the method was analysed. A reliable quantification (LOQ) and detection (LOD) of admixtures of $0.01 \%$ and $0.001 \%$ was achieved using $F 2$ as target, respectively. 


\section{Einleitung}

Die Tiergesundheit zählt in der Nutztierzüchtung zu den wichtigsten Merkmalskomplexen (Bishop et al., 2002). Langlebigkeit und Nutzungsdauer der Tiere sind für den Landwirt von großem Interesse und die Verbesserung von Gesundheit und Funktionalität rückt immer mehr in den Fokus der Zucht. Erkrankungen der Klauen gehören, neben Unfruchtbarkeit und Eutererkrankungen, aktuell zu den bedeutendsten Problemen bei Hochleistungskühen und stellen die dritthäufigsten Abgangsursachen dar (ADR, 1972-2012). Neben hohen ökonomischen Verlusten durch beeinträchtigte Milchleistung und Fruchtbarkeit, verkürzte Nutzungsdauer und hohe Behandlungskosten spielen diese Erkrankungen auch aus Sicht des Tierschutzes eine wesentliche Rolle, da das Allgemeinbefinden der Kühe, bedingt durch die mit den Erkrankungen einhergehenden Schmerzen, erheblich beeinflusst wird. Die Klauenrehe ist die bedeutendste Erkrankung der Klauen bei Milchkühen und Sohlenhämorrhagien gelten mitunter als Indikator für diese Erkrankung. Sie ist ein wichtiger prädisponierender Faktor für viele andere Klauenerkrankungen, und aufgrund der multifaktoriellen Ätiologie schwierig zu erfassen. Neben der Fütterung, Haltung und Hygiene werden vor allem die Geburt und die peripartalen Stoffwechselumstellungen, Laktation, Alter und auch die Genetik als prädisponierende Faktoren in der Literatur diskutiert (Lischer \& Ossent, 1994; Mülling \& Lischer, 2002). Die Heritabilitäten für Klauenerkrankungen sind eher gering, trotzdem ist die züchterische Bearbeitung durchaus möglich (König et al., 2005). Bisher wurden weder für Laminitis noch für andere Klauenerkrankungen des Rindes molekularbiologische Untersuchungen durchgeführt, um Gene oder SNP, die mit der Ausprägung der einzelnen Erkrankungen assoziiert sind, zu identifizieren. Gegenstand des ersten Teils der vorliegenden Arbeit war daher, die genetische Prädisposition für Sohlenhämorrhagien als Indikator für Laminitis zu untersuchen. Dazu wurde anhand validierter SNP aus zuvor ausgewählten funktionell-positionellen Kandidatengenen ein custom-made SNPChip entwickelt und damit 1.183 erstlaktierende Milchkühe untersucht. Ziel dieser Studie war die Identifizierung relevanter Gene, die an der Entstehung von Sohlenhämorrhagien beteiligt sind und die Bestimmung assoziierter SNP-Marker, die für die Selektion zur Verbesserung der Klauengesundheit genutzt werden können. 
Für den Landwirt oder Tierzüchter tragen neben den Leistungsmerkmalen eines Tieres auch funktionale Merkmale wie z. B. Exterieur, Gesundheit und Fruchtbarkeit zur Wirtschaftlichkeit bei. Darüber hinaus kann die Ausprägung eines Rassemerkmals, wie zum Beispiel der Farbphänotyp, die Vitalität oder das Temperament, über die Vermarktbarkeit eines Tieres entscheiden. Bei der Rinderrasse Galloway gibt es mehrere Farbschläge, einfarbig schwarz, rot oder blond und die markierten Farbvarianten belted, riggit oder white (Bundesverband deutscher Gallowayzüchter e. V.). Die White Galloway zeigen die vier verschiedenen Phänotypen sehr gut markiert, übermarkiert, sehr schwach markiert und völlig schwarz (Brenig et al., 2013). Neben der Zucht auf typvolle, bemuskelte Tiere mit gutem Interieur ist auch der Farbphänotyp für den Züchter wichtig. Der gewünschte Phänotyp bei White Galloway zeigt die Grundfarbe weiß mit schwarz markierten Ohren, Augen, Flotzmaul und Füßen. Die gezielte Zucht auf diesen Phänotyp war bisher nicht möglich, da bei Anpaarungen auch schwach markierte und völlig schwarze Nachkommen entstanden (Brenig et al., 2013). Im zweiten Teil der Arbeit wurde die Farbvererbung der White Galloway untersucht. Dazu wurden sowohl die molekularbiologischen Methoden der PCR, der Genomsequenzierung und der Insertionsbruchpunkt-Genotypisierung, als auch die zytologische Methode der FISH verwendet. Ziel dieser Studie war, den Vererbungsmodus aufzuklären, der die vier unterschiedlichen Farbphänotypen bedingt und beteiligte Gene bzw. ursächliche Mutationen zu identifizieren.

Für den Konsumenten von Fleisch oder Fleischprodukten ist die Zusammensetzung dieser Erzeugnisse, speziell die Tierartzugehörigkeit des Fleisches, sowohl aufgrund des Verbraucherschutzes als auch z. B. hinsichtlich religiöser Vorgaben oder gesundheitlicher Aspekte von besonderem Interesse. In den zurückliegenden Jahren ist das Vertrauen der Verbraucher in die Unbedenklichkeit der Deklaration von Nahrungsmitteln, u. a. aus tierischer Erzeugung, durch mehrere Verfehlungen und Irreführungen wie z. B. den „Gammel- oder Pferdefleischskandal“ stark erschüttert worden. Die sich häufenden Meldungen über kontaminierte und falsch deklarierte Lebensmittel führen dazu, dass die Überwachung der Lebensmittelproduktion vermehrt ins Interesse der Öffentlichkeit rückt. Die bisherigen quantitativen Methoden der Lebensmittelanalytik bezüglich der Tierartenidentifikation in fleischhaltigen Lebensmitteln basieren zumeist 
auf dem Nachweis von spezies-spezifischer DNA mittels real-time PCR. Jedoch ist hierbei die Spezifität und Sensitivität aufgrund verschiedener Kriterien eingeschränkt, was zu ungenauen Ergebnissen führt. Die Aufgabe im dritten Teil dieser Arbeit war die Entwicklung eines Testsystems, welches auf der ddPCR und dem nukleären F2 Gen basiert. Dieses soll zur quantitativen Bestimmung des Anteils unterschiedlicher Spezies in Fleisch und Fleischprodukten genutzt werden und stellt eine sehr genaue und fortschrittliche Methode dar, die zur routinemäßigen Qualitätskontrolle eingesetzt werden kann. 


\section{Genetische Grundlagen der Klauenrehe und Sohlenhämorrhagien beim Rind}

\subsection{Bedeutung und Verbreitung von Lahmheiten bei Milchkühen}

Die Leistungsansprüche an die Milchkuh, insbesondere in Bezug auf die Milchmenge, sind weltweit in den letzten Jahren rasant angestiegen. Einhergehend mit dem hohen Leistungsniveau treten aber auch eine verminderte Fruchtbarkeit und vermehrte Klauen- und Gliedmaßenerkrankungen auf. Die optimal auf die Bedürfnisse der Tiere abgestimmte Fütterung und ein Haltungssystem mit entsprechendem Kuhkomfort sind ein entscheidender Faktor für die hohe Leistung der Tiere (Fiedler \& Maierl, 2004).

Klauen- und Gliedmaßenerkrankungen gehören zu den bedeutendsten Problemen in der heutigen Milchviehhaltung. Als Abgangsursache bei Milchkühen in Deutschland lagen diese 1972 bei 2,8 \%, 1984 bei 4,5\%, 2004 bei 9,2\% und bis zum Jahre 2012 sind sie bereits auf $11 \%$ angestiegen (ADR, 1972-2012). Aktuell liegen sie damit an dritter Stelle der häufigsten Abgangsursachen nach Unfruchtbarkeit (21,1\%) und Euterkrankheiten (14,9 \%) (ADR, 1972-2012). Aus Abb. 1 geht hervor, dass in den letzten Jahrzehnten die Euter- und Klauengesundheit stetig schlechter geworden ist. Die Abgänge aufgrund von Unfruchtbarkeit dagegen sind bis ins Jahr 2000 rückläufig, allerdings ist seit den letzten 10 Jahren keine Verbesserung mehr zu verzeichnen.

Vergleichend dazu sind in den USA für das Jahr 2012 Abgänge aufgrund von Problemen der Klauen, Beine oder Lahmheit mit 5 \% angegeben (CDCB, 2012). Ähnlich ist es in Kanada, wo die Abgangsursachen der Milchkühe aufgrund von Klauenerkrankungen bei 6,3 \% liegen (CDIC, 2007-2012).

Klauenerkrankungen führen zu hohen ökonomischen Verlusten aufgrund einer verkürzten Nutzungsdauer (Booth et al., 2004; Sogstad et al., 2007), vermehrten veterinärmedizinischen Behandlungen, sowie verminderter Milch- und Fruchtbarkeitsleistung (Green et al., 2002; Sogstad et al., 2006; Amory et al., 2008). 


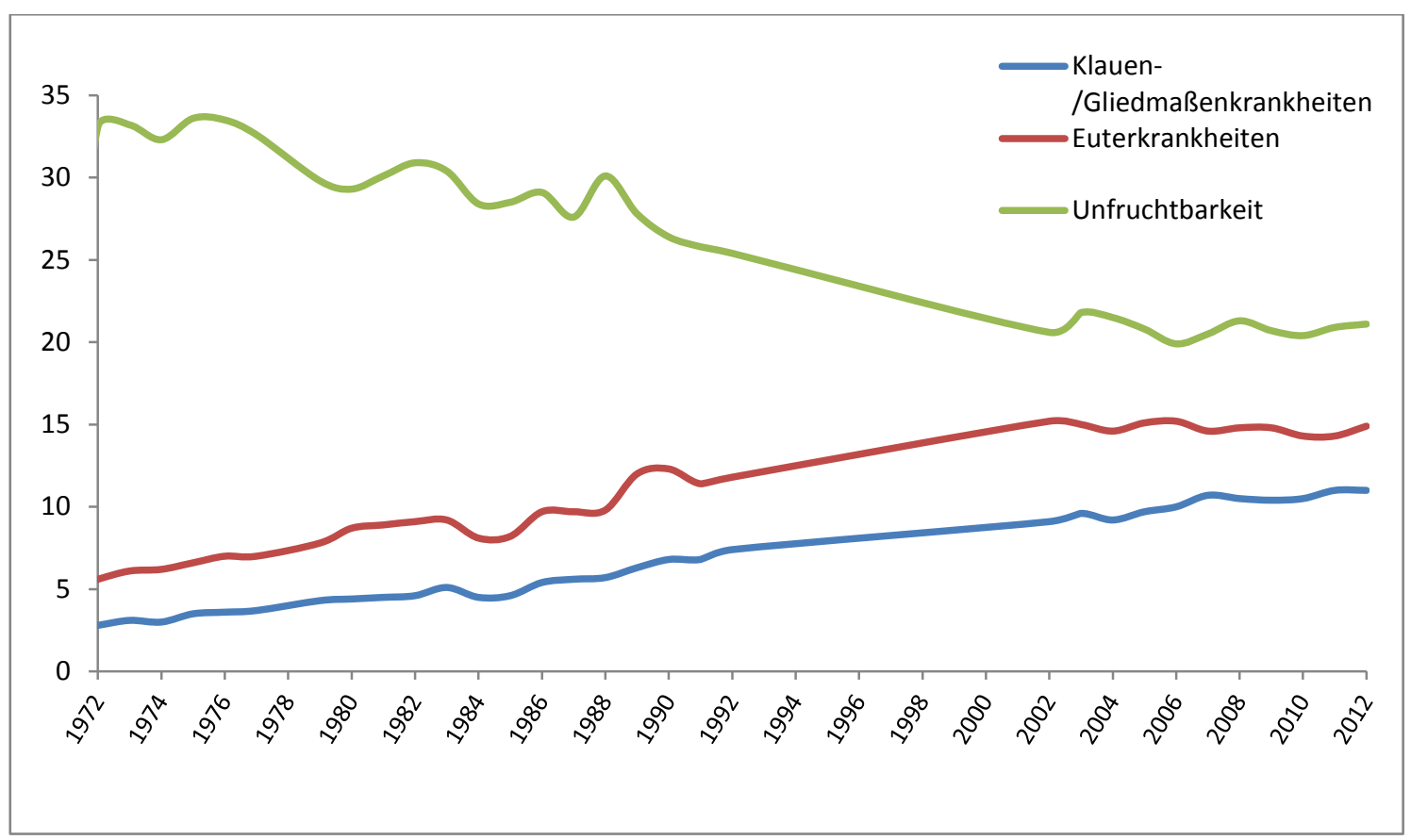

Abbildung 1: Trend für die Abgangsgründe Unfruchtbarkeit, Eutererkrankheiten und Klauen/Gliedmaßenkrankheiten der letzten 40 Jahre von MLP-Kühen in Deutschland (ADR, 1972-2012).

Kalkulationen für die durchschnittlichen Gesamtkosten pro Lahmheitsfall bzw. Klauenerkrankung liegen bei 55-192 Euro (Enting et al., 1997; Ettema \& Ostergaard, 2006; Bruijnis et al., 2010). Kossaibati und Esslemont (2000) beziffern die offensichtlichen und verborgenen Kosten allein für eine Laminitiserkrankung sogar bis zu 250 Euro je Kuh und Erkrankung (Kossaibati \& Esslemont, 2000). Die für die EU ermittelten Kosten und Verluste, die aufgrund von Lahmheiten entstehen, liegen bei einer Milliarde Euro (Benz, 2003).

Neben den betriebswirtschaftlichen Verlusten sind die Erkrankungen auch aus Sicht des Tierschutzes relevant, da die betroffenen Kühe über längere Zeit ein beeinträchtigtes Wohlbefinden zeigen. Dieses zeigt sich an verändertem Verhalten, wobei bei lahmen Kühen signifikant längere Liegezeiten pro Tag, reduzierte Bewegungsaktivität und abnorme Haltungen beobachtet wurden (Singh et al., 1993). In 90 \% der Fälle werden Lahmheiten durch Erkrankungen an der Klaue oder der umliegenden Haut verursacht, wobei 92 \% aller diagnostizierten Klauenleiden die Hintergliedmaßen betreffen (Vermunt, 1992; Vermunt \& Greenough, 1994; Clarkson et al., 1996; Murray et al., 1996; Shearer, 1998; Mülling \& Lischer, 2002). Die Hauptgründe hierfür sind die Gewichtsverteilung, die gerade während der Laktation vermehrt auf den hinteren Glied- 
maßen liegt und die höhere Belastung auf diese, wenn die Tiere mit ihren Vorderbeinen in der Liegebox stehen, die Hinterbeine sich aber auf dem Spaltenboden befinden. In niederländischen Studien wird berichtet, dass bei mindestens $70 \%$ der Kühe eines Bestandes jährlich mindestens eine Erkrankung an den Klauen auftritt (Somers et al., 2003; van der Waaij et al., 2005).

\subsection{Krankheitsbild, Ursachen und Entstehung der Klauenrehe bzw. Sohlen- hämorrhagien}

In den großen Milchviehbetrieben werden die Kühe zumeist ganzjährig im Stall gehalten (Fiedler \& Maierl, 2004). Da die Kuh von Natur aus ein Weichbodenläufer ist, geht von harten Böden ein großer Effekt auf die Klauengesundheit der Tiere aus. Dazu kommt die hohe Milchleistung, die nur mit sehr gutem Management realisiert werden kann. Die Gründe für vermehrt auftretende Klauenerkrankungen bei Milchkühen in intensiver Haltung sind nicht monokausal, sondern meist durch das Zusammenwirken verschiedener Faktoren wie Haltung, Management und Fütterung bedingt (Mülling \& Lischer, 2002).

Die am häufigsten vorkommende Klauenerkrankung ist die Klauenrehe (Laminitis). Sie tritt mit einer Prävalenz von >30 \% auf (van der Waaij et al., 2005; Swalve et al., 2008; van der Linde et al., 2010; Nielsen et al., 2013). Die nicht bakterielle Entzündung der Klauenlederhaut (Pododermatitis aseptica diffusa) wird aufgrund der Ausprägung der klinischen Symptome und sichtbaren Veränderungen an der Klaue in eine akute, subakute, chronische und chronisch-rezidivierende Form eingeteilt. Abgesehen von den klinischen Stadien wird auch eine subklinische Form beschrieben, die nicht mit einer Lahmheit einhergeht (Lischer \& Ossent, 1994; Vermunt \& Greenough, 1994). Alle Formen der Klauenrehe können zur chronisch oder chronisch-rezidivierenden Rehe führen (Nuss \& Steiner, 2004). Sowohl die subklinischen als auch die klinischen Stadien der Klauenrehe werden als Primärursache für die Entstehung von Lahmheiten und weiteren Klauenerkrankungen angesehen. Dazu zählen Weiße Linie Defekte, Doppelsohlenbildung, Ballenhornerosion, Ballenfäule und Sohlengeschwüre (Greenough \& Vermunt, 1991; Lischer \& Ossent, 1994; Mülling \& Lischer, 2002; Bergsten, 2003; Mülling, 2007). 
Die akute Form der Rehe tritt beim Rind verhältnismäßig selten auf und zeigt sich durch hochgradige Lahmheit, gekrümmten Rücken und nur sehr vorsichtige Bewegung (Mülling \& Lischer, 2002). An der Klaue sind neben Wärme und erhöhter Pulsation keine sichtbaren Veränderungen wahrnehmbar (Mülling \& Lischer, 2002).

Die häufiger auftretende subakute und chronische Form der Klauenrehe kann in Milchviehbetrieben zu einem schwerwiegenden Herdenproblem werden (Lischer \& Ossent, 1994). Im subakuten Stadium kommen Blutungen im Sohlenhorn und der weißen Linie sowie weiches, gelbliches Horn vor, was ein Anzeichen für eine schon mehrere Tage andauernde Krankheit ist. Die chronische Rehe entwickelt sich über einen längeren Zeitraum und ist vor allem an den charakteristischen Verformungen (Rinnenbildungen, konkave Auskehlung der Vorderwand) der Klauen zu erkennen, während systemische Symptome fehlen (Lischer \& Ossent, 1994; Vermunt \& Greenough, 1994; Mülling \& Lischer, 2002).

Am häufigsten tritt beim Milchrind die subklinische Form der Klauenrehe auf (Peterse, 1979; Greenough \& Vermunt, 1991; Vermunt \& Greenough, 1994), die von Peterse et al. (1979) erstmalig beschrieben wurde (Peterse, 1979). Hierbei treten zum Zeitpunkt der pathophysiologischen Veränderungen keine klinischen Symptome auf, jedoch fällt das Horn durch Farb- und Konsistenzveränderungen auf (Vermunt \& Greenough, 1994). Läsionen in den Lederhautgefäßen führen zu Einlagerungen von Blut bzw. Blutbestandteilen. Diese Hämorrhagien sind erst nach zwei bis drei Monaten sichtbar, was bedeutet, dass die subklinische Klauenrehe erst mit einer erheblichen Zeitverzögerung diagnostiziert werden kann (Maclean, 1971; Bradley et al., 1989; Lischer \& Ossent, 1994). Das Horn der betroffenen Klauen wird weicher, zeigt eine gelbliche Verfärbung und oftmals Hämorrhagien (Abb. 2). Diese sind speziell in den belasteten Oberflächen der Klaue, wie der weißen Linie, der Sohlenspitze, sowie in den axialen Seiten der Sohlen-Ballen-Verbindung zu finden (Greenough \& Vermunt, 1991; Vermunt \& Greenough, 1994). Aus den genannten Gründen wurden Sohlenhämorrhagien schon sehr früh als wichtiger Hinweis auf Laminitis angesehen (Nilsson, 1963; ToussaintRaven, 1973; Andersson \& Bergman, 1980) und deshalb auch als Indikator für diese Krankheit betrachtet (Greenough \& Vermunt, 1991; Bergsten, 1994; Bergsten \& Frank, 1996b, 1996a; van der Waaij et al., 2005). 

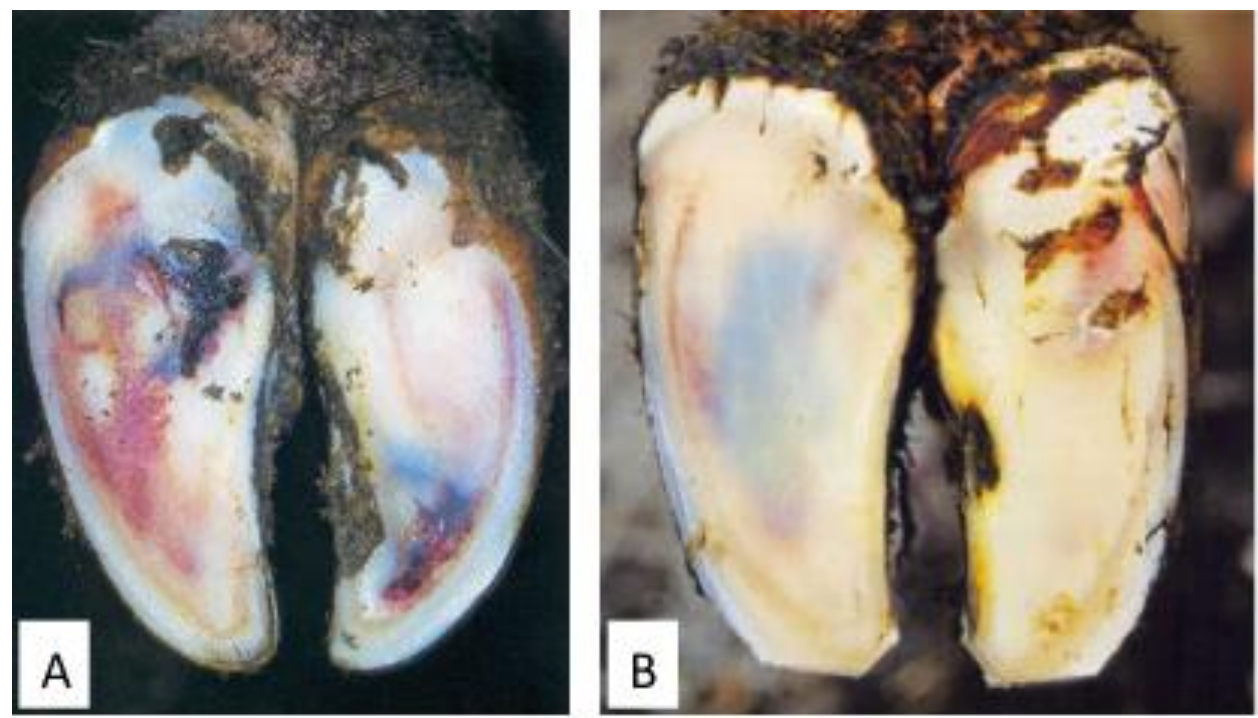

Abbildung 2: Darstellung der sichtbaren Klauenveränderungen, wie Einblutungen (A) und gelbliches Horn (B) bei subklinischer Klauenrehe (Top Agrar Fachbuch, 2003).

Bei mehr als $80 \%$ der Kühe in unterschiedlichen Laktationsstadien treten vorwiegend milde Hämorrhagien an mindestens einer der acht Hauptklauen auf. Die hinteren Außenklauen sind hiervon am meisten betroffen (Murray et al., 1996). Färsen sind häufiger von mit Laminitis zusammenhängenden Läsionen der Klauen betroffen als mehrfach abgekalbte Kühe (Bergsten, 1994; Sogstad et al., 2005; Nielsen et al., 2013).

Die Ätiologie der Klauenrehe ist aufgrund der Vielzahl unterschiedlichster Faktoren äußerst schwierig und bis heute nicht hinreichend geklärt. Über die Bedeutung der einzelnen Faktoren bestehen verschiedene Ansichten in der Literatur (Boosman et al., 1991; Lischer \& Ossent, 1994; Nocek, 1997; Mülling \& Lischer, 2002). Allerdings wird übereinstimmend beschrieben, dass es sich bei der Klauenrehe um eine systemische Erkrankung multifaktoriellen Ursprungs handelt, welche sich in den Klauen manifestiert. Sie kann allerdings auch ausschließlich durch mechanische Faktoren ausgelöst werden. In der Mehrzahl gelten aber die Fütterung, das Haltungssystem und der physiologische Zustand des Rindes (Trächtigkeit, Geburt bzw. peripartaler Zeitraum, Laktationsstadium, Alter und Verhalten) als wichtige Risikofaktoren, sowie vorausgegangene Erkrankungen, die Jahreszeit und genetische Komponenten (Maclean, 1971; Greenough \& Vermunt, 1991; Lischer \& Ossent, 1994; Vermunt \& Greenough, 1994; Nocek, 1997; Bergsten, 2003). Zu den weiteren Faktoren zählen bezüglich des Managements eines Betriebes der Kuhkomfort, die Hygiene, die soziale Integration der Fär- 
sen und Trockensteher sowie die Klauenpflege (Mülling et al., 2006). Tiere in der präund postpartalen Periode sind besonders gefährdet, denn mehr als $50 \%$ der Rehefälle werden in diesem Zeitraum diagnostiziert (Lischer \& Ossent, 1994). Überwiegend treten die Hämorrhagien während der ersten sechs Monate der Laktation auf (van der Waaij et al., 2005). Bei peripartalen Stoffwechselumstellungen von rohfaserreicher Trockensteherfütterung zu intensiver Kraftfutterfütterung kann es zur Entstehung einer subklinischen Pansenazidose kommen, die als Grund für Klauenrehe angesehen wird (Peterse, 1979; Vermunt \& Greenough, 1994; Nocek, 1997). Jedoch wird dies in der Literatur kontrovers diskutiert (Brandejsky et al., 1994; Momcilovic et al., 2000; Donovan et al., 2004; Lean et al., 2013), da in einigen Versuchen kein Zusammenhang zwischen Pansenazidose und Klauenrehe nachweisbar war und Azidose und Laminitis auch unabhängig voneinander auftreten können. Vasoaktive Substanzen, wie Histamin, Tyramin, Milchsäure, Serotonin und Endotoxine, die aufgrund von Azidose und Systemerkrankungen im Gastrointestinaltrakt produziert werden, beeinflussen die Gefäßdurchblutung der Zehen. Die Klauenrehe kann sich somit durch die Schäden der Gefäßstrukturen der Lederhaut manifestieren. Häufige Krankheiten der Hochleistungskühe, bei denen die genannten vasoaktiven Substanzen produziert werden, sind neben Pansenazidose auch Mastitis und Metritis (Lean et al., 2013). Außerdem werden Euterödeme, Nachgeburtsverhalten sowie Labmagenverlagerungen als Faktoren zur Entstehung postuliert (Lischer \& Ossent, 1994). Die heutige Auffassung ist, dass es durch das Zusammenspiel der vielen prädisponierenden Faktoren sowohl zur Störung der physiologischen Zelldifferenzierung und Hornbildung in der Dermis, als auch zu einer Veränderung der vaskulären Reaktivität und Mikrozirkulation kommt (Mülling \& Lischer, 2002).

Die genauen Prozesse der Pathogenese sind bisher noch nicht hinreichend geklärt. Die gängige Erklärung zu den Prozessen der Entstehung lässt sich laut Ossent \& Lischer (1998) in drei Phasen abgrenzen: Phase 1: Störungen im Lederhaut-Gefäßsystem und Lösung der dermal-epidermalen Verbindung, Phase 2: Absinken des Klauenbeins und Kompression von Sohlen- und Ballenlederhaut und Phase 3: Bildung von Läsionen in der Hornkapsel (Einblutungen, weiches, gelbes Horn, Deformation der Hornkapsel, doppelte Sohle) (Ossent \& Lischer, 1998). Zur Aufklärung der biologischen Prozesse haben Tølbøll et al. (2012) durch Flüssigkeitschromatographie mit Tandem- 
Massenspektrometrie (LC-MS/MS) Untersuchungen an unterschiedlichen Klauengeweben durchgeführt und 316 Proteine identifiziert, die potentiell aufgrund ihrer Zellfunktionen und biologischen Prozesse in die Pathogenese der subklinischen Klauenrehe involviert sein können. Weitere Studien müssen folgen, in denen krankheitsspezifische Unterschiede in der Proteinexpression untersucht werden, um die bisher ungeklärten Mechanismen und relevanten Biomarker zu charakterisieren (Tølbøll et al., 2012).

Unterschiedliche Autoren betonen, dass die Klauenrehe nicht im Sinne einer klassischen Entzündung abläuft und der Begriff Laminitis deshalb nur noch sehr eingeschränkt verwendet und dessen Korrektheit infrage gestellt wird. Die genaue Lokalisation des pathologischen Geschehens in der Rinderklaue ist nicht nur in den Lamellen der Wandlederhaut angesiedelt wie beim Pferd, sondern auch das Sohlen- und Ballensegment des Koriums sind betroffen (Vermunt, 1992; Lischer \& Ossent, 1994; Mülling \& Lischer, 2002). Die Veränderungen bei der subklinischen Rehe sind eher degenerativ als entzündlich. Aufgrund dessen wird der Begriff Laminitis auch im Zusammenhang mit dieser Form diskutiert und diese Erkrankung vermehrt auch als „Claw horn disruption“ (CHD) bezeichnet (Shearer, 1998; Hoblet \& Weiss, 2001; Le Fevre et al., 2001; Vermunt, 2007; Machado et al., 2010).

Oftmals wird die Klauenrehe vom Rind mit der Hufrehe des Pferdes verglichen und wechselseitig als Modell zur Erforschung der jeweils anderen Spezies genutzt. Die intensive Erforschung bezüglich der Zusammenhänge zwischen systemischen Erkrankungen, vor allem Stoffwechselstörungen, und Veränderungen im Huf, legen nahe, dass mehr Gemeinsamkeiten zwischen der Reheerkrankung der beiden Spezies bestehen als in den letzten 10-20 Jahren angenommen. Bei beiden Spezies ist es eine systemische Erkrankung, welche sich lokal im Zehenendorgan manifestiert, dort Schäden verursacht und gravierende Folgen für das Zehenendorgan und das Tier hat. Die klinischen Symptome und der Grad der Lahmheit werden durch die Art und das Ausmaß der lokalen Gewebeschäden in Klaue bzw. Huf bestimmt. Hinsichtlich der Pathomorphologie unterscheiden sich die beiden Spezies. Beim Rind werden in der Klaue Kollagenabbau und chronische $\mathrm{Ab}$ - und Umbauprozesse im Klauenbeinträger beschrieben, und beim Pferd stehen entzündliche Veränderungen im Vordergrund, sowie Nekrosen und Gewebeseperationen (Mülling, 2011). 


\subsection{Genetik der Klauenkrankheiten}

Ein genetischer Einfluss auf die Entwicklung einer Klauenrehe und die damit einhergehenden Klauenerkrankungen wird von vielen Autoren diskutiert (Lischer \& Ossent, 1994; Vermunt \& Greenough, 1994; Mülling \& Lischer, 2002). Eine direkte züchterische Bearbeitung einzelner Klauenkrankheiten ist möglich, da ausreichend additivgenetische Unterschiede (Varianz) vorhanden sind (König et al., 2005; Swalve et al., 2005; van der Waaij et al., 2005; van der Linde et al., 2010). Klauenerkrankungen besitzen, wie viele andere Gesundheitsmerkmale, nur eine geringe bis moderate Erblichkeit. Heritabilitäten $\left(\mathrm{h}^{2}\right)$ wurden in zahlreichen Studien auf der Basis unterschiedlicher Modelle und Betrachtungen unter anderem für Sohlenhämorrhagien, Sohlengeschwüre, Weiße Linien Defekte, Laminitis, Tylom, Dermatitis digitalis und interdigitalis nachgewiesen und lagen im Bereich von 0,01-0,17 (König et al., 2005; Harder et al., 2006; Swalve et al., 2008; Laursen et al., 2009; Johansson et al., 2011; Gernand et al., 2012; Chapinal et al., 2013; Odegard et al., 2013; van der Spek et al., 2013; Weber et al., 2013).

Die geschätzten Heritabilitäten für Laminitis und Sohlenhämorrhagien liegen zwischen 0,04 und 0,17 (Tab. 1). Schöpke et al. (2013) konnten in einer Studie für Laminitis bzw. Sohlenhämorrhagien eine Heritabilität von 0,09 ermitteln (Schöpke et al., 2013) und damit vergleichbare Studien an niederländischen Populationen bestätigen (van der Waaij et al., 2005; van der Linde et al., 2010).

Tabelle 1: Zusammenstellung einiger Studien aus der Literatur zu geschätzten Heritabilitäten für Laminitis und Sohlenhämorrhagien bei Holstein Friesian Kühen

\begin{tabular}{llll}
\hline Merkmal & $\begin{array}{l}\text { Heritabilität } \\
\left(\mathrm{h}^{2}\right)\end{array}$ & Modell & Autor \\
\hline Laminitis & 0,14 & Schwellenwertmodell & König \& Swalve, 2006 \\
& 0,13 & Lineares Modell & Swalve et al., 2008 \\
& 0,17 & Schwellenwertmodell & \\
& $0,10-0,12$ & Schwellenwertmodell & König et al., 2008 \\
& 0,06 & Schwellenwertmodell & Gernand et al., 2012 \\
\hline Sohlenhämorrhagien & 0,08 & Schwellenwertmodell & v. d. Waaij et al., 2005 \\
& 0,06 & Lineares Modell & v. d. Linde et al., 2010 \\
& 0,04 & Lineares Modell & Johansson et al., 2011 \\
& 0,08 & Schwellenwertmodell & Schöpke et al., 2013 \\
\hline
\end{tabular}


Diese etwas höheren Schätzwerte von Swalve et al. (2008) könnten dadurch begründet sein, dass wiederholte Leistungen, Kühe verschiedener Paritäten und ein nur von einer Person erhobenes, umfangreiches Datenmaterial zur Berechnung genutzt wurden (Swalve et al., 2008).

Genetische Korrelationen zwischen Klauenerkrankungen und Exterieurmerkmalen des Fundaments wurden von vielen Autoren untersucht und beschrieben. Dabei zeigten einige Studien deutliche genetische Korrelationen (König et al., 2005; van der Waaij et al., 2005), wobei andere schlussfolgerten, dass die genetischen Korrelationen eher gering sind (Swalve et al., 2008; Uggla et al., 2008). König und Swalve (2006) konnten in ihren Studien eine deutlich positive genetische Korrelation zwischen Laminitis und Hinterbeinstellung $(0,39)$ bzw. Sprunggelenk $(0,41)$ feststellen, die besagt, dass Bullen mit wenig kranken Töchtern auch bessere Sprunggelenksqualität und parallele Hinterbeinstellung vererben. Die genetische Korrelation zwischen Laminitis und den Klauenmaßen zeigt nur eine schwach ausgeprägte Tendenz, wobei weniger Laminitisbefunde zu erwarten sind, wenn die Väter höhere Trachtenmaße und härtere Klauen aufwiesen (König \& Swalve, 2006). Van der Linde et al. (2010) konnten geringe bis moderate Korrelationen nachweisen und definierten Exterieurmerkmale als nützlichen Indikator für Klauengesundheit. Allerdings können diese Gesundheitsmerkmale, aufgrund der geringeren Selektion bei ausschließlicher Nutzung der Exterieurmerkmale, die Indexmerkmale nicht ersetzen (van der Linde et al., 2010).

Genetische Korrelationen zwischen den Klauenerkrankungen wurden unter anderem von Swalve et al. (2008) anhand eines multivariaten linearen Tiermodelles geschätzt und ergaben für Laminitis positive Korrelationen zu Dermatitis digitalis $(0,12)$, Dermatitis interdigitalis $(0,31)$, Weiße Linie Defekt $(0,15)$, Tylom $(0,17)$ und Klauensohlengeschwüren $(0,49)$ (Swalve et al., 2008).

Des Weiteren wird von einer genetischen Prädisposition bestimmter Rassen und Kuhlinien berichtet (Maclean, 1965; Andersson \& Lundstrom, 1981). In älteren Studien wurde bei Jersey Rindern aus den USA, Südafrika und England eine vererbte Form der Laminitis beschrieben (Lischer \& Ossent, 1994). Die Tatsache, dass Klauen- bzw. Exterieurmerkmale heritabel sind, könnte die ermittelten Unterschiede in der Anfälligkeit für Klauenrehe bei den verschiedenen Rassen erklären (Vermunt \& Greenough, 1994). In unterschiedlichen Ländern wurde beobachtet, dass Holstein Friesian Kühe eine höhere 
Anfälligkeit für Klauenläsionen und Lahmheit aufweisen (Vaarst et al., 1998; Holzhauer et al., 2006; Barker et al., 2010). Swedish Red zum Beispiel zeigen eine bessere Klauengesundheit als Swedish Holstein Friesian, die öfter von mit Laminitis assoziierten Läsionen der Klauen betroffen sind (Nilsson, 1963; Andersson \& Lundstrom, 1981; Bergsten, 1994; Manske et al., 2002). Olmos et al. (2009) fanden sogar signifikante Unterschiede bei der Betrachtung der Parameter Locomotion Score, klinischer Lahmheit und den Klauenerkrankungen Dermatitis digitalis, Doppelte Sohle, Weiße Linie Defekt und Klauengeschwür zwischen verschiedenen genetischen Gruppen von Holstein Friesian Kühen (Olmos et al., 2009).

Bisher wurden bezüglich der Klauenerkrankungen beim Rind weder Kandidatengenansätze noch GWAS-Studien durchgeführt und Marker identifiziert, die zur Aufklärung der genetischen Hintergründe der Klauenrehe bzw. Sohlenhämorrhagien beitragen. Die Untersuchungen beim Rind beziehen sich hauptsächlich auf Schätzungen zur Heritabilität der verschiedenen Klauenerkrankungen oder genetischen Korrelationen zwischen diesen bzw. den in der Zuchtwertschätzung (ZWS) genutzten Fundamentmerkmalen. Beim Pferd und Schwein allerdings wurden bereits Untersuchungen zu den genetischen Grundlagen der Hufrehe und Lahmheit realisiert (Onteru et al., 2008; Coyne et al., 2009; Pawlak et al., 2014; Wang et al., 2014).

\subsection{Diskussion}

Weltweit basiert die Milchproduktion auf intensiven Produktionsmethoden, wobei große Milchkuhherden in ganzjähriger Stallhaltung mit Betonböden und eingestreuten Liegeboxen gehalten werden. Die modernen Haltungsformen sind hierbei nicht optimal, da Kühe von Natur aus Weichbodenläufer sind und die harte Bodenbeschaffenheit mit oftmals langen Stehzeiten für die Klauen der Tiere nicht vorteilhaft ist. Da sich Schmerzen und somit ein schlechtes Wohlbefinden negativ auf den gesamten Organismus auswirken, sinkt einhergehend mit Klauenerkrankungen, sowohl die Milchleistung als auch die Fruchtbarkeit der Tiere (Fiedler \& Maierl, 2004).

In Deutschland sind Klauen- und Gliedmaßenerkrankungen eine der Hauptabgangsursachen. Die Aspekte des Tierschutzes, des Verbraucherschutzes und der Ökonomie begründen die Tiergesundheit als eines der wichtigsten Merkmalskomplexe in der 
Nutztierzüchtung (Bishop et al., 2002) und stellen in allen Nutztierrassen in Zukunft ein immerwährendes Zuchtziel dar. Im Jahr 2011 ist von der niedersächsischen Landesregierung der „Tierschutzplan Niedersachsen” ins Leben gerufen worden mit dem Ziel, gesellschaftlich akzeptierte und vom Tierhalter umsetzbare Haltungsbedingungen für Nutztiere zu etablieren, die das Tierwohl belegbar zur Verbesserung des Tierschutzes gewährleisten. Die Erfassung tierzuchtfachlicher Kritikpunkte an den derzeitigen Haltungsformen und Optimierungsmaßnahmen mit einem definierten Zielzeitpunkt sind die Kernelemente des Planes. Speziell für Milchkühe werden hier u. a. die zu geringe Lebenszeit sowie die gehäuft auftretenden Euter- und Klauenkrankheiten thematisiert. Ein Konzept zur Zuchtauswahl auf "Gesamtvitalität” ist erarbeitet, allerdings bleibt zu berücksichtigen, dass eine geänderte Zuchtauswahl aufgrund von Leistungsbegrenzungen und zusätzlich zu beachtender Merkmale insgesamt zu einem geringeren Zuchtfortschritt und höheren Züchtungskosten führen würde (Niedersächsisches Ministerium für Ernährung, 2011).

Von den Abteilungen der Fakultät für Agrarwissenschaften der Universität Göttingen wurden im Rahmen eines BMELV geförderten Forschungsprojektes Perspektiven für ein europäisches Tierschutzlabel erarbeitet. Spezifische Bewertungssysteme für sieben Spezies und Haltungsformen wurden ermittelt, die auf den Prinzipien der guten Fütterung, Tierhaltung, Gesundheit und artgemäßem Verhalten aufbauen. Es gilt eindeutige Kriterien entsprechend dem Stand der Forschung festzulegen, die das Tierverhalten und Aspekte der Haltung, des Managements und der Tiergesundheit gleichermaßen berücksichtigen (Deimel et al., 2010). Hauptursachen zahlreicher Gesundheitsprobleme sind die genetische Selektion und die in der Vergangenheit dominierende Ausrichtung der Zucht auf hohe Milchleistungen. Diese beeinflussen nicht nur die Form und Größe der Tiere, sondern auch die Verhaltensbedürfnisse und die adaptiven Regulationsmechanismen der Kühe. Das Animal Health and Welfare (AHAW) Panel verweist in diesem Zusammenhang auf die in unterschiedlichen Untersuchungen nachgewiesene Korrelation zwischen hohen Milchleistungen und dem Auftreten von Mastitis, Reproduktionsproblemen, Stoffwechselkrankheiten und Lahmheiten. Entsprechend lautet die Empfehlung des Panels, bei der Züchtung der Tiere in Zukunft die Auswahlkriterien kritisch zu überprüfen und verstärkt die Fitness der Tiere (Fruchtbarkeit, Gesundheit, 
Langlebigkeit) in den Mittelpunkt zu rücken (AHAW (Panel on Animal Health and Welfare), 2009).

Durch züchterische Selektion haben die landwirtschaftlichen Nutztiere bereits ein beachtliches Leistungsniveau erreicht, so dass nun vermehrt auch funktionale Merkmale in den Vordergrund treten, die zur Wirtschaftlichkeit beitragen (Swalve, 2012). Speziell bei der Milchkuh konnten bei diesen Merkmalen, wie z. B. Fruchtbarkeit, Tiergesundheit, Nutzungsdauer und Verhalten, kaum züchterische Verbesserungen erzielt werden. Ein Problem diesbezüglich ist die genaue Definition des Merkmals, die Schwierigkeit der Merkmalserfassung und die häufig geringe Heritabilität dieser Merkmale. Zusätzlich existieren antagonistische Beziehungen zu den bevorzugten Selektionsmerkmalen und letztlich spielt deren geringe Gewichtung im Zuchtziel auch eine entscheidende Rolle (Gesellschaft für Tierzuchtwissenschaften, 2003).

\section{Züchterische Möglichkeiten zur Verbesserung der Klauengesundheit}

Die bisherigen züchterischen Anstrengungen zur Verbesserung der Klauengesundheit und des Fundaments in der deutschen Holsteinzucht beruhen lediglich auf den subjektiv erfassten Fundamentmerkmalen im Rahmen der linearen Exterieurbeurteilung. Dazu zählen neben der Hinterbeinwinkelung auch der Klauenwinkel, die Sprunggelenksqualität sowie die Hinterbeinstellung. Da bisher für die Merkmale der Klauengesundheit noch keine geeigneten Selektionsmechanismen zur Verfügung standen, blieben die Klauenkrankheiten in der Milchrinderzucht bisher unberücksichtigt (König \& Swalve, 2006). Selektionsexperimente für die Zucht auf Mastitisresistenz, die in Skandinavien bereits seit 30 Jahren durchgeführt werden, zeigen jedoch Erfolg (Heringstad et al., 2000). Auch Zuchtplanungsrechnungen in der deutschen Holstein Friesian Population für Widerstandsfähigkeit gegen Laminitis zeigen, dass durch direkte Selektion auf ein Gesundheitsmerkmal, selbst bei niedriger Heritabilität, der gewünschte Erfolg auf phänotypischer Ebene erreicht werden kann (König, 2012). Die Erfassung von Gesundheitsdaten der Klauen und somit die Einbindung der Klauengesundheit in vorhandene Zuchtprogramme kann definitv einen wichtigen Beitrag zur Verbesserung der Klauengesundheit leisten (König \& Swalve, 2006). Ein substanzieller Zuchtfortschritt für niedrig erbliche Gesundheitsmerkmale kann jedoch nur erreicht werden, wenn diese Merkmale auch an Töchtern der Bullen erhoben werden. Auf die- 
se Weise kann der Selektionserfolg im Merkmal Laminitis pro Generation und die Genauigkeit der Zuchtwertschätzung eines Bullen mehr als verdoppelt werden, wenn Laminitisbefunde von 50 Töchtern als Indexmerkmale berücksichtigt werden (König \& Swalve, 2006).

Die Leistungsprüfung für Merkmale der Gesundheit bzw. Krankheit kann laut Swalve (2008) in drei Ebenen gegliedert werden: Das Sammeln von Krankheitsdaten als unterste Ebene, die gezielte Leistungsprüfung der ganzen Herde zu einem Zeitpunkt als mittlere Ebene, und als oberste Ebene die Erfassung der Prädisposition für Erkrankungen mittels geeigneter Hilfsparameter an allen Tieren einer Herde (Swalve, 2008). Eine Beurteilung der Prädisposition aufgrund genetischer Ursachen kann bei ausreichender molekulargenetischer Datenbasis und entsprechenden Gentests gemacht werden. Die Nutzung hochdichter SNP-Chips würde derartige Tests auf molekulargenetischer Ebene ermöglichen. Dabei ist eine sehr präzise Phänotypisierung unbedingt zu beachten (Swalve, 2012).

\section{Planung und Durchführung des Forschungsprojektes}

Ziel der vorliegenden Arbeit war, die genetischen Komponenten auf die Klauengesundheit näher zu untersuchen. Dabei standen Laminitis bzw. Sohlenhämorrhagien als Indikator für diese Krankheit im Vordergrund.

Für die Beurteilung der genetischen Prädisposition ist eine exakte Phänotypisierung ein entscheidender Faktor. Die Datenerhebung von Klauenerkrankungen fand zum Zeitpunkt der Klauenpflege statt. Die Aussagekraft und Zuverlässigkeit der Daten aus der routinemäßigen Pflege der Klauen wurde bereits durch zahlreiche Studien in den vergangenen Jahren belegt (van der Waaij et al., 2005; Swalve et al., 2008; van der Linde et al., 2010). Die große Abhängigkeit von verschiedenen Umweltfaktoren begründet das Auftreten von Genotypen durch Umweltinteraktionen. Die Versuchsbetriebe wurden aufgrund gleicher Haltungs- und Managmentvoraussetzungen ausgewählt (Schöpke et al., 2013), um das in Deutschland meist genutzte Haltungs- und Fütterungssystem für große Milchviehherden widerzuspiegeln: ganzjährige Offenstallhaltung, Spaltenboden, Liegeboxen mit Stroheinstreu und Totale-Mischrationsfütterung 
(TMR). Trotzdem muss bedacht werden, dass bei der Fütterung in unterschiedlichen Betrieben die Grundfuttergehalte schwanken und unterschiedliche FuttermittelHersteller genutzt werden. Die beprobten Tiere befanden sich alle im ersten Laktationsdrittel: $62 \%$ waren weniger als 100 Tage in Milch, nur $10 \%$ der Kühe waren über 200 Tage in Milch. Es handelte sich um die erste Klauenpflege der Tiere während der Laktation. Mehrmalige Besuche von sieben großen Milchviehherden dienten zusätzlich der Standardisierung. Hinzu kommt der Einsatz nur eines geschulten Klauenpflegers, der in allen Betrieben sowohl die Klauenpflege durchführte als auch die Beurteilung des Gesundheitsstatus der Tiere dokumentierte, was die Personeneffekte bezüglich der Phänotypisierung auf ein Minimum beschränken konnte.

In anderen Studien, die genetische Korrelationen und Heritabilitäten von Klauenerkrankungen ermittelten, gab es bei der Phänotypisierung größere Unterschiede. Bei sehr viel größerem Datenmaterial ( $n=27-64.000$ Kühe), das von mehreren hundert bis tausend Herden ( $n=466-4.188$ ) stammte, wurde dementsprechend mit vielen Klauenpflegern ( $n=6-217)$ gearbeitet (van der Waaij et al., 2005; van der Linde et al., 2010; Buch et al., 2011; Chapinal et al., 2013; van der Spek et al., 2013).

In dieser Arbeit ( $n=1.962$ Kühe) wurden Laminitis bzw. Sohlenhämorrhagien mit einer Prävalenzrate von 57,3 \% als dominierende Klauenkrankheit erfasst. In vergleichbaren Studien wurden geringere Prävalenzen von ca. 30 \% angegeben (Swalve et al., 2005; van der Waaij et al., 2005; Swalve et al., 2008; van der Linde et al., 2010). Die verhältnismäßig hohe Frequenz hier liegt daran, dass sowohl klinische als auch subklinische Fälle erfasst wurden, und die Befundung zum kritischsten Zeitpunkt der jungen Kuh (1. Laktationsdrittel) stattfand (Schöpke, 2013).

Zu Beginn der Studie waren keine QTL-Daten zu Klauenerkrankungen bekannt. Bei den äußeren Merkmalen (Exterior traits) finden sich 13 QTL zu Fundamentmerkmalen wie "feet and legs", „foot diagonal” oder „rear leg set” (Hiendleder et al., 2003; Ashwell et al., 2005; Buitenhuis et al., 2007). Da in den Datenbanken bisher keine Gesundheitsmerkmale der Klauen gelistet sind, wurde aufgrund nachgewiesener genetischer Korrelationen zwischen Klauenerkrankungen und Exterieurmerkmalen mit deren QTL in dem vorliegenden Projekt gearbeitet. Dazu zählten "feet and legs score”, „foot diagonal”, 
„rear leg set”, „rear legs rear view”, „foot angle”, „quality of feet and legs”, „heel depth”, „rear legs side view”, „hock quality”, „lameness” und „,bone quality”.

Für die QTL-Regionen zu Fundamentmerkmalen beim Rind und zusätzlich auch für QTLBereiche für Fundamentmerkmale vom Schwein (Projektpartner FBN, Dummerstorf) wurden die syntänischen Bereiche zum Menschen bestimmt, um Kandidatengene für die Nutztierspezies zu ermitteln. Dabei macht man sich zu Nutzen, dass beim Mensch sehr dicht besetzte Genkarten existieren und die Anordnung der Gene (Syntänie) ebenso wie die kodierenden Sequenzen in einem bestimmten Chromosomenabschnitt zwischen verschiedenen Säugetierspezies in der Regel stark konserviert sind (Chowdhary et al., 1998).

Die Kandidatengene zu Klauenerkrankungen für diese Studie wurden durch in silico Analysen und komparative Genomkarten anhand des humanen Genoms zur sinnvollen Eingrenzung für Folgeuntersuchungen ausgewählt. Die identifizierten mehr als 1.000 Gene wurden den Biofunktionen degenerativer und/oder entzündlicher Erkrankungen des Bewegungsapparates, Störungen im Kohlenhydrat-, Kalzium-, Vitamin- und Mineralstoffwechsel sowie der Zellsignalkaskade der katabolen und anabolen Prozesse in Knochen und Bindegewebe zugeordnet. Eine Vielzahl der ausgewählten potentiellen Kandidatengene zur Klauengesundheit, wie z. B. GABRG2, AKAP2, ISOC1, ADAMTS19, MGMT, WISP2, WFDC5 und STK4, wurden durch verschiedene Studien bestätigt (Cole et al., 2011; Fan et al., 2011).

Der „Custom-made SNP-Chip” ist ein individuell gefertigter Array, der es ermöglicht, mit zuvor ausgewählten SNP spezielle Genombereiche zu genotypisieren oder eine Feinkartierung krankheitsassoziierter Regionen durchzuführen. Durch die extrem hohe Markerdichte und somit die gleichmäßige Verteilung der SNP über das gesamte Genom lässt sich das hohe Kopplungsungleichgewicht für die Identifikation von Markern nutzen (Meuwissen et al., 2001). Die Verwendung dieser molekularen Informationen kann bei quantitativen Merkmalen zum Durchbruch führen (Dekkers \& Hospital, 2002), allerdings sind für diese Methoden sehr präzise und konkrete Phänotypen unabdingbar. 
Aufgrund der Tatsache, dass die Zuverlässigkeit bei Verdoppelung der Anzahl an genotypisierten Tieren mehr steigt als bei der Anzahl der Marker (VanRaden et al., 2009), wurden für diese Studie 384 validierte SNP ausgewählt und damit 1.183 phänotypisierte Milchkühe untersucht.

Die Analyse der Daten ergab eine hoch signifikante Assoziation zwischen dem SNP (HapMap54883-rs29017173, A/G) in IQGAP1 (GenelD: 532715, BTA21) und dem Krankheitsstatus für Sohlenhämorrhagien. Anhand eines gemischten Schwellenwertmodells (ASREML), wurde der Anteil der SNP-Varianz in Data Set I $(n=1.962$; gesamtes Datenmaterial) auf 15,3 \% und in Data Set II ( $n=1.183$; Datenmaterial für die SNP-Chip Typisierung) auf 35,2 \% geschätzt.

In zukünftigen Studien muss nun geprüft werden, ob die Assoziation auch für andere Herden, andere Rassen und Holstein Friesian Kühe in anderen Ländern gilt.

\section{IQGAP1 als Kandidatengen für Sohlenhämorrhagien}

Das bovine IQGAP1 Gen ist auf Chromosom 21 lokalisiert (National Center for Biotechnology Information (NCBI), Gene ID: 532715) und kodiert für das Gerüst-Protein „IQ motif containing GTPase activating protein 1", welches ubiquitär exprimiert wird (White et al., 2009). IQGAP1 moduliert mehrere fundamentale zelluläre Funktionen, wie z. B. die Zell-Zell-Adhäsion, Transkription, Zytoskelett-Architektur und Signaltransduktion (Ren et al., 2007). Urao et al. (2010) konnten die wichtige Rolle des IQGAP1 in der postischämischen Neovaskularisation und der Gewebereparatur nachweisen, welche durch Regulierung der Endothelzellen vermittelten Angiogenese und reaktiven Sauerstoffspezies (ROS)-Produktion in ischämischen Geweben und entzündlicher Infiltration der Zellen stattfindet. Zudem wiesen IQGAP1 Knockout-Mäuse eine reduzierte Kapillardichte, Wiederherstellung des Blutflusses an den Extremitäten, und $\alpha$-Aktin positive Arteriolen auf. Mäusen, denen IQGAP1 fehlt und die einer femoralen Arterien Ligatur unterworfen wurden, zeigten erhöhte Gewebeschäden, gekennzeichnet durch Nagelbettdegeneration, Zehenödeme und Nekrose (Urao et al., 2010).

Nach den Ergebnissen der Assoziationsanalyse wurden die kodierenden Bereiche sowie die angrenzenden Exon-/Introngrenzen für von Sohlenhämorrhagien betroffenen $(n=10)$ und gesunden Tieren $(n=6)$ vergleichend sequenziert. Es wurden mehrere, sowohl intronische als auch exonische, Polymorphismen identifiziert. Jedoch war keiner 
funktionell und/oder stand in signifikantem Zusammenhang mit dem Auftreten von Hämorrhagien. In weiteren Untersuchungen des Forschungsprojektes muss nun festgestellt werden, ob in anderen wichtigen Genbereichen, wie z. B. dem Promotorbereich, mögliche Sequenzvariationen (Polymorphismen, Duplikation, Insertion) vorhanden sind oder Genexpressionsunterschiede bestehen. 


\section{Farbvererbung bei White Galloway und White Park}

\subsection{Rassemerkmale}

Galloway zählen zu den Fleischrinderrassen, sind klein- bis mittelrahmig, robust und hornlos. Sie stammen aus dem Südwesten Schottlands und sind heute weltweit verbreitet. Gallowayrinder haben eine überdurchschnittliche Futterverwertung und einen deutlich niedrigeren Erhaltungsbedarf. Zudem sind sie friedfertig, langlebig, fruchtbar und leichtkalbig. Ihr Fell besteht aus langem, gewellten Deckhaar und feinem, dichten Unterhaar, was sie für die ganzjährige Freilandhaltung prädestiniert. Eine Besonderheit dieser Rasse sind ihre unterschiedlichen Farbzeichnungen. Die Fellfarbe kann einfarbig sein, wobei hier in schwarz, blond oder rot unterschieden wird. Außerdem gibt es noch drei mehrfarbige Farbschläge, die als Belted, Riggit oder White bezeichnet werden. Die Pigmentierung bei diesen Farbschlägen kann entsprechend schwarz, blond oder rot sein. In einigen Ländern sind die Belted Galloway als eigene Rasse anerkannt. In Deutschland gelten sowohl Riggit, als auch Belted und White als Farbschlag der Rasse Galloway. Anpaarungen zwischen den unterschiedlichen Farbschlägen sind erlaubt, im Interesse der Reinhaltung der Genetik wird vom Bundesverband Deutscher GallowayZüchter davon ausdrücklich abgeraten (Bundesverband deutscher Gallowayzüchter e. V.).

Der Ursprung der White Galloway geht auf die Einkreuzung des englischen White Park Rindes zurück. Es wird vermutet, dass die White Park Herde vom Cadzow Park in Hamilton, welches an die Region Galloway angrenzt, den Ursprung der speziellen Farbzeichnungen der White Galloway darstellt (Suncrest White Galloway Cattle Stud, 2011). White Galloway haben die Grundfarbe weiß bis cremefarben und tragen im Idealfall schwarze Markierungen (Abzeichen) an Flotzmaul, Ohren, Augenumrandungen und Füßen. Mitunter können auch Pigmentierungen an anderen Körperstellen vorkommen. Die Tiere sind überzeichnet oder die Markierungen (insbesondere an den Füßen) fehlen, laut Rassebeschreibung sind kleinere Fellflecken zulässig und untermarkierte Tiere werden nicht als Farbfehler angesehen (Bundesverband deutscher Gallowayzüchter e. V.). Aufgrund von Züchterinformationen werden bei White Galloway vier unterschiedliche Farbphänotypen beschrieben, deren Pigmentierung in 
schwarz, rot oder blond auftreten können: wsg = sehr gut markiert an Ohren, Flotzmaul, Augenrändern, sowie distalen Gliedmaßen; wsü = übermarkiert, d.h. sie zeigen neben den oben genannten Markierungen weitere an zusätzlichen Körperteilen; wss = sehr schwach markiert, Markierungen fehlen, insbesondere an den distalen Gliedmaßen; wsch = völlig schwarze White Galloway (Abb. 3). Dem Zuchtziel entsprechen primär Tiere mit sehr gut markiertem Phänotyp (wsg), gefolgt von den übermarkierten Tieren (wsü) (Brenig et al., 2013).
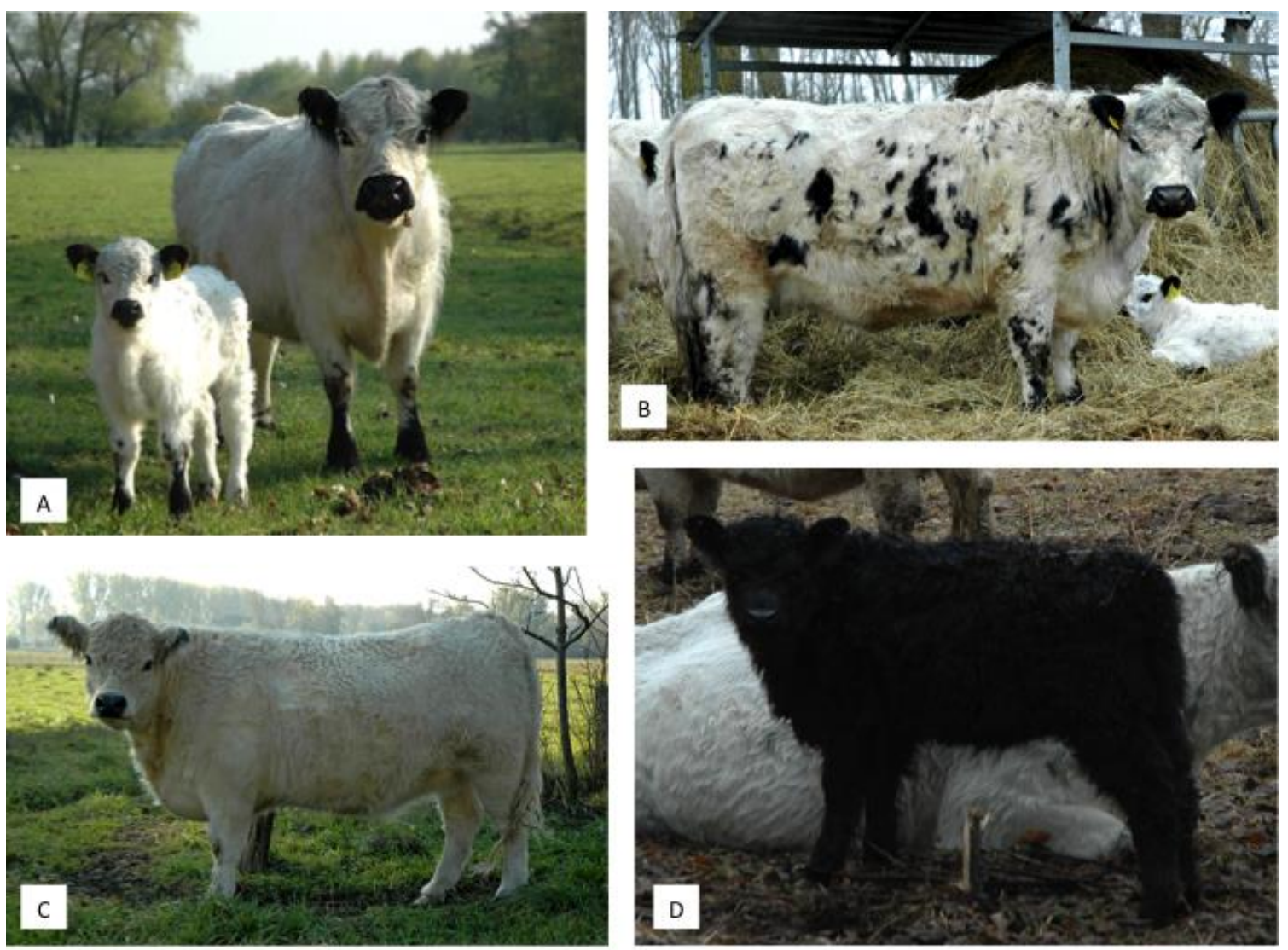

Abbildung 3: White Galloway zeigen vier verschiedene Farbphänotypen: (A) sehr gut markiert, wsg (B) übermarkiert, wsü (C) sehr schwach markiert, wss (D) völlig schwarz, wsch (Mit freundlicher Genehmigung der White Galloway Züchter).

Allerdings führen Anpaarungen von Tieren mit dem bevorzugten Phänotyp auch zu Nachkommen mit der unerwünschten Fellzeichnung schwach markiert oder völlig schwarzer Fellfarbe (Tab. 2). 
Tabelle 2: Auswertung der Datenbank des „White Galloway Stars”-Projektes gemäß den Anpaarungen der Elterntiere und deren Nachkommen mit Farbzeichnungen ( $n=656$ Nachkommen)

\begin{tabular}{llllllllll}
\hline \multicolumn{1}{c}{ Eltern } & \multicolumn{7}{c}{ Nachkommen } \\
Vater & Mutter & \multicolumn{2}{l}{ wsg/wsü } & \multicolumn{2}{c}{ wss } & \multicolumn{2}{l}{ wsch } & $\begin{array}{l}\text { Nachkommen } \\
\text { erwartet }\end{array}$ \\
\hline & & $\mathrm{n}$ & $\%$ & $\mathrm{n}$ & $\%$ & $\mathrm{n}$ & $\%$ & \\
\hline wss & wsg/wsü & 29 & 65,90 & 15 & 34,10 & 0 & 0 & $50: 50: 0$ \\
wss & wss & 0 & 0 & 9 & 100,00 & 0 & 0 & $0: 100: 0$ \\
wsg/wsü & wsg/wsü & 247 & 53,23 & 105 & 22,63 & 112 & 24,14 & $50: 25: 50$ \\
wsg/wsü & wss & 66 & 55,93 & 52 & 44,07 & 0 & 0 & $50: 50: 0$ \\
wsg/wsü & wsch & 12 & 57,14 & 0 & 0 & 9 & 42,86 & $50: 0: 50$ \\
\hline
\end{tabular}

Das englische White Park Rind ist die älteste noch heute erhaltene Hausrindrasse der Welt. Sie existiert bereits seit ca. 2.500 Jahren (White Park Cattle Society Ltd.) und gilt als gefährdet. Zuchtbestände findet man in dem Ursprungsland Großbritannien sowie in Deutschland, Dänemark, USA und Australien (Oklahoma State University, 1998). In Deutschland leben ca. 50 weibliche und 4 männliche White Park Rinder, die zur Zucht eingesetzt werden (U. Hesse, persönl. Mitteilung, 09.05.2014). In Großbritannien sind ca. 3.000 White Park im englischen Herdbuch gelistet (J. Hampson, persönl. Mitteilung, 15.05.2014). Die Farbzeichnung dieser Tiere ist der der White Galloway sehr ähnlich. Die Fellfarbe ist weiß und bis auf Flotzmaul, Ohren, Augenumrandungen und Füße sind die Tiere unpigmentiert. Außerdem treten bei dieser Rasse auch die drei Farbphänotypen wsü, wss und wsch auf, die nahezu identisch zu denen der White Galloway sind (Brenig et al., 2013) (Abb. 4). Die weit gebogenen Hörner der Tiere sind schwarz gefleckt.

Die White Park Rinder sind nicht sehr nah verwandt mit dem British White oder American White Park. Obwohl alle drei Rassen dieselben Farbvariationen aufweisen, weist das Parkrind eine große genetische Distanz zu den anderen beiden Rassen auf. Die besondere Farbzeichnung zeigen auch noch andere Rassen wie Berrenda, N'guni, BON und Texas Longhorn. White Park sind genetisch weit entfernt von anderen britischen 
Rinderrassen, was durch Blut-Typisierungen bewiesen werden konnte (Oklahoma State University, 1998).

Die am nahesten verwandten Rassen zum White Park Rind sind die schottischen Highland und Galloway (Oklahoma State University, 1998). In einer phylogenetischen Studie wurde eine enge Verwandtschaft von White Park zu English Longhorn und Galloway nachgewiesen (Decker et al., 2009).
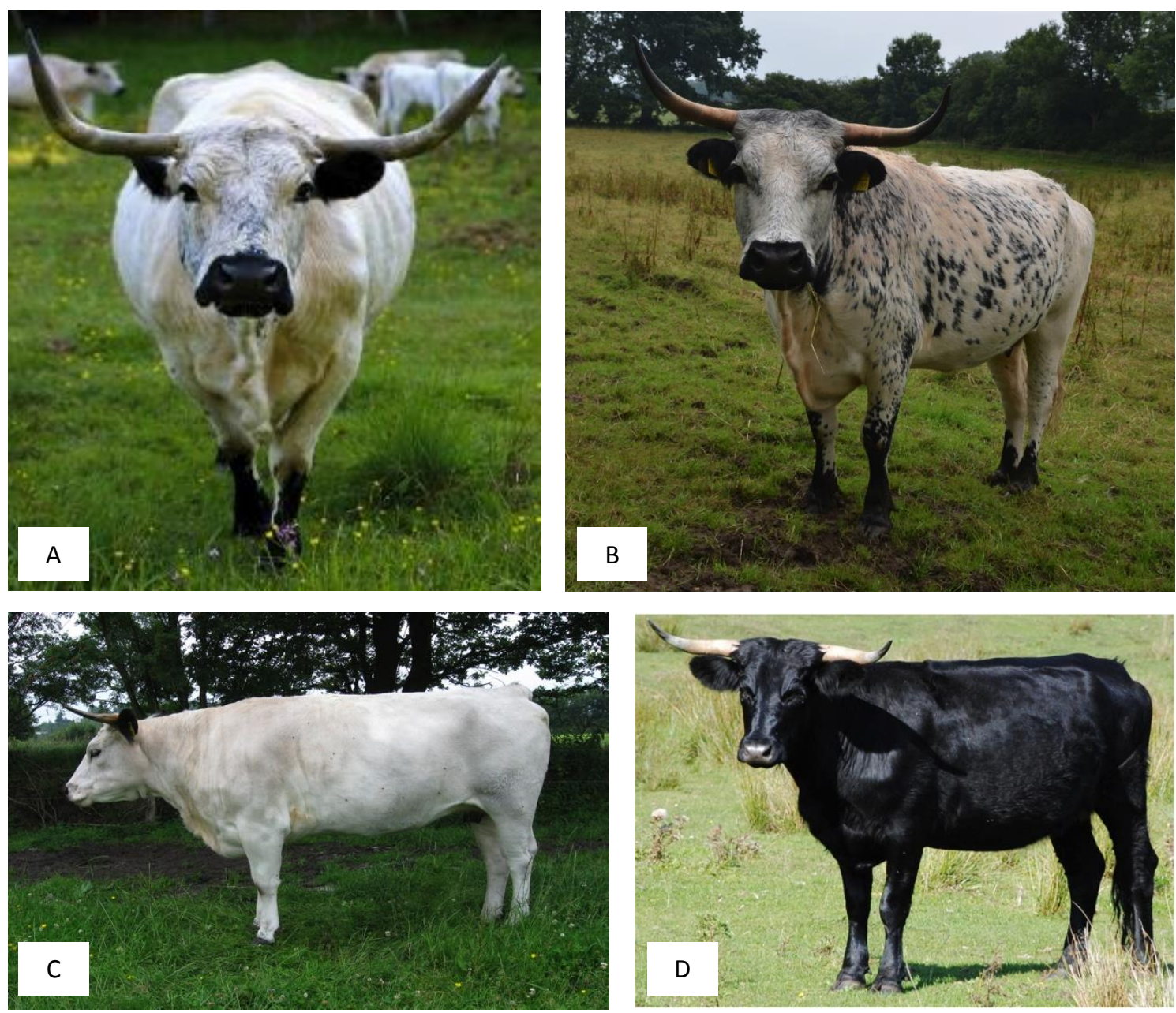

Abbildung 4: White Park zeigen vier verschiedene Farbphänotypen, ähnlich denen der White Galloway: (A) sehr gut markiert, wsg (B) übermarkiert, wsü (C) sehr schwach markiert, wss (D) schwarz, wsch (Mit freundlicher Genehmigung der White Park Züchter). 


\subsection{Genetik der Farbvererbung}

Für Züchter und Wissenschaftler sind die Fellfarben und Scheckungsmuster bei Rinderrassen von großem Interesse. Bereits aus den Höhlenmalereien von Lascaux, die auf ca. 15.000 vor unserer Zeitrechnung zurückdatiert werden, geht hervor, dass unterschiedliche Farbvarianten von domestizierten Tieren die Menschen fasziniert haben (Olson, 1999). Schon in den frühen Nutztierrassen waren die Fellfarben der Tiere sehr variabel und stellten für die Rassespezifität ein wichtiges Merkmal dar, welches auch zum Wert des Tieres beiträgt (Olson, 1999).

\section{Physiologie der Pigmentbildung}

Die Pigmentierung der Säugetiere resultiert aus der Melanin Synthese (Eumelanin/Phäomelanin), die ausschließlich in den Melanozyten, welche von den Melanoblasten abstammen, erfolgt. Melanoblasten stammen aus Zellen der Neuralleiste und wandern während der embryonalen Entwicklung durch die Unterhaut in die Epidermis, die Haarfollikel, den Uvealtrakt des Auges, die Haderian-Drüse und die Kochlea des Ohres, wo sie zu Melanozyten differenzieren. Dort erfolgt die Pigmentierung, die aus der Synthese von Eumelanin und Phäomelanin resultiert. In der Synthese ist Tyrosinase das limitierende Enzym in den Melanozyten, wobei ein geringer Tyrosinase Level zur Produktion von Phäomelanin (rot) führt und bei hohem Level Eumelanin (schwarz) gebildet wird. Störungen oder Veränderungen während der Migrationsprozesse in unterschiedlichen Körperregionen führen zur Ausbildung bestimmter Farbmuster (Brem, 1998).

Der Umfang der Pigmentierung des Fells hängt weitestgehend von dem Verhältnis der beiden Komponenten Eumelanin zu Phäomelanin ab. Bei einem hohen Gehalt an Eumelanin zeigt sich eine schwarze Fellfarbe, während ein hoher Gehalt an Phäomelanin zu einer rötlichen oder gelblichen Fellfarbe führt. Weiße Flecken kommen dann vor, wenn in Haut oder Haaren die Melanozyten vollständig fehlen (Olson, 1999).

Beim Menschen und auch bei vielen Tierarten ist eine große Anzahl Erbfehler verschiedener Organsysteme mit bestimmten Farbvarianten assoziiert, welches auf bestimmte Vorgänge während der Embryonalentwicklung zurückzuführen ist. Während der Neurulation werden zu beiden Seiten des Neuralrohres die Neuralleisten ausgebildet und die dort befindlichen Zellen wandern zu verschiedenen Orten des Körpers. Die 
Zellen sind die Vorläuferzellen der pigmentbildenden Melanozyten sowie einer Reihe verschiedener Sinnes- und Ganglienzellen, u. a. Ganglienzellen des Dickdarms. Dies erklärt z. B. die zum einen gestörte Dickdarmfunktion als auch die vollständig weiße Farbe bei Tieren, die am letalen weißen Fohlensyndrom (LWFS) erkrankt sind (Bellone, 2010). Mutationen in mit Pigmentierung assoziierten Genen können somit zu pleiotropen Effekten in der Haut (Melanom), im Reproduktionstrakt oder im Immunsystem führen. Diesbezüglich sind bei Rinderrassen z. B. das „White Heifer Disease” bei Shorthorn und blau-weißen Belgiern (Charlier et al., 1996), die größere Anfälligkeit für okulares Plattenepithelkarzinom bei den weißköpfigen Hereford und Simmentalern (Anderson, 1991; Reissmann \& Ludwig, 2013) und das „German White Fleckvieh Syndrome" bei Fleckvieh zu nennen (Philipp et al., 2011).

\section{Vererbung der Fellfarben}

Die Fellfärbung wird bedingt durch eine Anzahl verschiedener Gene, die unter anderem die Pigmentablagerung in den Haaren, die Ausprägung von Eumelanin und Phäomelanin oder die Verteilung der Pigmente an verschiedene Hautstellen steuern (Brade, 2003). Durch Interaktion verantwortlicher Gene konnten viele unterschiedliche Schattierungen entstehen. Zur verbesserten Anpassung der Tiere an unterschiedliche geographische Regionen haben auch Umweltbedingungen zu Mutationen in diesen Genen geführt (Seo et al., 2007).

Zur Aufklärung der molekularen Hintergründe wurden in den letzten Jahrzehnten besonders an Mäusen intensive Studien bezüglich der Pigmentierung betrieben. Es konnten dabei mehr als 120 Gene identifiziert werden, die für unterschiedliche Fellfarbvarianten verantwortlich sind (Jackson, 1997; Kobayashi et al., 1998; Nakamura et al., 2002). Bei anderen Tierarten sind bisher sehr viel weniger Loci und Gene für unterschiedliche Fellfarben bekannt.

Beim Rind sind zum jetzigen Zeitpunkt acht Gene und ihre dazugehörigen Allele identifiziert, welche die unterschiedlichen Fellfarben bei den Rassen hervorrufen. Das sind die Gene ASIP (Agouti-Locus), TYR (Albino-Locus), TYRP1 (Braun-Locus), KIT (coloursided, dominates weiß), KITLG (Roan-Locus), PMEL (Aufhellungs-Locus), MC1R (Extension-Locus) und MITF (white spotting) (Charlier et al., 1996; Nonneman et al., 1996; Reinsch et al., 1999; Seitz et al., 1999; Berryere et al., 2003; Guibert et al., 2004; 
Schmutz et al., 2004; Mohanty et al., 2008; Fontanesi et al., 2010; Philipp et al., 2011; Albrecht et al., 2012; Fontanesi et al., 2012; Schmutz \& Dreger, 2012).

Die hauptsächlich für die verschiedenen Fellfarben verantwortlichen Loci beim Rind sind der Extension (E)-, Agouti (A)-, Albino (C)-, Braun (B)-, Aufhellung (D)- und Roan (R)- Locus. Unterschiedliche Musterungen, die neben der Grundfarbe auftreten können, werden durch den blaze $(\mathrm{BI})$, brockling $(\mathrm{Bc})$, colour-sided $(\mathrm{Cs})$, brindle (Streifung) $(\mathrm{Br})$ oder belted $(\mathrm{Bt})$ Locus bestimmt. Diese entstehen oft aufgrund ihrer Wechselwirkung mit dem Scheckungs (S)-Locus oder anderen Genen (Seo et al., 2007).

Die Tyrosinaseaktivität wird reguliert durch das Melanozyten stimulierende Hormon (MSH) und den MSH-Rezeptor, der vom Extension (E)-Locus kodiert wird (Mountjoy et al., 1992; Barsh, 1996; Switonski et al., 2013). Der E-Locus wird in der Literatur als polymorph beschrieben (Switonski et al., 2013) und unterschiedliche Studien weisen eine Assoziation mit verschiedenen Farbvarianten beim Pferd, Schwein, Schaf, Hund und Huhn auf (Klungland et al., 1995; Marklund et al., 1996; Kijas et al., 1998; Vage et al., 1999; Newton et al., 2000; Kijas et al., 2001; Kerje et al., 2003). Das Melanocortin 1 Receptor (MC1R) Gen wird vor allem in den Melanozyten exprimiert und spielt eine bedeutende Rolle in der Melanogenese. Es ist das erste bovine Gen, das im Zusammenhang mit Fellfarben untersucht wurde. Klungland et al. (1995) kartierten es auf BTA18 (Klungland et al., 1995). Für den E-Locus sind drei Allele nachgewiesen: $E^{D}$, dominant für schwarz; $E^{+}$, das Wildtyp-Allel für rötlich-braun bis schwarz und $e$, das rezessive Allel für rot. Zusätzlich sind die Allele $E^{d 1}$ und $E^{d 2}$ bei Brown Swiss und $e^{f}$ bei Fleckvieh bestimmt worden, die gegenüber $E^{D}$ rezessiv sind (Graphodatskaya et al., 2002). Bei Homozygotie des e Allels, sind die Tiere nur in der Lage Phäomelanin zu produzieren (Klungland et al., 1995; Joerg et al., 1996). Tiere mit mindestens einem $E^{D}$ Allel produzieren in ihren Haaren nur Eumelanin (Klungland et al., 1995). Das Wildtyp-Allel $E^{+}$, welches einen normal funktionierenden Rezeptor für das MSH verschlüsselt, gilt als „neutrales” Allel.

An die normal funktionierenden MSH Rezeptoren (MSHR) bindet neben MSH auch das Agouti-Protein (A-Locus) mit hoher Affinität und verdrängt dort MSH. Das Protein wirkt somit als Antagonist für MSH (Brade, 2003). Der Agouti-Locus bezeichnet das Gen für das Agouti signal peptide (ASIP), dessen Funktion gleichzeitig durch den Melanocor- 
tinrezeptor 1 (MC1R) beeinflusst wird. Nur in Verbindung mit dem $E^{+}$Allel können die Allele des A-Locus exprimiert werden. Zwei Allele sind bekannt: $A^{+}$, welches braune Farbe produziert und $a$, das rezessiv schwarz bedingt, wenn die Tiere homozygot $E^{+} /$sind (Adalsteinsson et al., 1995). Es hat einen Einfluss auf die Ausprägung der Wildtypfarbe und rezessive Allele des A-Locus in Verbindung mit dem Wildtyp Allel des ELocus produzieren schwarzes Fell, weil E epistatisch zum A-Locus ist (Seo et al., 2007). Bei der Rasse Holstein Friesian sind auch sogenannte Umfärber bekannt, deren Farbe sich in den ersten Jahren von rot zu schwarz oder umgekehrt ändert. Es wird vermutet, dass der Phänotyp rezessiv vererbt wird, allerdings ist das kausale Gen bisher nicht identifiziert worden (Schmutz, 2002). Des Weiteren gibt es auch Holstein Friesian Tiere, die in Abwesenheit des e Allels und Anwesenheit des $E^{D}$ Allels eine rote Fellzeichnung tragen, die Variant Red (VR) genannt wird. Sie ist nicht von den e/e-Genotyp tragenden roten Holstein Friesian Tieren zu unterscheiden und wird im Vergleich zu schwarz dominant vererbt (Schmutz, 2002). Dreger \& Schmutz (2010) gelang es anhand von Kopplungsanalysen eine Region auf BTA27 zu identifizieren und sie vermuten das DEFB103 als ursächliches Gen für diesen Phänotyp (Dreger \& Schmutz, 2010).

Der Roan-Locus ist für die Schimmelfärbung, ein Gemisch aus weißen und pigmentierten Haaren verantwortlich, welches bei Shorthorn, blau-weißen Belgiern und Texas Longhorns vorkommt. Diese besondere Färbung wird nur bei heterozygotem Genotyp $\left(R / r^{+}\right)$vererbt, die homzygoten Tiere sind weiß $(R / R)$ oder farbig $\left(r^{+} / r^{+}\right)$. Das für diese Phänotypen verantwortliche Gen ist der Mast cell Growth Factor (MGF), der auch als KIT Ligand (KITLG) bezeichnet wird und auf BTA5 kartiert ist (Charlier et al., 1996; Seitz et al., 1999; Aasland et al., 2000).

Der Aufhellungs-Locus determiniert die dendritischen Fortsätze der Melanozyten. In Folge morphologischer Veränderungen kommt es zu geringeren bzw. unregelmäßigen Ablagerungen von Pigmenten (Eumelanin oder Phäomelanin), sodass phänotypisch eine Farbaufhellung des Felles zu erkennen ist. Das Wildtyp-Allel (Non-diluting) $d c^{+}$ist gegenüber der Aufhellungsmutante $D c$, wie sie z. B. beim Charolais vorkommt, rezessiv. Die meisten Charolais sind homozygot für $e$ und $D c$, d.h. durch das $D c$ wird die Rotpigmentierung aufgehellt (Brade, 2003). Das Premelanosome Protein (PMEL) Gen ist verantwortlich für die Aufhellung. Mehrere Mutationen in diesem Gen konnten bei 
Charolais, Highland und Galloway identifiziert werden. Bei Galloway und Highland ist blond (Dun) dominant über schwarz (Schmutz, 2002).

Der Albino-Locus wird von dem Tyrosinase (TYR) Gen gesteuert und ist allen anderen Pigmentloci vorgeschaltet, weil er bestimmt, ob überhaupt Pigmente gebildet werden. Das Wildtyp-Allel $C^{+}$ist dominant und die rezessive Mutante $c$ ist nicht in der Lage Tyrosinase zu bilden. Echte Albinos besitzen somit den Genotyp c/c (Brade, 2003; Schmutz et al., 2004).

Die weiße Scheckung in mehreren Rinderrassen ist auf die vier Allele des S-Locus $\left(S^{H}\right.$, Hereford Muster; $S^{P}$, Pinzgauer Muster oder Lineback; $S^{+}$, keine Scheckung, Wildtypallel; s, unregelmäßige Fleckung) zurückzuführen, der auf Chromosom 6 lokalisiert ist (Grosz \& MacNeil, 1999). Die Dominanzreihe lautet: $S^{H}=S^{P}>S^{+}>S$, wobei $S^{H}$ und $S^{P}$ kodominant zueinander und unvollständig dominant über $S^{+}$sind. Diese drei Allele erscheinen vollständig dominant über das $s$ Allel. Das $S^{H}$ Allel führt bei Homozygotie zu weißem Kopf, Bauch, Füßen, Schwanz und oftmals weißer Streifung über der Schulter. Bei $S^{H} / S^{+}$hat das Tier nur einen weißen Kopf. Das $S^{P}$ Allel bedingt weiße Streifen vom Widerrist über den Rücken, Hinterseite, Oberschenkel, Bauch bis zur Unterbrust. Das $S^{+}$Allel stellt das Wildtypallel, also den Phänotyp ohne Scheckung dar, wie z. B. beim Angus oder Jersey Rind. Das s Allel bedingt unregelmäßig pigmentierte Areale, mit in der Regel weißen Füßen, Bauch und Schwanz. Diese Färbung tritt bei Holstein Friesian, Fleckvieh und z. T. bei Jersey auf (Brade, 2003; Fontanesi et al., 2010).

Der S-Locus liegt auf BTA6 in einer Region, die das KIT Gen einschließt. Dieses kodiert für den Mast/stem cell growth factor Receptor und nimmt eine entscheidende Rolle in der Melanogenese, Erythropoese, Spermatogenese und T-Zelldifferenzierung ein (Besmer et al., 1993; Yoshida et al., 2001). Der weiße Scheckungslocus wurde von Cooper et al. (2006) auch bei Katzen nahe des KIT Gens lokalisiert (Cooper et al., 2006). Mehrere Studien beschreiben, dass das KIT Protein entscheidend für das Überleben, die Proliferation und Migration der Melanoblasten während der Embryogenese ist (Nishikawa et al., 1991; Bernex et al., 1996). In verschiedenen Säugetierarten, wie z. B. Pferd (Haase et al., 2009; Hauswirth et al., 2013), Schwein (Johansson Moller et al., 1996; Marklund et al., 1998; Fernandez-Rodriguez et al., 2014), Maus (Chabot et al., 1988; Cable et al., 1994) und Rind (Fontanesi et al., 2010; Hayes et al., 2010) konnten Mutationen im KIT Gen mit Änderungen der Fellfarbe assoziiert werden. 
Der Cs-Locus bedingt den „color-sided” Phänotyp. Es gibt zwei Allele, das cs $^{+}$als Wildtyp Allel und das Cs Allel, welches partiell dominant über $c s^{+}$ist (Brade, 2003). White Park Rinder mit pigmentierten Ohren, Maul und unteren Gliedmaßen sind homozygot $(C s / C s)$ (Olson, 1999). Heterozygote Tiere $\left(C s / C s^{+}\right)$zeigen ein unregelmäßig pigmentiertes Seitenmuster mit weißem Rücken und weißer Bauchseite. In der von Durkin et al. (2012) veröffentlichten Studie konnte eine neuartige Mutation des KIT Gens detektiert werden, die den „color-sided” Phänotyp bei Brown Swiss und blau-weißen Belgiern verursacht (Durkin et al., 2012).

Belted ist ein Farbmerkmal, bei dem über den gesamten mittleren Torso ein weißer Gürtel oder Band gezogen ist. Der restliche vordere und hintere Teil des Tieres ist dunkel gefärbt. Dieses Merkmal scheint bei Belted Galloway autosomal dominant vererbt zu werden. Das verantwortliche Gen bei Rindern ist bislang unbekannt (Schmutz, 2002). Allerdings wird bei Hampshire Schweinen das KIT Gen als verantwortlich vermutet, was bei Rindern aber ausgeschlossen wurde (Giuffra et al., 1999; Schmutz, 2002). Bei Mäusen, die eine Midtorso Gürtelzeichnung aufweisen, konnte die kausale Mutation im ADAMTS20 Gen ausfindig gemacht werden, welche rezessiv vererbt wird (Rao et al., 2003). Beim Rind scheint es eher ausgeschlossen, dass dieses Gen die Färbung ursächlich bedingt. Die Belted Zeichnung beim Rind, die vorwiegend beim Brown Swiss und Belted Galloway vorkommt, wurde von Drögemüller et al. (2009) auf BTA3 kartiert (Drögemüller et al., 2009).

Bei der weißen Fellfärbung von Rindern gibt es mehrere Gene, die epistatisch über dem MC1R Gen liegen. Eine Mutation im PMEL Gen bei Charolais führt bei homozygoter Ausprägung zu einem weißen Tier, obwohl dieses am E-Locus den Genotyp e/e für rote Fellfarbe aufweist (Kühn \& Weikard, 2007). Eine andere Mutation im KITLG Gen bedingt bei homozygoter Ausprägung das weiße Fell bei Shorthorns. Die anderen Genotypen zeigen sich durch ein rotes Fell oder die Roan-Färbung. Laut Schmutz (2002) hat die weiße Fellfarbe bei den White Galloway einen anderen Ursprung als die der zuvor genannten Rassen. Sie wird autosomal dominant vererbt, sowohl heterozygote als auch homozygote Tiere sind weiß und resultieren nicht aus der Verdünnung einer anderen Farbe (Schmutz, 2002). 
Neue Studien beim Menschen und verschiedenen Modellorganismen haben gezeigt, dass auch strukturelle Variationen, wie die Veränderungen der Kopienzahl (copy number variations, CNV), einen großen Teil der Unterschiede zwischen Individuen unterschiedlicher Spezies bedingen. Bei den Nutztieren Rind, Schwein und Schaf stehen diese in Verbindung mit Produktionsmerkmalen und Krankheiten (Bickhart \& Liu, 2014). Inversionen und chromosomale Translokationen können Auswirkungen auf den Phänotyp eines Tieres haben (Durkin et al., 2012).

In vielen Nutztierspezies, wie z. B. dem Schwein, der Ziege, dem Huhn, dem Schaf und dem Rind, wurden in verschiedenen Genen strukturelle Variationen gefunden, die in Zusammenhang mit der Fellfarbe stehen. Dazu gehören die Gene KIT, ASIP, PRLR, SPEF2, EDN3 und SOX5 (Elferink et al., 2008; Fontanesi et al., 2009; Wright et al., 2009; Fontanesi et al., 2011; Durkin et al., 2012; Rubin et al., 2012; Shinomiya et al., 2012; Brenig et al., 2013). In den Haarfollikeln bei Schafen ist die Expression des agouti signaling protein $(A S I P)$ Gen deutlich erhöht, wenn diese eine doppelte Kopienzahl des Gens aufweisen (Norris \& Whan, 2008; Fontanesi et al., 2009; Fontanesi et al., 2011). Somit steht die Duplikation in direktem Zusammenhang mit der typischen weißen Fellbzw. Wollfarbe bei domestizierten Schafen. Ebenso konnte bei Ziegen eine Duplikation des ASIP Gens festgestellt werden, die eine weiße Fellfärbung begünstigt (Fontanesi et al., 2009). Eine erbliche Form der gonadalen Hypoplasie bei finnischen und schwedischen Rinderrassen konnte mit Homozygotie für das Cs29 Allel assoziiert werden, also die Translokation eines DNA-Segments von BTA6 auf BTA29 (Venhoranta et al., 2013). Dieselbe Translokation resultiert in unterschiedlichen Farbphänotypen bei verschiedenen Rinderrassen (Durkin et al., 2012; Brenig et al., 2013) und bestätigt die Tatsache, dass chromosomale Translokationen auch den Phänotyp eines Tieres beeinflussen können. 


\subsection{Diskussion}

In der Geschichte der Domestikation von Nutztieren spielt die Farbzeichnung bzw. die Farbe eines Tieres eine entscheidende Rolle. Sie definiert als phänotypisches Merkmal sehr oft eine Rasse oder Linie, wie z. B. bei den White und Belted Galloway oder dem Fleckvieh. Neben der Funktion als Rassemerkmal hat die Fellfarbe durchaus auch ökonomische und gesundheitliche Auswirkungen. Tiere mit bestimmter Farbausprägung erzielen auf dem Markt höhere Preise. Allerdings muss auch erwähnt werden, dass einige Mutationen, die mit der Fellfarbe assoziiert werden, pleiotrope Effekte bedingen, welche die Gesundheit der Tiere in hohem Maße beeinflussen oder sogar tödlich sind (Reissmann \& Ludwig, 2013).

Bei domestizierten Tieren sind bisher mehr als 300 Loci und 150 Gene mit Fellfarbvariationen identifiziert worden (Larson \& Burger, 2013), wobei die Zahl der assoziierten Gene und Loci kontinuierlich ansteigt (Reissmann \& Ludwig, 2013). Mehrere Gene und die dazugehörigen Mutationen, welche die Farbvariationen erklären, konnten bereits entschlüsselt werden. Bei den verschiedenen Rinderrassen ist der Erkenntnisstand zur Vererbung der Farbzeichnung recht unterschiedlich und die Zahl der identifizierten Gene, die an der Farbvererbung beteiligt sind, eher gering (Schmutz, 2002).

\section{Das White Galloway Stars Projekt}

Das White Galloway Stars Projekt wurde von der Züchterin M. Bening sowie den Wissenschaftlern B. Brenig (Universität Göttingen) und H. H. Swalve (Universität HalleWittenberg) initiiert. Für das Projekt wurden bisher mehr als 660 Nachkommen und deren Elterntiere phänotypisiert und Informationen zum Pedigree jedes einzelnen Tieres erfasst. Bislang sind für 295 dieser White Galloway Tiere die molekularbiologischen Untersuchungen am Tierärztlichen Institut der Universität Göttingen durchgeführt worden.

Neben der Zucht auf erstklassige Gallowayrinder (Typ, Bemuskelung und Skelett) ist es den Züchtern der White Galloway ein wichtiges Anliegen, dass ihre Zuchttiere die gewünschten Markierungen (wsg, wsü) zeigen. Die molekularbiologischen Untersuchungen zeigten, dass eine Duplikation des KIT Gens (BTA6) mit Translokation auf Chromo- 
som 29 (Cs29), welche kürzlich bei „color-sided“ blau-weißen Belgiern und anderen Rassen beschrieben wurde, drei der unterschiedlichen Phänotypen erklärt (Abb.5).

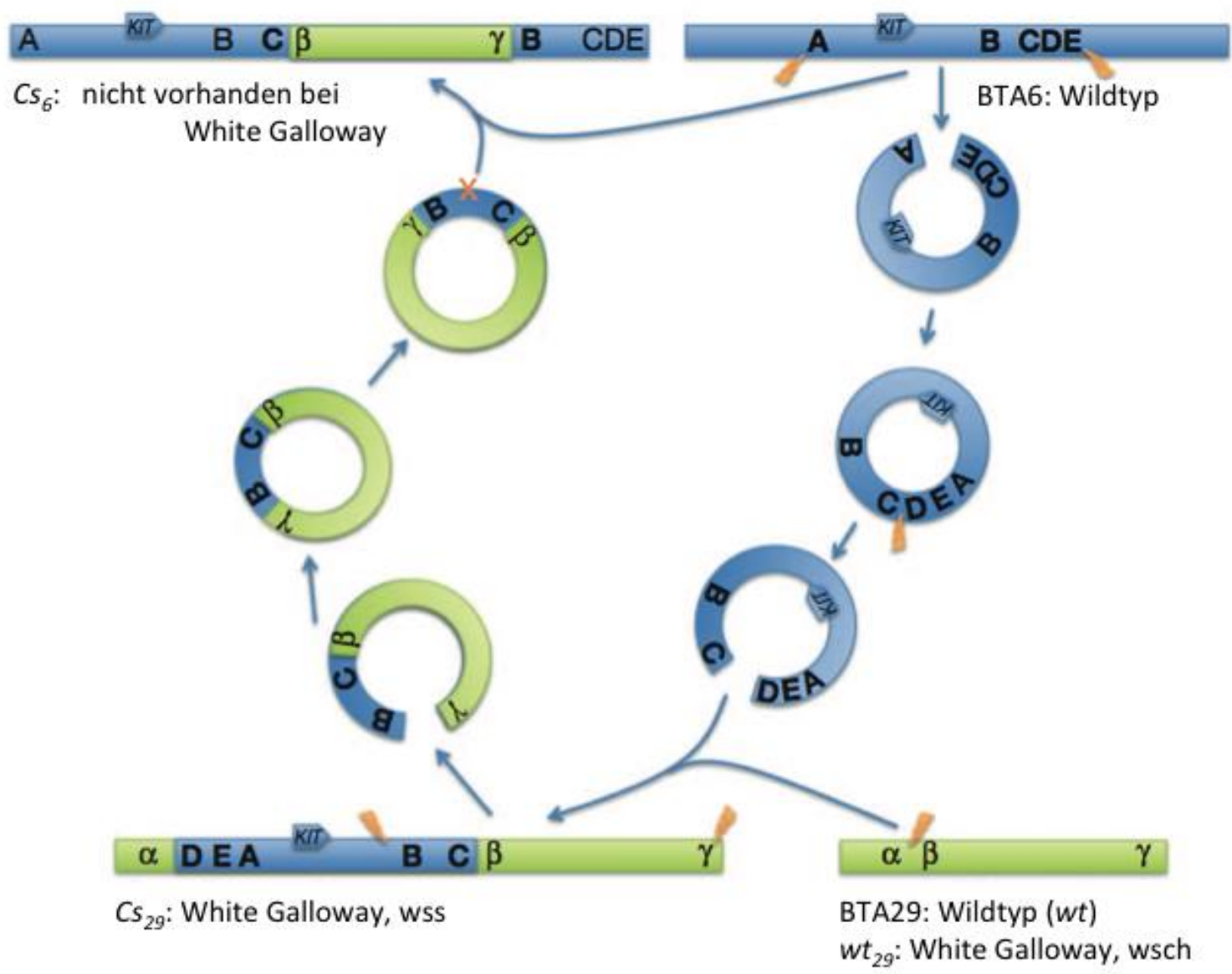

Abbildung 5: Modell zur Entstehung des Cs29 Allels durch Translokation eines zirkulären, das KIT Gen beinhaltenden, 480 kb großen DNA-Segments (modifiziert nach Durkin et al., 2012).

Gut und übermarkierte Tiere sind heterozygot für die Duplikation und Insertion $\left(C s_{29} / w t_{29}\right)$, schwach markierte Tiere sind homozygot $\left(C_{29} / C_{s_{29}}\right)$ und schwarze White Galloway tragen den homozygoten Wildtyp $\left(w t_{29} / w t_{29}\right)$ des Chromosom 29. Interessanterweise wurden bei Tieren der Rinderrasse White Park dieselben Genotypen detektiert. Den homozygoten Wildtyp $\left(w t_{29} / w t_{29}\right)$ weisen phänotypisch schwarze White Park auf, sehr gut und übermarkierte Tiere sind heterozygot $\left(\mathrm{Cs}_{29} / w t_{29}\right)$ und schwach markierte White Park sind homozygot für die Insertion auf BTA29 $\left(C s_{29} / C s_{29}\right)$. Der Erbgang wurde aufgrund dieser Ergebnisse als digen (komplex) autosomal (ko-) dominant bezeichnet. 
Es ist zu beachten, dass die normalerweise für die Kombination von zwei Allelen der paarigen Chromosomen verwendeten Begriffe "homo- und heterozygot" in diesem Fall für das Vorkommen der Duplikation/Insertion verwendet werden.

Die Ergebnisse der hier vorgestellten Studie deuten darauf hin, dass die verschiedenen White Galloway und White Park Phänotypen (wss vs. wsg/wsü) aufgrund eines Dosiseffekts entstehen. Dies beschreibt den Einfluss von Genen auf den Phänotyp, wobei die Menge eines bestimmten Genproduktes durch die jeweiligen Allele im Karyotyp eines Organismus bestimmt wird (2001). Das Ausmaß der schwarzen Markierungen ist hierbei abhängig von der Anzahl der duplizierten und insertierten KIT Gen Allele. Ob die geringen Unterschiede bei wsg relativ zu wsü genetisch bedingt sind, kann aus den bisherigen Untersuchungen noch nicht abgeleitet werden. Bisher können die Phänotypen wsg und wsü molekulargenetisch nicht unterschieden werden, da beide zu einem KIT Genotyp gehören. Sie sind heterozygot, d.h. in diesem Fall liegt die Duplikation des KIT Gens und die Reinsertion auf BTA29 lediglich in einer Kopie vor.

Durch die neuen Erkenntnisse über den Vererbungsmodus dieses Farbschlags der Gallowayrinder haben sich im Frühjahr/Sommer 2013 viele Züchter bereit erklärt, die sonst eher selten zur Zucht eingesetzten schwarzen und untermarkierten männlichen und weiblichen Tiere anzupaaren (H. Swalve, persönl. Mitteilung, 03.07.2013). Die Ergebnisse aus den molekularbiologischen Analysen werden somit in die Praxis umgesetzt. Aus Anpaarungen von wss $\left(C s_{29} / C s_{29}\right)$ und wsch Tieren $\left(w t_{29} / w t_{29}\right)$ sollten durchweg heterozygote Nachkommen $\left(C_{s_{2 g}} / w t_{29}\right)$ entstehen, die den Farbphänotyp sehr gut oder übermarkiert zeigen. Die zur Zucht eingesetzten Tiere weisen mindestens zwei Vorfahrengenerationen dieses Farbschlages auf und wurden anhand eines eigens vom RSH (Rinderzucht Schleswig-Holstein eG) entwickelten Zuchtprogramms angepaart. Die Abkalbungen sollen Ende Februar bis Ende Mai 2014 erfolgen. Die ersten geborenen Kälber bestätigen die Forschungsergebnisse. Drei Kälber weisen den primär gewünschten Farbphänotyp sehr gut markiert (wsg) auf, ein Kalb ist übermarkiert (wsü) (Abb. 6) (B. Brenig, persönl. Mitteilung, 24.04.2014). 

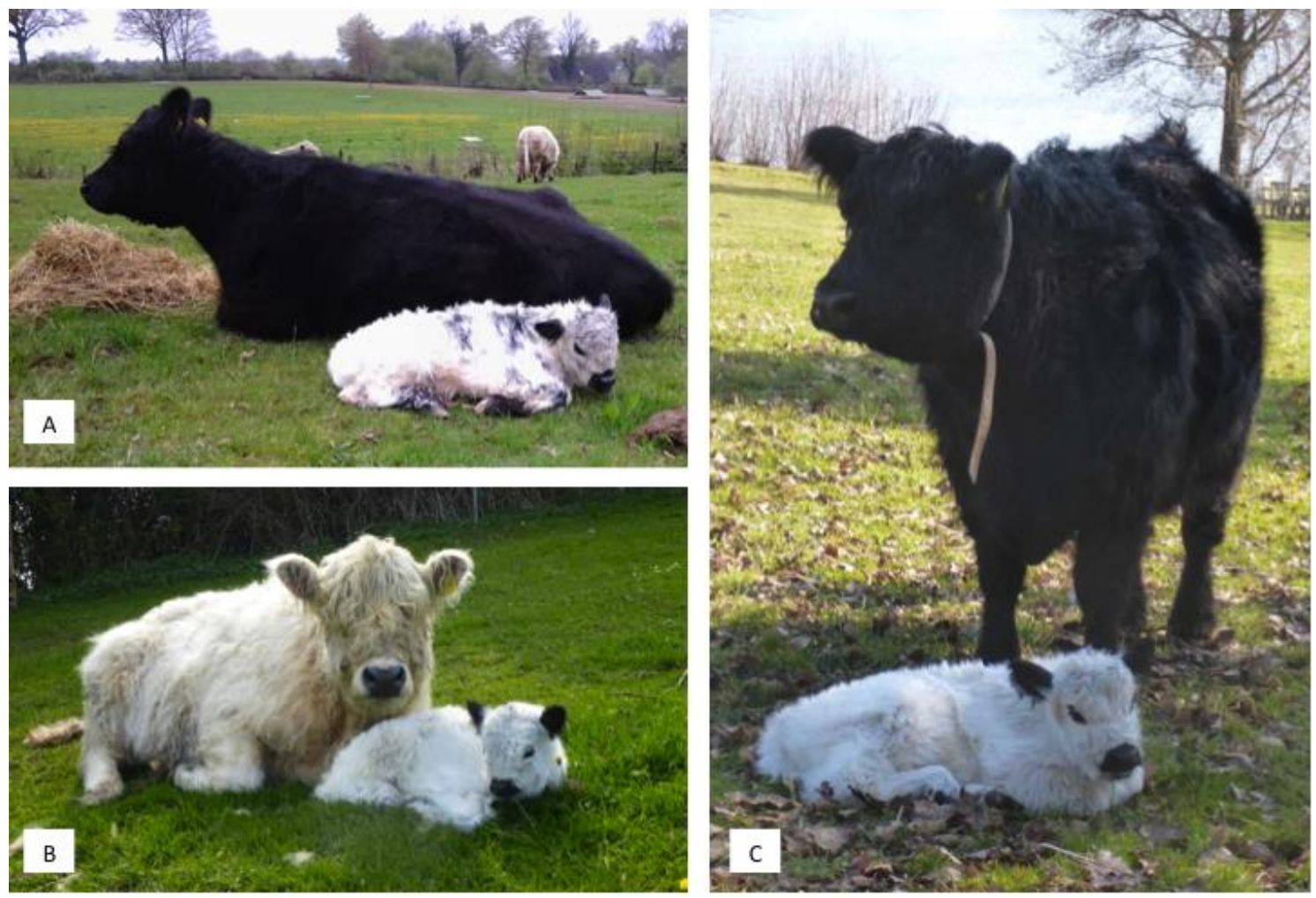

Abbildung 6: Erste Kälber ( $\mathrm{A}$ : wsü, $\mathrm{B}+\mathrm{C}$ : wsg) aus den Anpaarungsversuchen (wss $\mathrm{x}$ wsch) im Rahmen des „White Galloway Stars"-Projektes (Mit freundlicher Genehmigung der White Galloway Züchter).

Darüber hinaus können auch Umwelteinflüsse Auswirkungen auf die Farbzeichnung haben und aufgrunddessen wird es schwierig, belastbare Hypothesen aufzustellen bzw. zu erhärten oder abzulehnen.

Die exakte Charakterisierung eines Farbphänotyps und deren zugrundeliegendem Genotyp ist eine sehr schwierige Aufgabe, da nahezu identische Phänotypen innerhalb einer Spezies oder zwischen unterschiedlichen Arten von demselben Gen oder aber anderen Genen erzeugt werden, die in demselben Signalweg oder in unterschiedlichen Wegen agieren (Reissmann \& Ludwig, 2013). Weitere molekularbiologische Untersuchungen mit wsg und wsü markierten Tieren müssen folgen, um zu klären, ob der Unterschied im Ausmaß der Markierung genetisch bedingt ist. Ursächlich können z. B. die Beteiligung anderer Gene und/oder Wechselwirkung zwischen diesen, strukturelle Variationen, Expressionsunterschiede oder Umweltwirkungen sein. Des Weiteren können auch zusätzliche Mutationen im oder in unmittelbarer Nähe des Cs29 Allels in Frage kommen. 
Die Schwierigkeiten, um das Ausmaß bzw. das Verhältnis von schwarzer zu weißer Fellfarbe bei Holstein Friesian zu bestimmen, zeigen Hayes et al. (2010) in einer Studie zur Genauigkeit genomischer Vorhersagen komplexer Merkmale. Die drei Loci KIT, MITF und ein Locus auf BTA8 erklären zusammen $24 \%$ der Variation des Schwarzanteils bei diesen Tieren. Die restlichen 76\% erklärt wahrscheinlich eine große Anzahl weiterer Loci mit geringen Effekten (Hayes et al., 2010). Diese Tatsache könnte auch für das Ausmaß der Markierungen bei White Galloway und White Park (wsg vs. wsü) ursächlich sein. 


\section{Speziesbestimmung in Fleisch und Fleischprodukten}

\subsection{Rechtliche Grundlagen und Verfehlungen der Fleischdeklaration}

Nach den Vorgaben der EU-Richtlinie 2002/86/EG vom 6.11.2002 müssen auf Fleischprodukten genaue Angaben über die enthaltenen Fleischanteile gemacht werden (Amtsblatt der Europäischen Union, 2002). Auf verarbeiteten Lebensmitteln muss der Anteil einer jeweiligen Spezies, nicht aber die Herkunft einzelner Zutaten angegeben werden (BMELV, 2013a).

Eine genaue Rückverfolgbarkeit ist derzeit nur für Rindfleisch, Obst, Gemüse, Honig, Olivenöl, Bio-Lebensmittel und Fisch möglich (Bund für Lebensmittelrecht und Lebensmittelkunde e. V., 2014). Im Zuge der BSE-Krise im Jahr 2000 hat die EU neue Bestimmungen für ein umfassendes Registrierungs- und Etikettierungssystem von Rindern und Rindfleischprodukten erlassen (VO (EG) Nr. 1760/2000, (Amtsblatt der Europäischen Union, 2000). Die Kennzeichnung und Registrierung von Rindern umfasst nach dieser Verordnung u. a. Ohrmarken an beiden Ohren zur Einzelkennzeichnung, individuelle Tierpässe und Einzelregister in jedem Betrieb. Die obligatorische Etikettierung von Rindfleisch sieht neben den Angaben zur Herkunft auch Angaben darüber vor, wo das Tier oder die Tiere, von denen das Rindfleisch stammt, geboren, gemästet und geschlachtet wurden. Diese Regelung trat am 1. Januar 2002 in Kraft und gilt für Tiere, die nach dem 31. Dezember 1997 geboren wurden (Amtsblatt der Europäischen Union, 2000). Somit lässt sich jedes Stück Rindfleisch lückenlos über alle Produktionsund Vermarktungsstufen bis zum Erzeuger zurückverfolgen. Für Schweine-, Geflügel-, Schaf- und Ziegenfleisch ist eine verpflichtende Herkunftskennzeichnung in der EULebensmittel-Informationsverordnung bereits vorgesehen (Amtsblatt der Europäischen Union, 2013). In der VO 1169/2011 gibt es darüber hinaus Überlegungen zur verpflichtenden Kennzeichnung des Ursprungslandes bzw. Herkunftsortes bei Milch und Milch als Zutat, bei unverarbeiteten Lebensmitteln, Erzeugnissen aus einer Zutat sowie Zutaten, die über 50 \% eines Lebensmittels ausmachen (Amtsblatt der Europäischen Union, 2011; BMELV, 2013b). Bis zum 13.12.2014 soll ein Bericht der Kommission für die Kennzeichnung weiterer Fleischarten und für Fleisch als Zutat dem Europäischen Parlament und dem Rat vorgelegt und dann über eine Regelung ent- 
schieden werden (VO (EU) Nr. 1169/2011, (Amtsblatt der Europäischen Union, 2011). Wenn Zutaten eines Lebensmittels einen anderen als den ausgewiesenen Herkunftsort haben, muss dies gesondert vermerkt werden (BMELV, 2012).

Nicht deklarierte Substitution stellt einen Missbrauch der Fleischindustrie dar, bei dem höherwertiges Fleisch mit minderwertigem oder günstigerem Fleisch vermischt wird. Der erste Fall von betrügerischem Austausch ist im dreizehnten Jahrhundert dokumentiert worden und stammt aus Florenz in Italien (Singh \& Neelam, 2011). Eine weitere Möglichkeit des Betrugs stellt der Austausch von Fleisch gegen Fleisch einer anderen Spezies dar, wie z. B. Pferdefleisch anstelle von Rindfleisch besonders in Großbritannien und Irland, Rindfleisch gegen Kängurufleisch in Australien, und in anderen Ländern Katzenfleisch anstelle von Huhn oder Kaninchen, Ziegenfleisch für Hammelfleisch, Hammelfleisch für Wildfleisch und Katzen- und Hundefleisch für Ziegenfleisch (Kang'ethe et al., 1986). Trotz rechtlicher Vorgaben zur Deklaration von Fleisch und Fleischprodukten zeigen verschiedene Studien und der europaweite „Pferdefleischskandal“ im Jahr 2013 die Bedeutung und den Bedarf von Methoden zum eindeutigen Speziesnachweis in Lebensmitteln auf.

Hsieh et al. (1995) wiesen nach, dass in 16,6 \% der rohen oder gekochten Fleischprodukte Fleisch von Spezies beigemischt wurde, das nicht auf der Verpackung angegeben war (Hsieh et al., 1995). Dieselben Autoren untersuchten ein Jahr später Mett- und Fleischwürste aus Schweinefleisch auf Kontaminationen mit Fleisch anderer Spezies mittels eines ELISA (Enzyme Linked Immunosorbent Assay)-Kits. In 54 \% der Fleischwürste und sogar in 90 \% der Mettwürste wurde Fleisch nicht deklarierter Spezies nachgewiesen, wobei die Tierart Rind, gefolgt von Geflügel und Schaf, den Hauptanteil der nicht deklarierten Spezies ausmachte (Hsieh et al., 1996). In einer Studie aus der Türkei wurden Fleischanteile nicht deklarierter Spezies sogar in $22 \%$ der untersuchten Proben ( $n=100)$ gefunden (Ayaz et al., 2006). In einer aktuellen Studie wurden in industriell hergestellten Fleischprodukten, wie z. B. Hamburger, Schinken und Frankfurter, 5-8,8 \% Fleischbeimischungen anderer Spezies nachgewiesen, die aus religiösen Gründen verboten sind (Doosti et al., 2014).

In amtlich durchgeführten Analysen des Niedersächsischen Landesamtes für Verbraucherschutz und Lebensmittelsicherheit (LAVES) wurden im Zeitraum von Februar bis April 2013 ca. 503 Proben (Fertiggerichte, Burger, Frikadellen) auf Beimischungen von 
Pferdefleisch untersucht. In diesem kurzen Zeitraum wurden 10 Proben positiv auf nicht deklariertes Pferdefleisch getestet, was verdeutlicht, wie hoch die Beanstandungen aufgrund von Irreführungen oder Kennzeichnungsmängeln sind (Niedersächsisches Landesamt für Verbraucherschutz und Lebensmittelsicherheit, 2013).

Es ist jedoch nicht nur entscheidend nachzuweisen, ob dem rohen oder verarbeiteten Produkt Fleischanteile anderer Spezies beigemischt wurden, sondern auch wie hoch der Anteil der Beimischung ist. Hierfür bedarf es quantitativer Methoden, die Aufschluss darüber geben, ob es sich um eine bewusste Beimischung oder lediglich eine Kontamination handelt, die während des Verarbeitungsprozesses aufgetreten ist.

\subsection{Methoden zur Speziesbestimmung}

Möglichkeiten zur qualitativen Spezifizierung von Fleisch lassen sich in physikalische, chemische, anatomische, histologische und biologische Methoden unterteilen. Anhand des Schlachtkörpers kann z. B. durch die Zahnformel, Anzahl der Rippen, Farbe und Textur des Fleisches, Muskelfaserlänge und -durchmesser eine Speziesbestimmung erfolgen. Dazu kommen eine Vielzahl moderner molekularbiologischer Techniken, wie z. B. die Polymerasekettenreaktion (PCR), die eine Speziesbestimmung auch bei verarbeitetem oder verdorbenem Fleisch ermöglichen (Singh \& Neelam, 2011). Die aktuellen qualitativen oder semi-qualitativen Methoden zur Speziesbestimmung sind Immuno-basierte Methoden, wie z. B. ELISA, chromatographische Methoden (Flüssigchromatographie (LC), Hochleistungsflüssigchromatographie (HPLC)), Hybridisierungs-Methoden, PCR, Restriktions-Fragment-Längen-Polymorphismus (RFLP), Gelelektrophorese, Multiplex-PCR, nicht selektiv erweiterter polymorpher DNA (RAPD) und Real-Time PCR. Demgegenüber werden als quantitative Methoden chromatographische Verfahren oder Real-time PCR angewendet. Diese Methoden basieren größtenteils auf dem Nachweis mitochondrialer DNA oder spezies-spezifischer Proteine (Ballin et al., 2009; Giaretta et al., 2013). Die niedrigere Nachweisgrenze (LOD) bei Analysen basierend auf PCR-Techniken im Vergleich zu proteinbasierten Methoden und die immer ausführlicher werdenden DNA-Sequenz Daten führten zu einer Änderung der Speziesbestimmung von Proteinen hin zu DNA-Analysen, insbesondere mittels PCRMethoden (Ballin et al., 2009). 
Derzeit kommerziell erhältliche Kits zur Identifizierung von DNA nutzen verschiedene PCR-Techniken basierend auf nukleärer (gDNA) oder mitochondrialer DNA (mtDNA), ELISA oder DNA-Hybridisierungs-Chips. Qualitative Verfahren erzielten dabei Nachweisgrenzen von 0,25-1 \% und quantitative Verfahren können bis zu einem DNAGehalt von 0,05 \% den Speziesanteil bestimmen (Cibus Biotech GmbH, 2014; Greiner bio-one, 2014; R-Biopharm AG, 2014; Transia GmbH, 2014). Neben zahlreichen kommerziellen Nachweissystemen gibt es eine Vielzahl unterschiedlicher Studien zur Bestimmung verschiedener Spezies in Fleisch und Fleischprodukten. Matsunaga et al. (1999) entwickelten eine Multiplex-PCR basierend auf dem mitochondrialen $C y$ tochrome B Gen, um sechs unterschiedliche Spezies im Fleisch nachzuweisen. Es gelang ihnen mit dieser Methode Ziegen-, Hühner-, Rinder-, Schaf-, Schweine- und Pferde-DNA in rohem und gegartem Fleisch zu detektieren. Die Nachweisgrenze dieser Methode lag bei 0,25 ng DNA (Matsunaga et al., 1999). Maede entwickelte 2006 ein Verfahren zur Speziesbestimmung in Lebensmitteln, bei dem eine Kombination bereits publizierter PCR-Systeme und neuer Primerkombinationen genutzt wurde. Dabei konnte porcine, bovine, ovine, aviäre, cervine und equine DNA, begründet auf dem Nachweis von mtDNA (Cytohrome $b$ Gen) und gDNA (Growth hormone Gen), detektiert werden. Auf eine PCR folgt hierbei eine Restriktionsspaltung (PCR-RFLP) oder eine DNA-Sequenzierung. Bei diesem System lagen die Nachweisgrenzen z. B. für Schwein, Rind, Huhn, Pute und Wild bei $1 \%$ und für Pferd bei 0,1 \% (Maede, 2006). Von Laube et al. (2003) wurden drei TaqMan ${ }^{T M}$-quantitative PCR (qPCR)-Testsysteme zur Bestimmung der enthaltenen Spezies entwickelt, die in verarbeiteten Fleischprodukten die Spezies Rind und Schwein von 16 bzw. 18 anderen Spezies mit einer Sensitivität von $0,1 \%$ unterscheiden konnten (Laube et al., 2003). Dieses Verfahren wurde von derselben Arbeitsgruppe weiterentwickelt und ermöglichte die Detektion geringster Mengen (LOD 0,1 \%) Rind, Schwein, Schaf, Ziege, Huhn, Ente und Pute in verarbeitetem Fleisch und Konserven aus einem Pool von 23 lebensmittelrelevanten Tierarten (Laube et al., 2007b). Des Weiteren wurde eine Quantifizierung zur Bestimmung des Speziesanteils in Relation zum gesamten Fleischanteil des Lebensmittels durchgeführt. Die Quantifizierungsgrenze (LOQ) dieses Testverfahrens lag in einer Größenordnung zwischen 10100 Genomkopien (Laube et al., 2007a). Außerdem wurde der Einfluss des Verarbeitungsgrades der Proben in Hinblick auf die Quantifizierung untersucht. Die Ergebnisse 
zeigten, dass für Konserven zum Gebrauch unter tropischen Bedingungen $(F=12,2)$ die Nachweisegrenze von anderen Fleischanteilen bei $\geq 1 \%$ lag und in geringer verarbeiteten Fleischprodukten $(F=0,8)$ ebenso wie in normalen Konserven $(F=3,4) \geq 0,1 \%$ quantifiziert werden kann.

\section{3 ddPCR als Methode zur Quantifizierung}

Das Prinzip der digitalen PCR (dPCR) wurde bereits 1992 von Sykes et al. vorgestellt. Es beruht auf einer Endpunkt-Messung und Poisson-Statistik, wodurch die Möglichkeit besteht, Nukleinsäuren ohne Standardkurve zu quantifizieren (Pinheiro et al., 2012). Die Moleküle des zu untersuchenden DNA-Gemisches werden für die digitale PCR in eine große Anzahl einzelner Reaktionskompartimente verteilt. Dabei ist die Anzahl der Templatemoleküle geringer als die der Reaktionskompartimente, sodass Kompartimente leer bleiben oder mit einem, zwei oder wenigen Molekülen belegt sind. Nach erfolgter Endpunkt-PCR unter Verwendung fluoreszenzmarkierter Hydrolyse-Sonden werden positive und negative Reaktionskompartimente gezählt und die Quantifizierung der Anzahl der Ausgangsmoleküle erfolgt unter Berücksichtigung der PoissonVerteilung. Der negative natürliche Logarithmus der Fraktion der leeren Reaktionskompartimente multipliziert mit der gesamten Anzahl der Kompartimente entspricht der Zahl der Moleküle in dem gesamten Ansatz $\left(-\ln \left(\theta_{0}\right) \times n\right)$. Bei der dPCR wird kein externer Mengenstandard benötigt (Baker, 2012), und diese Methode wird hauptsächlich zur relativen Quantifizierung eingesetzt. Durch die Vereinzelung der Moleküle können geringe Mengen eines bestimmten Zielfragments quantifiziert werden und somit eine sehr geringe Kopienzahl des eingesetzten Templates in einem großen Hintergrund aus Kontrollfragmenten detektiert werden (Lo et al., 2007; Bhat et al., 2009). Die droplet digitale PCR (ddPCR) ist eine Weiterentwicklung der dPCR und wurde vor wenigen Jahren auf den Markt gebracht (Sykes et al., 1992; Hindson et al., 2011; Pinheiro et al., 2012). Sie ermöglicht die genaue Messung der Menge eines TargetMoleküls in einer Probe (Pinheiro et al., 2012). In einer aktuellen Studie wurde mittels ddPCR die Anwendbarkeit dieser Methode zur Quantifizierung von gentechnisch veränderten Organismen (GVO) in Lebensmittel-, Futter- und Saatproben nachgewiesen (Morisset et al., 2013). 


\subsection{Diskussion}

Durch die Aufdeckung zahlreicher Skandale hinsichtlich nicht deklarierter Spezies in Lebensmitteln ist die Notwendigkeit einer kostengünstigen und zuverlässigen Methode zur Bestimmung und Quantifizierung von unterschiedlichen Spezies in Fleisch und prozessierten Fleischprodukten von großem Industrie- und Verbraucherinteresse. In der hier vorgestellten Studie wurde ein neues System entwickelt, welches eine direkte relative Quantifizierung enthaltener DNA der Spezies Rind, Schwein und Pferd in Fleisch oder verarbeiteten Fleischprodukten ermöglicht. Dazu wurde die ddPCR genutzt, die es erlaubt, geringste Mengen eines Ziel-Fragments in einem großen Hintergrund aus Kontrollfragmenten zu detektieren. Aufgrund der Vereinzelung des PCR-Ansatzes in mehrere Tausend einzelne Reaktionskompartimente ist die ddPCR somit weitestgehend unabhängig von PCR-Inhibitoren, Kreuzreaktionen von DNA-Templates und PrimerDimeren (Nakano et al., 2003).

Die Vorteile der digitalen PCR gegenüber der Real-Time PCR liegen in ihrer höheren Sensitivität und Präzision. Bei der qPCR wird die Präzision mit abnehmender DNAMenge beeinträchtigt. Des Weiteren ist die Verwendung eines externen Standards zur Quantifizierung besonders bei hochverarbeiteten Fleischprodukten problematisch, da Amplifikationseffizienzen und DNA-Qualitäten in der Referenzprobe von der Testprobe abweichen können (Ballin et al., 2009). Außerdem ist es schwierig, mittels qPCR Allelfrequenzen unter 1 \% Häufigkeit nachzuweisen.

Im Gegensatz dazu können mittels dPCR Unterschiede in der Genexpression von 30 \% oder weniger unterschieden, Variationen von fünf oder sechs Kopien quantifiziert oder Allelfrequenzen von 0,1 \% nachgewiesen werden (Baker, 2012). Die Vorteile der dPCR machen die ddPCR zu einer effizienten Methode, die in Routinelaboren zur Fleischkontrolle genutzt werden kann.

In der Literatur wird als gängige Methode zur Bestimmung von Spuren unterschiedlicher Spezies in Fleisch/Fleischprodukten die mitochondriale DNA in PCR-Methoden beschrieben. Da die meisten Zellen eine hohe Kopienzahl mtDNA im Vergleich zur gDNA enthalten, kann eine sehr viel geringere Nachweisgrenze als bei der single-copy DNA realisiert werden (Ballin et al., 2009). Aufgrund der oben genannten Vorteile der mtDNA ist es durchaus sinnvoll, auf dieser Grundlage qualitative Speziesbestimmungen durchzuführen, was in sehr vielen verschiedenen Studien, basierend auf dem $C y$ - 
tochrome B Gen, gezeigt wurde (Matsunaga et al., 1999; Maede, 2006; Ballin et al., 2009). Allerdings ist zu beachten, dass die mtDNA eine etwa 5-10x höhere Mutationsrate als die gDNA aufweist (Payne et al., 2013). Bereits in den späten 1960er Jahren wurde vermutet, dass Unterschiede in der Menge von mtDNA pro Mitochondrium in verschiedenen Zelltypen unterschiedlicher Säugetierspezies bestehen und es möglicherweise Unterschiede zwischen adultem Gewebe und schnellwachsenden Zelltypen gibt (Nass, 1969; Robin \& Wong, 1988). Ende der 80er Jahre wurde von Robin \& Wong (1988) gezeigt, dass die Menge von mtDNA pro Mitochondrium weitestgehend konstant zwischen Säugetierzelltypen und Spezies ist. Außerdem wurde nachgewiesen, dass die Anzahl Mitochondrien zu jeder Zeit und in jedem Stadium durch die Balance zwischen ihrer Biogenese und Degradation bestimmt wird. Daher variiert die Anzahl Mitochondrien innerhalb der Zelle und folglich der mtDNA-Gehalt einer Zelle. Dadurch wird verdeutlicht, dass eine Quantifizierung basierend auf mtDNA, aufgrund des variierenden Gehalts an Mitochondrien DNA in unterschiedlichen Geweben sehr zweifelhaft ist (Robin \& Wong, 1988; Ballin et al., 2009).

Dies wurde auch in den eigenen Versuchen verdeutlicht, wobei im Vergleich von Fettund Muskelgewebe ein bis zu sechsfacher Unterschied in der mtDNA-Konzentration gemessen wurde. Infolgedessen kann der Fehler bei der Verwendung von mtDNA auf das bis zu Zehnfache ansteigen, wenn bei der Quantifizierung falsch deklarierter Speziesanteile zwei Bestimmungen durchgeführt werden (eine für deklariert, eine für nicht deklariert). Das Problem einer Quantifizierung mittels mtDNA liegt in der Zusammensetzung des verarbeiteten Fleisches, da dieses zusätzlich zum Muskelfleisch oft auch Fett, Sehnen oder Innereien enthält, wodurch das Ergebnis verfälscht werden kann.

Bei der Quantifizierung basierend auf nukleärer DNA ist die Zusammensetzung des Fleisches nicht von Bedeutung. In der Literatur wird beschrieben, dass quantitative Speziesbestimmungen auf Grundlage von Genom-/Genom-Äquivalenten anstelle von gewichtsbezogenen Anteilen (w/w) erfasst werden müssen. Dennoch ist zu beachten, dass die Genomgröße der unterschiedlichen Spezies, die DNA-Degeneration aufgrund des Verarbeitungsprozesses, die Anzahl an Zellen pro Unit Masse, der Grad der Ploidie und die Extrahierbarkeit der DNA einen Einfluss auf die Genauigkeit der Quantifizierung aufweisen (Laube et al., 2007a; Ballin et al., 2009). Generell muss für ZellkernDNA-basierte Verfahren zur Speziesquantifizierung beachtet werden, dass eine direkte 
Übertragbarkeit der ermittelten DNA-Konzentrationen auf den Fleischanteil im untersuchten Produkt nur begrenzt möglich ist, da verschiedene Gewebe bei gleichem Gewicht durchaus unterschiedliche Mengen Kern-DNA enthalten können. Biase et al. (2002) stellten bei der DNA-Extraktion aus verschiedenen Geweben fest, dass Fettzellen einen deutlich geringeren DNA-Gehalt aufweisen als Zellen anderer Körpergewebe, wie z. B. Leber, Muskel, Haut und Niere. Dies ist darauf zurückzuführen, dass Lipide das Zellvolumen erhöhen, die Zellzahl jedoch verringern (Biase et al., 2002). Die Zellen der Leber können durch eine gestörte Mitose polyploid sein und auch die Skelettmuskulatur besteht z. T. aus mehrkernigen Zellen, welche durch Fusion entstehen (Davoli \& de Lange, 2011).

Als single-copy Gen wurde für das Testverfahren der Gerinnungsfaktor Prothrombin (F2) ausgewählt, da dieser in allen Säugetieren vorkommt und davon ausgegangen werden kann, dass die Mutationsrate in diesem Gen eher gering ist, da dies sonst letale Auswirkungen auf das Tier hat. Des Weiteren weist das F2 Gen ausreichende Variabilität zwischen unterschiedlichen Spezies auf, um eine spezies-spezifische Detektion, nicht nur für die drei in dieser Studie getesteten Spezies Rind, Schwein und Pferd zu ermöglichen. Bei den Ergebnissen wurden für die Fleischmischungen (Pferd in Rindoder Schweinefleisch) gute Wiederfindungsraten erzielt, obwohl die Schwierigkeit in der Homogenisierung bestand. Dabei mussten aus Proben von insgesamt $100 \mathrm{~g}, \mathrm{Mi}-$ schungsverhältnisse von $50 \%, 10 \%, 1 \%, 0,1 \%$ und 0,01\% hergestellt werden und als repräsentative Proben zur Extraktion dienen. Die Ergebnisse des hier entwickelten ddPCR-Testverfahrens, basierend auf nukleärer DNA, mit einer Nachweisgrenze (LOD) von 0,001 \% und einer Quantifizierungsgrenze (LOQ) von 0,01 \% für DNA-in-DNA und Fleisch-in-Fleisch Mischungen sind sehr gut.

Bisher wurde vom Gesetzgeber kein vorgegebener Grenzwert festgelegt, wonach unterschieden wird, ob es sich um bewusste Beimischung oder Kontamination handelt. Zurzeit geht man davon aus, dass es sich bei einem Nachweis von $\geq 2,5 \%$ Pferde-DNA bzw. nicht deklarierter Tierarten-DNA um eine bewusste Beimischung und somit Irreführung handelt und das Erzeugnis somit als nicht verkehrsfähig gilt. Bei einem Wert $<2,5 \%$ ergeht eine Empfehlung an die zuständige Behörde zur Klärung der Pferdefleischkontamination. Es wird diskutiert, ob dieser Grenzwert bei gesicherter Analytik auf $1 \%$ herabgesetzt wird (Laube et al., 2007a). 


\section{Literaturverzeichnis}

Aasland, M., Klungland, H., \& Lien, S. (2000). Two polymorphisms in the bovine mast cell growth factor gene (MGF). Animal genetics, 31(5), 345.

Adalsteinsson, S., Bjarnadottir, S., Vage, D. I., \& Jonmundsson, J. V. (1995). Brown coat color in Icelandic cattle produced by the loci Extension and Agouti. The Journal of heredity, 86(5), 395-398.

ADR. (1972-2012). Jahresberichte der Arbeitsgemeinschaft deutscher Rinderzüchter e.V., Rinderproduktion in Deutschland.

AHAW (Panel on Animal Health and Welfare). (2009). Scientific Opinion on the overall effects of farming systems on dairy cow welfare and disease. Scientific Opinion of the Panel on Animal Health and Welfare on a request from European Commission on welfare of dairy cows (Question No EFSA-Q-2006-113). The EFSA Journal, 1143, 1-38.

Albrecht, E., Komolka, K., Kuzinski, J., \& Maak, S. (2012). Agouti revisited: transcript quantification of the ASIP gene in bovine tissues related to protein expression and localization. PloS one, 7(4), e35282.

Amory, J. R., Barker, Z. E., Wright, J. L., Mason, S. A., Blowey, R. W., \& Green, L. E. (2008). Associations between sole ulcer, white line disease and digital dermatitis and the milk yield of 1824 dairy cows on 30 dairy cow farms in England and Wales from February 2003-November 2004. Preventive veterinary medicine, 83(3-4), 381-391.

Amtsblatt der Europäischen Union. (2000). Verordnung (EG) Nr. 1760/2000 des Europäischen Parlaments und des Rates vom 17. Juli 2000 zur Einführung eines Systems zur Kennzeichnung und Registrierung von Rindern und über die Etikettierung von Rindfleisch und Rindfleischerzeugnissen sowie zur Aufhebung der Verordnung (EG) Nr. 820/97 des Rates.

Amtsblatt der Europäischen Union. (2002). Richtline 2002/86/EG der Kommission vom 6. November 2002 zur Änderung der Richtlinie 2001/101/EG hinsichtlich des Datums, ab dem der Handel mit Erzeugnissen untersagt ist, die mit der Richtlinie 2000/13/EG des Europäischen Parlaments und des Rates nicht übereinstimmen. 
Amtsblatt der Europäischen Union. (2011). Verordnung (EU) Nr. 1169/2011 des Europäischen Parlaments und des Rates vom 25. Oktober 2011 betreffend die Information der Verbraucher über Lebensmittel und zur Änderung der Verordnung (EG) Nr. 1924/2006 und (EG) Nr. 1925/2006 des Europäischen Parlaments und des Rates zur Aufhebung der Richtlinie 87/250/EWG der Kommission, der Richtlinie 90/496/EWG des Rates, der Richtlinie 1999/10/EG der Kommission, der Richtlinie 200/13/EG des Europäischen Parlaments und des Rates, des Richtlinien 2002/67/EG und 2008/5/EG der Kommission und der Verordnung (EG) Nr. 608/2004 der Kommission.

Amtsblatt der Europäischen Union. (2013). Durchführungsverordnung (EU) Nr. 1337/2013 der Kommission vom 13. Dezember 2013 mit Durchführungsbestimmungen zur Verordnung (EU) Nr. 1169/2011 des Europäischen Parlaments und des Rates hinsichtlich der Angabe des Ursprungslandes bzw. Herkunftsortes von frischem, gekühltem oder gefrorenem Schweine-, Schaf-, Ziegen- und Geflügelfleisch.

Anderson, D. E. (1991). Genetic study of eye cancer in cattle. The Journal of heredity, 82(1), 21-26.

Andersson, L., \& Bergman, A. (1980). Pathology of bovine laminitis especially as regards vascular lesions. Acta veterinaria Scandinavica, 21(4), 559-566.

Andersson, L., \& Lundstrom, K. (1981). The influence of breed, age, body weight and season on digital diseases and hoof size in dairy cows. Zentralblatt fur Veterinarmedizin. Reihe A, 28(2), 141-151.

Ashwell, M. S., Heyen, D. W., Weller, J. I., Ron, M., Sonstegard, T. S., Van Tassell, C. P., \& Lewin, H. A. (2005). Detection of quantitative trait loci influencing conformation traits and calving ease in Holstein-Friesian cattle. Journal of dairy science, 88(11), 4111-4119.

Ayaz, Y., Ayaz, N. D., \& Erol, I. (2006). Detection of species in meat and meat products using enzyme-linked immunosorbent assay. Journal of Muscle Foods, 17(2), 214-220.

Baker, M. (2012). Digital PCR hits its stride. Nature Methods, 9(6), 541-544.

Ballin, N. Z., Vogensen, F. K., \& Karlsson, A. H. (2009). Species determination - Can we detect and quantify meat adulteration? Meat science, 83(2), 165-174. 
Barker, Z. E., Leach, K. A., Whay, H. R., Bell, N. J., \& Main, D. C. (2010). Assessment of lameness prevalence and associated risk factors in dairy herds in England and Wales. Journal of dairy science, 93(3), 932-941.

Barsh, G. S. (1996). The genetics of pigmentation: from fancy genes to complex traits. Trends in genetics : TIG, 12(8), 299-305.

Bellone, R. R. (2010). Pleiotropic effects of pigmentation genes in horses. Animal genetics, 41 Suppl 2, 100-110.

Benz, B. (2003). Weiche Laufflächen für Milchvieh bringen den notwendigen Kuhkomfort. Nutztierpraxis Aktuell, Ausgabe 4.

Bergsten, C. (1994). Haemorrhages of the sole horn of dairy cows as a retrospective indicator of laminitis: an epidemiological study. Acta veterinaria Scandinavica, 35(1), 55-66.

Bergsten, C. (2003). Causes, risk factors, and prevention of laminitis and related claw lesions. Acta veterinaria Scandinavica. Supplementum, 98, 157-166.

Bergsten, C., \& Frank, B. (1996a). Sole haemorrhages in tied heifers in early gestation as an indicator of laminitis: effects of diet and flooring. Acta veterinaria Scandinavica, 37(4), 375-381.

Bergsten, C., \& Frank, B. (1996b). Sole haemorrhages in tied primiparous cows as an indicator of periparturient laminitis: effects of diet, flooring and season. Acta veterinaria Scandinavica, 37(4), 383-394.

Bernex, F., De Sepulveda, P., Kress, C., Elbaz, C., Delouis, C., \& Panthier, J. J. (1996). Spatial and temporal patterns of c-kit-expressing cells in WlacZ/+ and WlacZ/WlacZ mouse embryos. Development, 122(10), 3023-3033.

Berryere, T. G., Schmutz, S. M., Schimpf, R. J., Cowan, C. M., \& Potter, J. (2003). TYRP1 is associated with dun coat colour in Dexter cattle or how now brown cow? Animal genetics, 34(3), 169-175.

Besmer, P., Manova, K., Duttlinger, R., Huang, E. J., Packer, A., Gyssler, C., \& Bachvarova, R. F. (1993). The kit-ligand (steel factor) and its receptor c-kit/W: pleiotropic roles in gametogenesis and melanogenesis. Development, 125-137. 
Bhat, S., Herrmann, J., Armishaw, P., Corbisier, P., \& Emslie, K. R. (2009). Single molecule detection in nanofluidic digital array enables accurate measurement of DNA copy number. Analytical and bioanalytical chemistry, 394(2), 457-467.

Biase, F. H., Franco, M. M., Goulart, L. R., \& Antunes, R. C. (2002). Protocol for extraction of genomic DNA from swine solid tissues. Genetics and Molecular Biology, 25(3), 313-315.

Bickhart, D. M., \& Liu, G. E. (2014). The challenges and importance of structural variation detection in livestock. Frontiers in genetics, 5, 37.

Bishop, S. C., Chesnais, J., \& Stear, M. J. (2002, 18.-24.8.). Breeding for disease resistance: issues and opportunities. Paper presented at the 7th World Congress on Genetics Applied to Livestock Production, Montpellier, France.

BMELV. (2012). Einheitliche Kennzeichnung von Lebensmitteln in der EU schafft mehr Transparenz für Verbraucher. from http://www.bmelv.de/SharedDocs/Standardartikel/Ernaehrung/SichereLebens mittel/Kennzeichnung/Ueberarbeitung-EU-Lebensmittel-

Naehrwertkennzeichnungsrecht.htmI\#doc431912bodyText6, abgerufen am 14.06.2013.

BMELV. (2013a). Europaweiter Betrug mit Pferdefleisch-Maßnahmen des BMELV. from http://www.bmelv.de/SharedDocs/Standardartikel/Ernaehrung/SichereLebens mittel/Kennzeichnung/Pferdefleisch.html;jsessionid=38B59051A53E9A7E7151A 318F79ECAFE.2_cid358, abgerufen am 17.06.2013.

BMELV. (2013b). Pressemitteilung Nr. 63 vom 25.02.13: EU-Landwirtschaftsminister beraten über Konsequenzen aus dem Kennzeichnungsbetrug mit Pferdefleisch. from http://www.bmelv.de/SharedDocs/Pressemitteilungen/2013/063-AlPferdefleisch.html, abgerufen am 17.06.2013.

Boosman, R., Nemeth, F., \& Gruys, E. (1991). Bovine laminitis: clinical aspects, pathology and pathogenesis with reference to acute equine laminitis. The Veterinary quarterly, 13(3), 163-171.

Booth, C. J., Warnick, L. D., Grohn, Y. T., Maizon, D. O., Guard, C. L., \& Janssen, D. (2004). Effect of lameness on culling in dairy cows. Journal of dairy science, 87(12), 4115-4122. 
Brade, W. (2003). Farbvererbung bei Rindern. Der praktische Tierarzt, 84(Heft 2), 132140.

Bradley, H. K., Shannon, D., \& Neilson, D. R. (1989). Subclinical laminitis in dairy heifers. The Veterinary record, 125(8), 177-179.

Brandejsky, F., Stanek, C., \& Schuh, M. (1994). Zur Pathogenese der subklinischen Klauenrehe beim Milchrind: Untersuchungen von Klauenstatus, Pansenstatus und Blutgerinnungsfaktoren. Deutsche Tierärztliche Wochenschrift, 101(2), 6871.

Brechner, E., Dinkelaker, B., \& Dreesmann, D. (2001). Kompaktlexikon der Biologie (Vol. Band 1). Heidelberg: Spektrum Akademischer Verlag.

Brem, G. (1998). Haustierfarben. In G. Brem (Ed.), Exterieurbeurteilung landwirtschaftlicher Nutztiere (pp. 90-111). Stuttgart, Germany: Eugen Ulmer Verlag.

Brenig, B., Beck, J., Floren, C., Bornemann-Kolatzki, K., Wiedemann, I., Hennecke, S., Swalve, H., \& Schutz, E. (2013). Molecular genetics of coat colour variations in White Galloway and White Park cattle. Animal genetics, 44(4), 450-453.

Bruijnis, M. R., Hogeveen, H., \& Stassen, E. N. (2010). Assessing economic consequences of foot disorders in dairy cattle using a dynamic stochastic simulation model. Journal of dairy science, 93(6), 2419-2432.

Buch, L. H., Sorensen, A. C., Lassen, J., Berg, P., Eriksson, J. A., Jakobsen, J. H., \& Sorensen, M. K. (2011). Hygiene-related and feed-related hoof diseases show different patterns of genetic correlations to clinical mastitis and female fertility. Journal of dairy science, 94(3), 1540-1551.

Buitenhuis, A. J., Lund, M. S., Thomasen, J. R., Thomsen, B., Nielsen, V. H., Bendixen, C., \& Guldbrandtsen, B. (2007). Detection of quantitative trait loci affecting lameness and leg conformation traits in Danish Holstein cattle. Journal of dairy science, 90(1), 472-481.

Bund für Lebensmittelrecht und Lebensmittelkunde e. V. (2014). Lebensmittel Herkunft. from http://www.bll.de/de/lebensmittel/kennzeichnung/herkunft/_2, abgerufen am 13.02.2014. 
Bundesverband deutscher Gallowayzüchter e. V. from www.galloway-deutschland.de, abgerufen am 02.01.2014.

Cable, J., Huszar, D., Jaenisch, R., \& Steel, K. P. (1994). Effects of mutations at the W locus (c-kit) on inner ear pigmentation and function in the mouse. Pigment cell research / sponsored by the European Society for Pigment Cell Research and the International Pigment Cell Society, 7(1), 17-32.

CDCB. (2012). Council on Dairy Cattle Breeding. from https://www.cdcb.us/publish/dhi/current/cullall.html, abgerufen am 16.04.2014.

CDIC. (2007-2012). Canadian Dairy Information Centre. from http://dairyinfo.gc.ca/index_e.php?s1=dff-fcil\&s2=mrr-pcle\&s3=cr-tr, abgerufen am 16.04.2014.

Chabot, B., Stephenson, D. A., Chapman, V. M., Besmer, P., \& Bernstein, A. (1988). The proto-oncogene c-kit encoding a transmembrane tyrosine kinase receptor maps to the mouse W locus. Nature, 335(6185), 88-89.

Chapinal, N., Koeck, A., Sewalem, A., Kelton, D. F., Mason, S., Cramer, G., \& Miglior, F. (2013). Genetic parameters for hoof lesions and their relationship with feet and leg traits in Canadian Holstein cows. Journal of dairy science, 96(4), 2596-2604.

Charlier, C., Denys, B., Belanche, J. I., Coppieters, W., Grobet, L., Mni, M., Womack, J., Hanset, R., \& Georges, M. (1996). Microsatellite mapping of the bovine roan locus: a major determinant of White Heifer disease. Mammalian genome : official journal of the International Mammalian Genome Society, 7(2), 138-142.

Chowdhary, B. P., Raudsepp, T., Fronicke, L., \& Scherthan, H. (1998). Emerging patterns of comparative genome organization in some mammalian species as revealed by Zoo-FISH. Genome research, 8(6), 577-589.

Cibus Biotech GmbH. (2014). from http://www.cibusbiotech.de/de/dienstleistungen/tierarten/, abgerufen am 22.01.2014.

Clarkson, M. J., Downham, D. Y., Faull, W. B., Hughes, J. W., Manson, F. J., Merritt, J. B., Murray, R. D., Russell, W. B., Sutherst, J. E., \& Ward, W. R. (1996). Incidence and prevalence of lameness in dairy cattle. The Veterinary record, 138(23), 563567. 
Cole, J. B., Wiggans, G. R., Ma, L., Sonstegard, T. S., Lawlor, T. J., Jr., Crooker, B. A., Van Tassell, C. P., Yang, J., Wang, S., Matukumalli, L. K., \& Da, Y. (2011). Genomewide association analysis of thirty one production, health, reproduction and body conformation traits in contemporary U.S. Holstein cows. BMC genomics, $12,408$.

Cooper, M. P., Fretwell, N., Bailey, S. J., \& Lyons, L. A. (2006). White spotting in the domestic cat (Felis catus) maps near KIT on feline chromosome B1. Animal Genetics, 37, 163-165.

Coyne, M. J., Cousin, H., Loftus, J. P., Johnson, P. J., Belknap, J. K., Gradil, C. M., Black, S. J., \& Alfandari, D. (2009). Cloning and expression of ADAM-related metalloproteases in equine laminitis. Veterinary immunology and immunopathology, 129(3-4), 231-241.

Davoli, T., \& de Lange, T. (2011). The causes and consequences of polyploidy in normal development and cancer. Annual review of cell and developmental biology, 27, 585-610.

Decker, J. E., Pires, J. C., Conant, G. C., McKay, S. D., Heaton, M. P., Chen, K., Cooper, A., Vilkki, J., Seabury, C. M., Caetano, A. R., Johnson, G. S., Brenneman, R. A., Hanotte, O., Eggert, L. S., Wiener, P., Kim, J. J., Kim, K. S., Sonstegard, T. S., Van Tassell, C. P., Neibergs, H. L., McEwan, J. C., Brauning, R., Coutinho, L. L., Babar, M. E., Wilson, G. A., McClure, M. C., Rolf, M. M., Kim, J., Schnabel, R. D., \& Taylor, J. F. (2009). Resolving the evolution of extant and extinct ruminants with high-throughput phylogenomics. Proceedings of the National Academy of Sciences of the United States of America, 106(44), 18644-18649.

Deimel, I., Franz, A., Frentrup, M., von Meyer, M., Spiller, A., \& Theuvsen, L. (2010). Perspektiven für ein Europäisches Tierschutzlabel. BLE Projektkennziffer $08 \mathrm{HS} 010$.

Dekkers, J. C., \& Hospital, F. (2002). The use of molecular genetics in the improvement of agricultural populations. Nature reviews. Genetics, 3(1), 22-32.

Donovan, G. A., Risco, C. A., Temple, G. M., Tran, T. Q., \& van Horn, H. H. (2004). Influence of transition diets on occurence of subclinical laminitis in Holstein dairy cows. Journal of dairy science, 87(1), 73-84.

Doosti, A., Ghasemi Dehkordi, P., \& Rahimi, E. (2014). Molecular assay to fraud identification of meat products. Journal of food science and technology, 51(1), 148-152. 
Dreger, D. L., \& Schmutz, S. M. (2010). The variant red coat colour phenotype of Holstein cattle maps to BTA27. Animal genetics, 41(1), 109-112.

Drögemüller, C., Engensteiner, M., Moser, S., Rieder, S., \& Leeb, T. (2009). Genetic mapping of the belt pattern in Brown Swiss cattle to BTA3. Animal genetics, 40(2), 225-229.

Durkin, K., Coppieters, W., Drogemuller, C., Ahariz, N., Cambisano, N., Druet, T., Fasquelle, C., Haile, A., Horin, P., Huang, L., Kamatani, Y., Karim, L., Lathrop, M., Moser, S., Oldenbroek, K., Rieder, S., Sartelet, A., Solkner, J., Stalhammar, H., Zelenika, D., Zhang, Z., Leeb, T., Georges, M., \& Charlier, C. (2012). Serial translocation by means of circular intermediates underlies colour sidedness in cattle. Nature, 482(7383), 81-84.

Elferink, M. G., Vallee, A. A., Jungerius, A. P., Crooijmans, R. P., \& Groenen, M. A. (2008). Partial duplication of the PRLR and SPEF2 genes at the late feathering locus in chicken. BMC genomics, 9, 391.

Enting, H., Kooij, D., A.A., D., Huirne, R. B. M., \& Noordhuizen-Stassen, E. N. (1997). Economic losses due to clinical lameness in dairy cattle. Livest Prod Sci, 49, 259267.

Ettema, J. F., \& Ostergaard, S. (2006). Economic decision making on prevention and control of clinical lameness in Danish dairy herds. Livestock Science, 102, 92106.

Fan, B., Onteru, S. K., Du, Z. Q., Garrick, D. J., Stalder, K. J., \& Rothschild, M. F. (2011). Genome-wide association study identifies Loci for body composition and structural soundness traits in pigs. PloS one, 6(2), e14726.

Fernandez-Rodriguez, A., Estelle, J., Blin, A., Munoz, M., Crechet, F., Demenais, F., Vincent-Naulleau, S., \& Bourneuf, E. (2014). KIT and melanoma predisposition in pigs: sequence variants and association analysis. Animal genetics, 45(3), 445448.

Ferreira, J., \& Zwinderman, A. (2006). On the Benjamini-Hochberg method. The Annals of Statistics, 34(4), 1827-1849.

Fiedler, A., \& Maierl, J. (2004). Managment der Klauengesundheit beim Rind. Gelsenkirchen: Verlag Th. Mann. 
Fontanesi, L., Beretti, F., Martelli, P. L., Colombo, M., Dall'olio, S., Occidente, M., Portolano, B., Casadio, R., Matassino, D., \& Russo, V. (2011). A first comparative map of copy number variations in the sheep genome. Genomics, 97(3), 158165.

Fontanesi, L., Beretti, F., Riggio, V., Gomez Gonzalez, E., Dall'Olio, S., Davoli, R., Russo, V., \& Portolano, B. (2009). Copy number variation and missense mutations of the agouti signaling protein (ASIP) gene in goat breeds with different coat colors. Cytogenetic and genome research, 126(4), 333-347.

Fontanesi, L., Scotti, E., \& Russo, V. (2012). Haplotype variability in the bovine MITF gene and association with piebaldism in Holstein and Simmental cattle breeds. Animal Genetics, 43, 250-256.

Fontanesi, L., Tazzoli, M., Russo, V., \& Beever, J. (2010). Genetic heterogeneity at the bovine KIT gene in cattle breeds carrying different putative alleles at the spotting locus. Animal genetics, 41(3), 295-303.

Gernand, E., Rehbein, P., von Borstel, U. U., \& Konig, S. (2012). Incidences of and genetic parameters for mastitis, claw disorders, and common health traits recorded in dairy cattle contract herds. Journal of dairy science, 95(4), 21442156.

Gesellschaft für Tierzuchtwissenschaften. (2003). Stellungnahme zur Zukunft der Tierzuchtforschung und Genomanalyse. from http://www.tierzuchtwissenschaft.de/Publikationen.html, abgerufen am 02.03.2014.

Giaretta, N., Di Giuseppe, A. M., Lippert, M., Parente, A., \& Di Maro, A. (2013). Myoglobin as marker in meat adulteration: a UPLC method for determining the presence of pork meat in raw beef burger. Food chemistry, 141(3), 1814-1820.

Giuffra, E., Evans, G., Tornsten, A., Wales, R., Day, A., Looft, H., Plastow, G., \& Andersson, L. (1999). The Belt mutation in pigs is an allele at the Dominant white (I/KIT) locus. Mammalian genome : official journal of the International Mammalian Genome Society, 10(12), 1132-1136.

Graphodatskaya, D., Joerg, H., \& Stranzinger, G. (2002). Molecular and pharmacological characterisation of the MSH-R alleles in Swiss cattle breeds. Journal of receptor and signal transduction research, 22(1-4), 421-430. 
Green, L. E., Hedges, V. J., Schukken, Y. H., Blowey, R. W., \& Packington, A. J. (2002). The impact of clinical lameness on the milk yield of dairy cows. Journal of dairy science, 85(9), 2250-2256.

Greenough, P. R., \& Vermunt, J. J. (1991). Evaluation of subclinical laminitis in a dairy herd and observations on associated nutritional and management factors. The Veterinary record, 128(1), 11-17.

Greiner bio-one. (2014). $\quad$ CarnoCheck. from http://www.greinerbioone.com/de/germany/articles/catalogue/articles/353_1 /, abgerufen am 22.01.2014.

Grosz, M. D., \& MacNeil, M. D. (1999). The "spotted" locus maps to bovine chromosome 6 in a Hereford-Cross population. The Journal of heredity, 90(1), 233-236.

Guibert, S., Girardot, M., Leveziel, H., Julien, R., \& Oulmouden, A. (2004). Pheomelanin coat colour dilution in French cattle breeds is not correlated with the TYR, TYRP1 and DCT transcription levels. Pigment cell research / sponsored by the European Society for Pigment Cell Research and the International Pigment Cell Society, 17(4), 337-345.

Haase, B., Brooks, S. A., Tozaki, T., Burger, D., Poncet, P. A., Rieder, S., Hasegawa, T., Penedo, C., \& Leeb, T. (2009). Seven novel KIT mutations in horses with white coat colour phenotypes. Animal genetics, 40(5), 623-629.

Harder, B., Bennewitz, J., Hinrichs, D., \& Kalm, E. (2006). Genetic parameters for health traits and their relationship to different persistency traits in German Holstein dairy cattle. Journal of dairy science, 89(8), 3202-3212.

Hauswirth, R., Jude, R., Haase, B., Bellone, R. R., Archer, S., Holl, H., Brooks, S. A., Tozaki, T., Penedo, M. C., Rieder, S., \& Leeb, T. (2013). Novel variants in the KIT and PAX3 genes in horses with white-spotted coat colour phenotypes. Animal genetics, 44(6), 763-765.

Hayes, B. J., Pryce, J., Chamberlain, A. J., Bowman, P. J., \& Goddard, M. E. (2010). Genetic architecture of complex traits and accuracy of genomic prediction: coat colour, milk-fat percentage, and type in Holstein cattle as contrasting model traits. PLoS genetics, 6(9), e1001139. 
Hayya, J., Armstrong, D., \& Gressis, N. (1975). A note on the ratio of two normally distributed variables. Management Science, 21(11), 1338-1341.

Heringstad, B., Klemetsdal, G., \& Ruane, J. (2000). Selection for mastitis resistance in dairy cattle: a review with focus on the situation in the Nordic countries. Livestock Production Science, 64, 95-106.

Hiendleder, S., Thomsen, H., Reinsch, N., Bennewitz, J., Leyhe-Horn, B., Looft, C., Xu, N., Medjugorac, I., Russ, I., Kuhn, C., Brockmann, G. A., Blumel, J., Brenig, B., Reinhardt, F., Reents, R., Averdunk, G., Schwerin, M., Forster, M., Kalm, E., \& Erhardt, G. (2003). Mapping of QTL for Body Conformation and Behavior in Cattle. The Journal of heredity, 94(6), 496-506.

Hindson, B. J., Ness, K. D., Masquelier, D. A., Belgrader, P., Heredia, N. J., Makarewicz, A. J., Bright, I. J., Lucero, M. Y., Hiddessen, A. L., Legler, T. C., Kitano, T. K., Hodel, M. R., Petersen, J. F., Wyatt, P. W., Steenblock, E. R., Shah, P. H., Bousse, L. J., Troup, C. B., Mellen, J. C., Wittmann, D. K., Erndt, N. G., Cauley, T. H., Koehler, R. T., So, A. P., Dube, S., Rose, K. A., Montesclaros, L., Wang, S., Stumbo, D. P., Hodges, S. P., Romine, S., Milanovich, F. P., White, H. E., Regan, J. F., Karlin-Neumann, G. A., Hindson, C. M., Saxonov, S., \& Colston, B. W. (2011). High-throughput droplet digital PCR system for absolute quantitation of DNA copy number. Analytical chemistry, 83(22), 8604-8610.

Hinkley, D. V. (1969). On the ratio of two correlated normal random variables. Biometrika, 56(3), 635-639.

Hoblet, K. H., \& Weiss, W. (2001). Metabolic hoof horn disease. Claw horn disruption. The Veterinary clinics of North America. Food animal practice, 17(1), 111-127, vi-vii.

Holzhauer, M., Hardenberg, C., Bartels, C. J., \& Frankena, K. (2006). Herd- and cowlevel prevalence of digital dermatitis in the Netherlands and associated risk factors. Journal of dairy science, 89(2), 580-588.

Hsieh, Y. H. P., Johnson, M. A., Wetzstein, C. J., \& Green, N. R. (1996). Detection of species adulteration in pork products using agar-gel immunodiffusion and enzyme-linked immunosorbent assay. Journal of Food Quality, 19, 1-13.

Hsieh, Y. H. P., Woodward, B. B., \& Ho, S. H. (1995). Detection of species substitution in raw and cooked meats using immunoassays. Journal of Food Protection, 58(5), 555-559. 
Jackson, I. J. (1997). Homologous pigmentation mutations in human, mouse and other model organisms. Human molecular genetics, 6(10), 1613-1624.

Joerg, H., Fries, H. R., Meijerink, E., \& Stranzinger, G. F. (1996). Red coat color in Holstein cattle is associated with a deletion in the MSHR gene. Mammalian genome : official journal of the International Mammalian Genome Society, 7(4), 317-318.

Johansson, K., Eriksson, J.-A., Nielsen, U. S., Pösö, J., \& Aamand, G. P. (2011). Genetic Evaluation of Claw Health in Denmark, Finland and Sweden. Interbull Bull, 44, 224-228.

Johansson Moller, M., Chaudhary, R., Hellmen, E., Hoyheim, B., Chowdhary, B., \& Andersson, L. (1996). Pigs with the dominant white coat color phenotype carry a duplication of the KIT gene encoding the mast/stem cell growth factor receptor. Mammalian genome : official journal of the International Mammalian Genome Society, 7(11), 822-830.

Kang'ethe, E. K., Gathuma, J. M., \& Lindqvist, K. J. (1986). Identification of the species of origin of fresh, cooked and canned meat and meat products using antisera to thermostable muscle antigens by Ouchterlony's double diffusion test. Journal of the Science of Food and Agriculture, 37, 157-164.

Kerje, S., Lind, J., Schutz, K., Jensen, P., \& Andersson, L. (2003). Melanocortin 1receptor (MC1R) mutations are associated with plumage colour in chicken. Animal genetics, 34(4), 241-248.

Kijas, J. M., Moller, M., Plastow, G., \& Andersson, L. (2001). A frameshift mutation in MC1R and a high frequency of somatic reversions cause black spotting in pigs. Genetics, 158(2), 779-785.

Kijas, J. M., Wales, R., Tornsten, A., Chardon, P., Moller, M., \& Andersson, L. (1998). Melanocortin receptor 1 (MC1R) mutations and coat color in pigs. Genetics, 150(3), 1177-1185.

Klungland, H., Vage, D. I., Gomez-Raya, L., Adalsteinsson, S., \& Lien, S. (1995). The role of melanocyte-stimulating hormone (MSH) receptor in bovine coat color determination. Mammalian genome : official journal of the International Mammalian Genome Society, 6(9), 636-639. 
Kobayashi, T., Imokawa, G., Bennett, D. C., \& Hearing, V. J. (1998). Tyrosinase stabilization by Tyrp1 (the brown locus protein). The Journal of biological chemistry, 273(48), 31801-31805.

König, S. (2012). Resistenz und Suszeptibilität gegen Krankheiten. Nova Acta Leopoldina, 388, 191-203.

König, S., Sharifi, A. R., Wentrot, H., Landmann, D., Eise, M., \& Simianer, H. (2005). Genetic parameters of claw and foot disorders estimated with logistic models. Journal of dairy science, 88(9), 3316-3325.

König, S., \& Swalve, H. H. (2006). Modellkalkulationen zu züchterischen Möglichkeiten auf Klauengesundheit beim Milchrind. Züchtungskunde, 78(5), 345-356.

Kossaibati, M. A., \& Esslemont, R. J. (2000, 03.-07.09.). The incidence of lameness in 50 dairy herds in England. Paper presented at the XI Int. Symp. Disorders of the Ruminant Digit, Parma, Italy.

Kriegesmann, B., Dierkes, B., Leeb, T., Jansen, S., \& Brenig, B. (2001). Two breedspecific bovine MC1-R alleles in Brown Swiss and Saler breeds. Journal of dairy science, 84(7), 1768-1771.

Kühn, C., \& Weikard, R. (2007). An investigation into the genetic background of coat colour dilution in a Charolais $\times$ German Holstein F2 resource population. Animal Genetics, 38, 109-113.

Larson, G., \& Burger, J. (2013). A population genetics view of animal domestication. Trends in genetics : TIG, 29(4), 197-205.

Laube, I., Spiegelberg, A., Butschke, A., Zagon, J., Schauzu, M., Kroh, L., \& Broll, H. (2003). Methods for the detection of beef and pork in foods using real-time polymerase chain reaction. International Journal of Food Science and Technology, 38, 111-118.

Laube, I., Zagon, J., \& Broll, H. (2007a). Quantitative determination of commercially relevant species in foods by real-time PCR. International Journal of Food Science and Technology, 42, 336-341.

Laube, I., Zagon, J., Spiegelberg, A., Butschke, A., Kroh, L., \& Broll, H. (2007b). Development and design of a 'ready-to-use' reaction plate for a PCR-based 
simultaneous detection of animal species used in foods. International Journal of Food Science and Technology, 42, 9-17.

Laursen, M. V., Boelling, D., \& Mark, T. (2009). Genetic parameters for claw and leg health, foot and leg conformation, and locomotion in Danish Holsteins. Journal of dairy science, 92(4), 1770-1777.

Le Fevre, A. M., Logue, D. N., Offer, J. E., McKendrick, I., \& Gettinby, G. (2001). Correlations of measurements of subclinical claw horn lesions in dairy cattle. The Veterinary record, 148(5), 135-138.

Lean, I. J., Westwood, C. T., Golder, H. M., \& Vermunt, J. J. (2013). Impact of nutrition on lameness and claw health in cattle. Livestock Science, 156, 71-87.

Lischer, C., \& Ossent, P. (1994). [Laminitis in cattle: a literature review]. Tierärztliche Praxis, 22(5), 424-432.

Lo, Y. M., Lun, F. M., Chan, K. C., Tsui, N. B., Chong, K. C., Lau, T. K., Leung, T. Y., Zee, B. C., Cantor, C. R., \& Chiu, R. W. (2007). Digital PCR for the molecular detection of fetal chromosomal aneuploidy. Proceedings of the National Academy of Sciences of the United States of America, 104(32), 13116-13121.

Machado, V. S., Caixeta, L. S., McArt, J. A., \& Bicalho, R. C. (2010). The effect of claw horn disruption lesions and body condition score at dry-off on survivability, reproductive performance, and milk production in the subsequent lactation. Journal of dairy science, 93(9), 4071-4078.

Maclean, C. W. (1965). Observations on Acute Laminitis of Cattle in South Hampshire. The Veterinary record, 77, 662-672.

Maclean, C. W. (1971). The histopathology of laminitis in dairy cows. Journal of comparative pathology, 81(4), 563-570.

Maede, D. (2006). A strategy for molecular species detectionin meat and meat products by PCR-RFLP and DNA sequencing using mitochondrial and chromosomal sequences. European Food Research and Technology, 224, 209217.

Manske, T., Hultgren, J., \& Bergsten, C. (2002). The effect of claw trimming on the hoof health of Swedish dairy cattle. Preventive veterinary medicine, 54(2), 113-129. 
Marklund, L., Moller, M. J., Sandberg, K., \& Andersson, L. (1996). A missense mutation in the gene for melanocyte-stimulating hormone receptor (MC1R) is associated with the chestnut coat color in horses. Mammalian genome : official journal of the International Mammalian Genome Society, 7(12), 895-899.

Marklund, S., Kijas, J., Rodriguez-Martinez, H., Ronnstrand, L., Funa, K., Moller, M., Lange, D., Edfors-Lilja, I., \& Andersson, L. (1998). Molecular basis for the dominant white phenotype in the domestic pig. Genome research, 8(8), 826833.

Matsunaga, T., Chikuni, K., Tanabe, R., Muroya, S., Shibata, K., Yamada, J., \& Shinmura, Y. (1999). A quick and simple method for the identification of meat species and meat products by PCR assay. Meat science, 51(2), 143-148.

Meuwissen, T. H., Hayes, B. J., \& Goddard, M. E. (2001). Prediction of total genetic value using genome-wide dense marker maps. Genetics, 157(4), 1819-1829.

Mohanty, T. R., Seo, K. S., Park, K. M., Choi, T. J., Choe, H. S., Baik, D. H., \& Hwang, I. H. (2008). Molecular variation in pigmentation genes contributing to coat colour in native Korean Hanwoo cattle. Animal genetics, 39(5), 550-553.

Momcilovic, D., Herbein, J. H., Whittier, W. D., \& Polan, C. E. (2000). Metabolic alturations associated with an attempt to induce laminitis in dairy calves. Journal of Dairy Sciences, 83(3), 518-525.

Morisset, D., Stebih, D., Milavec, M., Gruden, K., \& Zel, J. (2013). Quantitative analysis of food and feed samples with droplet digital PCR. PloS one, 8(5), e62583.

Mountjoy, K. G., Robbins, L. S., Mortrud, M. T., \& Cone, R. D. (1992). The cloning of a family of genes that encode the melanocortin receptors. Science, 257(5074), 1248-1251.

Mülling, C. K. (2007, 29.7-04.08). Metabolic disorders and laminitis in cattle-a review. Paper presented at the XIII International conference of production diseases in farm animals, Leipzig, Germany.

Mülling, C. K. (2011, 07.-08.10.). Klauenrehe und Hufrehe: Gemeinsamkeiten und Differenzen. Paper presented at the Internationale Konferenz "Prophylaxe von Herden- bzw. Produktionskrankheiten" (ICPPD), Leipzig, Germany. 
Mülling, C. K., Green, L. E., Barker, Z., Scaife, J., Amory, J., \& Speijers, M. (2006, 15.19.10.). Risk factors associated with foot lameness in dairy cattle and a suggested approach for lameness reduction. Paper presented at the XXIV World Buiatrics Congress, Nice, France.

Mülling, C. K., \& Lischer, C. J. (2002, 18.-23.8.). New Aspects on Etiology and Pathogenesis of Laminitis in Cattle. Paper presented at the XXII World Buiatrics Congress, Hannover, Germany.

Murray, R. D., Downham, D. Y., Clarkson, M. J., Faull, W. B., Hughes, J. W., Manson, F. J., Merritt, J. B., Russell, W. B., Sutherst, J. E., \& Ward, W. R. (1996). Epidemiology of lameness in dairy cattle: description and analysis of foot lesions. The Veterinary record, 138(24), 586-591.

Nakamura, M., Tobin, D. J., Richards-Smith, B., Sundberg, J. P., \& Paus, R. (2002). Mutant laboratory mice with abnormalities in pigmentation: annotated tables. Journal of dermatological science, 28(1), 1-33.

Nakano, M., Komatsu, J., Matsuura, S., Takashima, K., Katsura, S., \& Mizuno, A. (2003). Single-molecule PCR using water-in-oil emulsion. Journal of Biotechnology, 102, 117-124.

Nass, M. M. (1969). Mitochondrial DNA: Advances, Problems, and Goals. Science, 165(3888), 25-35.

Newton, J. M., Wilkie, A. L., He, L., Jordan, S. A., Metallinos, D. L., Holmes, N. G., Jackson, I. J., \& Barsh, G. S. (2000). Melanocortin 1 receptor variation in the domestic dog. Mammalian genome : official journal of the International Mammalian Genome Society, 11(1), 24-30.

Niedersächsisches Landesamt für Verbraucherschutz und Lebensmittelsicherheit. (2013). Nicht deklariertes Pferdefleisch in Fertiggerichten: Ergebnisse in Niedesachsen. from http://www.laves.niedersachsen.de/portal/live.php?navigation_id=20104\&arti cle_id=114072\&_psmand=23\#4._Ergebnisse_in_Niedersachsen, abgerufen am 13.03.2014.

Niedersächsisches Ministerium für Ernährung, L. u. V. M. (2011). Tierschutzplan Niedersachsen. from http://www.ml.niedersachsen.de/portal/live.php?navigation_id=28272\&article _id=98191\&_psmand=7, abgerufen am 13.03.2014. 
Nielsen, C., Stengarde, L., Bergsten, C., \& Emanuelson, U. (2013). Relationship between herd-level incidence rate of energy-related postpartum diseases, general risk factors and claw lesions in individual dairy cows recorded at maintenance claw trimming. Acta veterinaria Scandinavica, 55, 55.

Nilsson, S. A. (1963). Clinical, morphological and experimental studies of laminitis in cattle. Acta veterinaria Scandinavica, 4(Suppl. I), 304.

Nishikawa, S., Kusakabe, M., Yoshinaga, K., Ogawa, M., Hayashi, S., Kunisada, T., Era, T., \& Sakakura, T. (1991). In utero manipulation of coat color formation by a monoclonal anti-c-kit antibody: two distinct waves of c-kit-dependency during melanocyte development. The EMBO journal, 10(8), 2111-2118.

Nocek, J. E. (1997). Bovine acidosis: implications on laminitis. Journal of dairy science, $80(5), 1005-1028$.

Nonneman, D., Shibuya, H., \& Johnson, G. S. (1996). A BstUI PCR/RFLP in the bovine tyrosinase-related protein-1 (TYRP1) gene. Animal Genetics, 27, 218-219.

Norris, B. J., \& Whan, V. A. (2008). A gene duplication affecting expression of the ovine ASIP gene is responsible for white and black sheep. Genome research, 18(8), 1282-1293.

Nuss, K., \& Steiner, A. (2004). Spezielle Diagnostik und Therapie. In A. Fiedler, J. Maierl \& K. Nuss (Eds.), Erkrankungen der Klauen und Zehen des Rindes. Stuttgart: Schattauer Verlag.

Odegard, C., Svendsen, M., \& Heringstad, B. (2013). Genetic analyses of claw health in Norwegian Red cows. Journal of dairy science, 96(11), 7274-7283.

Oklahoma State University. (1998). Breeds of Livestock. from http://www.ansi.okstate.edu/breeds/cattle/whitepark/index.htm, abgerufen am 15.03.2014.

Olmos, G., Boyle, L., Horan, B., Berry, D. P., O'Connor, P., Mee, J. F., \& Hanlon, A. (2009). Effect of genetic group and feed system on locomotion score, clinical lameness and hoof disorders of pasture-based Holstein-Friesian cows. Animal : an international journal of animal bioscience, 3(1), 96-107. 
Olson, T. A. (1999). Genetics of colour variation. In R. F. A. Ruvinsky (Ed.), The Genetics of Cattle (pp. 33-54). Wallingford, UK: CABI.

Onteru, S. K., Fan, B., Mote, B., Serenius, T., Nikkilae, M., Stalder, K. J., \& Rothschild, M. F. (2008). SNP discovery in genes affecting leg health traits in pigs. Developments in biologicals, 132, 337-342.

Ossent, P., \& Lischer, C. (1998). Bovine Laminitis: The Lesions and their Pathogenesis. In Practice, 20, 415-427.

Parzen, E. (1962). On estimation of a probability density function and mode. Annals of Mathematical Statistics, 33(3), 1065-1076.

Pawlak, E. A., Geor, R. J., Watts, M. R., Black, S. J., Johnson, P. J., \& Belknap, J. K. (2014). Regulation of hypoxia-inducible factor-1alpha and related genes in equine digital lamellae and in cultured keratinocytes. Equine veterinary journal, 46(2), 203-209.

Payne, B. A., Wilson, I. J., Yu-Wai-Man, P., Coxhead, J., Deehan, D., Horvath, R., Taylor, R. W., Samuels, D. C., Santibanez-Koref, M., \& Chinnery, P. F. (2013). Universal heteroplasmy of human mitochondrial DNA. Hum Mol Genet, 22(2), 384-390.

Peterse, D. J. (1979). [Nutrition as a possible factor in the pathogenesis of ulcers of the sole in cattle (author's transl)]. Tijdschrift voor diergeneeskunde, 104(24), 966970.

Philipp, U., Lupp, B., Momke, S., Stein, V., Tipold, A., Eule, J. C., Rehage, J., \& Distl, O. (2011). A MITF mutation associated with a dominant white phenotype and bilateral deafness in German Fleckvieh cattle. PloS one, 6(12), e28857.

Pinheiro, L. B., Coleman, V. A., Hindson, C. M., Herrmann, J., Hindson, B. J., Bhat, S., \& Emslie, K. R. (2012). Evaluation of a droplet digital polymerase chain reaction format for DNA copy number quantification. Analytical chemistry, 84(2), 10031011.

R-Biopharm AG. (2014). from http://www.r-biopharm.com/de/produkte/lebensmittelfuttermittelanalytik/tierartennachweis, abgerufen am 22.01.2014.

Rao, C., Foernzler, D., Loftus, S. K., Liu, S., McPherson, J. D., Jungers, K. A., Apte, S. S., Pavan, W. J., \& Beier, D. R. (2003). A defect in a novel ADAMTS family member 
is the cause of the belted white-spotting mutation. Development, 130(19), 4665-4672.

Reinsch, N., Thomsen, H., Xu, N., Brink, M., Looft, C., Kalm, E., Brockmann, G. A., Grupe, S., Kuhn, C., Schwerin, M., Leyhe, B., Hiendleder, S., Erhardt, G., Medjugorac, I., Russ, I., Forster, M., Reents, R., \& Averdunk, G. (1999). A QTL for the degree of spotting in cattle shows synteny with the KIT locus on chromosome 6 . The Journal of heredity, 90(6), 629-634.

Reissmann, M., \& Ludwig, A. (2013). Pleiotropic effects of coat colour-associated mutations in humans, mice and other mammals. Seminars in cell \& developmental biology, 24(6-7), 576-586.

Ren, J. G., Li, Z., \& Sacks, D. B. (2007). IQGAP1 modulates activation of B-Raf. Proceedings of the National Academy of Sciences of the United States of America, 104(25), 10465-10469.

Robin, E. D., \& Wong, R. (1988). Mitochondrial DNA molecules and virtual number of mitochondria per cell in mammalian cells. Journal of cellular physiology, 136(3), 507-513.

Rosenblatt, M. (1956). Remarks on some nonparametric estimates of a density function. Annals of Mathematical Statistics, 27(3), 832-837.

Rouzaud, F., Martin, J., Gallet, P. F., Delourme, D., Goulemot-Leger, V., Amigues, Y., Menissier, F., Leveziel, H., Julien, R., \& Oulmouden, A. (2000). A first genotyping assay of French cattle breeds based on a new allele of the extension gene encoding the melanocortin-1 receptor (Mc1r). Genetics, selection, evolution : GSE, 32(5), 511-520.

Rubin, C. J., Megens, H. J., Martinez Barrio, A., Maqbool, K., Sayyab, S., Schwochow, D., Wang, C., Carlborg, O., Jern, P., Jorgensen, C. B., Archibald, A. L., Fredholm, M., Groenen, M. A., \& Andersson, L. (2012). Strong signatures of selection in the domestic pig genome. Proceedings of the National Academy of Sciences of the United States of America, 109(48), 19529-19536.

Schmutz, S. M. (2002). Genetics of coat color in cattle. from http://homepage.usask.ca/ schmutz/, abgerufen am 07.01.2014.

Schmutz, S. M., Berryere, T. G., Ciobanu, D. C., Mileham, A. J., Schmidtz, B. H., \& Fredholm, M. (2004). A form of albinism in cattle is caused by a tyrosinase 
frameshift mutation. Mammalian genome : official journal of the International Mammalian Genome Society, 15(1), 62-67.

Schmutz, S. M., \& Dreger, D. L. (2012). Interaction of MC1R and PMEL alleles on solid coat colors in Highland cattle. Animal Genetics, 44, 9-13.

Schöpke, K., Weidling, S., Pijl, R., \& Swalve, H. H. (2013). Relationships between bovine hoof disorders, body condition traits, and test-day yields. Journal of dairy science, 96(1), 679-689.

Seitz, J. J., Schmutz, S. M., Thue, T. D., \& Buchanan, F. C. (1999). A missense mutation in the bovine MGF gene is associated with the roan phenotype in Belgian Blue and Shorthorn cattle. Mammalian genome : official journal of the International Mammalian Genome Society, 10(7), 710-712.

Seo, K., Mohanty, T. R., Choi, T., \& Hwang, I. (2007). Biology of epidermal and hair pigmentation in cattle: a mini-review. Veterinary dermatology, 18(6), 392-400.

Shearer, J. K. (1998). Lameness in Cattle: Causes and Consequences. Bov Pract, 32(1), 79-85.

Shinomiya, A., Kayashima, Y., Kinoshita, K., Mizutani, M., Namikawa, T., Matsuda, Y., \& Akiyama, T. (2012). Gene duplication of endothelin 3 is closely correlated with the hyperpigmentation of the internal organs (Fibromelanosis) in silky chickens. Genetics, 190(2), 627-638.

Singh, S. S., Ward, W. R., Lautenbach, K., \& Murray, R. D. (1993). Behaviour of lame and normal dairy cows in cubicles and in a straw yard. The Veterinary record, 133(9), 204-208.

Singh, V. P., \& Neelam, S. (2011). Meat Species Specifications to ensure the Quality of Meat - A review. International Journal of Meat Science, 1(1), 15-26.

Sogstad, A. M., Fjeldaas, T., \& Osteras, O. (2005). Lameness and claw lesions of the Norwegian red dairy cattle housed in free stalls in relation to environment, parity and stage of lactation. Acta veterinaria Scandinavica, 46(4), 203-217.

Sogstad, A. M., Osteras, O., \& Fjeldaas, T. (2006). Bovine claw and limb disorders related to reproductive performance and production diseases. Journal of dairy science, 89(7), 2519-2528. 
Sogstad, A. M., Osteras, O., Fjeldaas, T., \& Nafstad, O. (2007). Bovine claw and limb disorders related to culling and carcass characteristics. Livest Sci, 106, 87-95.

Somers, J. G., Frankena, K., Noordhuizen-Stassen, E. N., \& Metz, J. H. (2003). Prevalence of claw disorders in Dutch dairy cows exposed to several floor systems. Journal of dairy science, 86(6), 2082-2093.

Suncrest White Galloway Cattle Stud. (2011). from http://www.suncreststud.co.nz/whitegallowaystudbackground.html, abgerufen am 19.02.2014.

Swalve, H. H. (2008). Züchterische Möglichkeiten zur Verbesserung der Tiergesundheit. Züchtungskunde, 80, 5-10.

Swalve, H. H. (2012). Aktueller Stand der züchterischen Verbesserung von Gesundheit und Funktionalität beim Nutztier. Züchtungskunde, 84(1), 32-38.

Swalve, H. H., Alkhoder, H., \& Pijl, R. (2008). Estimates of breeding values for sires based on diagnoses recorded at hoof trimming: Relationships with EBV for conformation traits. Interbull Bull, 38, 87-90.

Swalve, H. H., Pijl, R., Bethge, M., Rosner, F., \& Wensch-Dorendorf, M. (2005, 05.08.06.2005). Analysis of genetic and environmental effects on claw disorders diagnosed at hoof trimming. Paper presented at the 56th annual meeting of the European Association for Animal Production, Uppsala, Sweden.

Switonski, M., Mankowska, M., \& Salamon, S. (2013). Family of melanocortin receptor (MCR) genes in mammals-mutations, polymorphisms and phenotypic effects. Journal of applied genetics, 54(4), 461-472.

Sykes, P. J., Neoh, S. H., Brisco, M. J., Hughes, E., Condon, J., \& Morley, A. A. (1992). Quantitation of targets for PCR by use of limiting dilution. BioTechniques, 13(3), 444-449.

Tølbøll, T. H., Danscher, A. M., Andersen, P. H., Codrea, M. C., \& Bendixen, E. (2012). Proteomics: a new tool in bovine claw disease research. Veterinary journal, 193(3), 694-700.

Top Agrar Fachbuch. (2003). Klauenprobleme schneller lösen. Münster: Landwirtschaftsverlag $\mathrm{GmbH}$. 
Toussaint-Raven, E. (1973). Determination of weight bearing by the cows foot. Dutch Journal of Veterinary Medicine, 5, 1237-1243.

Transia

$\mathrm{GmbH}$.

(2014).

from

http://www.transia.de/index.php?option=com_content\&view=categories\&id=1 12\&Itemid=176\&lang=de, abgerufen am 22.01.2014.

Uggla, E., Jakobsen, J. H., Bergsten, C., Eriksson, J.-A., \& Strandberg, E. (2008). Genetic Correlations between Claw Health and Feed and Leg Conformation Traits in Swedish Dairy Cows. Interbull Bull, 38, 91-95.

Urao, N., Razvi, M., Oshikawa, J., McKinney, R. D., Chavda, R., Bahou, W. F., Fukai, T., \& Ushio-Fukai, M. (2010). IQGAP1 is involved in post-ischemic neovascularization by regulating angiogenesis and macrophage infiltration. PloS one, 5(10), e13440.

Vaarst, M., Hindhede, J., \& Enevoldsen, C. (1998). Sole disorders in conventionally managed and organic dairy herds using different housing systems. The Journal of dairy research, 65(2), 175-186.

Vage, D. I., Klungland, H., Lu, D., \& Cone, R. D. (1999). Molecular and pharmacological characterization of dominant black coat color in sheep. Mammalian genome: official journal of the International Mammalian Genome Society, 10(1), 39-43.

van der Linde, C., de Jong, G., Koenen, E. P., \& Eding, H. (2010). Claw health index for Dutch dairy cattle based on claw trimming and conformation data. Journal of dairy science, 93(10), 4883-4891.

van der Spek, D., van Arendonk, J. A., Vallee, A. A., \& Bovenhuis, H. (2013). Genetic parameters for claw disorders and the effect of preselecting cows for trimming. Journal of dairy science, 96(9), 6070-6078.

van der Waaij, E. H., Holzhauer, M., Ellen, E., Kamphuis, C., \& de Jong, G. (2005). Genetic parameters for claw disorders in Dutch dairy cattle and correlations with conformation traits. Journal of dairy science, 88(10), 3672-3678.

VanRaden, P. M., Van Tassell, C. P., Wiggans, G. R., Sonstegard, T. S., Schnabel, R. D., Taylor, J. F., \& Schenkel, F. S. (2009). Invited review: reliability of genomic predictions for North American Holstein bulls. Journal of dairy science, 92(1), 16-24. 
Venhoranta, H., Pausch, H., Wysocki, M., Szczerbal, I., Hanninen, R., Taponen, J., Uimari, P., Flisikowski, K., Lohi, H., Fries, R., Switonski, M., \& Andersson, M. (2013). Ectopic KIT copy number variation underlies impaired migration of primordial germ cells associated with gonadal hypoplasia in cattle (Bos taurus). PloS one, 8(9), e75659.

Vermunt, J. J. (1992). "Subclinical" laminitis in dairy cattle. New Zealand veterinary journal, 40(4), 133-138.

Vermunt, J. J. (2007). One step closer to unravelling the pathophysiology of claw horn disruption: for the sake of the cows' welfare. Veterinary journal, 174(2), 219220.

Vermunt, J. J., \& Greenough, P. R. (1994). Predisposing factors of laminitis in cattle. The British veterinary journal, 150(2), 151-164.

Wang, L., Pawlak, E. A., Johnson, P. J., Belknap, J. K., Alfandari, D., \& Black, S. J. (2014). Expression and activity of collagenases in the digital laminae of horses with carbohydrate overload-induced acute laminitis. Journal of veterinary internal medicine / American College of Veterinary Internal Medicine, 28(1), 215-222.

Weber, A., Stamer, E., Junge, W., \& Thaller, G. (2013). Genetic parameters for lameness and claw and leg diseases in dairy cows. Journal of dairy science, 96(5), 3310-3318.

White, C. D., Brown, M. D., \& Sacks, D. B. (2009). IQGAPs in Cancer: A Family of Scaffold Proteins underlying Tumorigenesis. FEBS Letter 583(12), 1817-1824.

White Park Cattle Society Ltd. from http://www.whiteparkcattlesociety.ltd.uk/, abgerufen am 25.04.2014.

Wright, D., Boije, H., Meadows, J. R., Bed'hom, B., Gourichon, D., Vieaud, A., TixierBoichard, M., Rubin, C. J., Imsland, F., Hallbook, F., \& Andersson, L. (2009). Copy number variation in intron 1 of SOX5 causes the Pea-comb phenotype in chickens. PLoS genetics, 5(6), e1000512.

Xie, C., \& Tammi, M. (2009). CNV-seq, a new method to detect copy number variation using high-throughput sequencing. BMC Bioinformatics, 10(1), 80. 
Yoshida, H., Kunisada, T., Grimm, T., Nishimura, E. K., Nishioka, E., \& Nishikawa, S. I. (2001). Review: melanocyte migration and survival controlled by SCF/c-kit expression. The journal of investigative dermatology. Symposium proceedings / the Society for Investigative Dermatology, Inc. [and] European Society for Dermatological Research, 6(1), 1-5. 


\title{
A study based on records taken at time of hoof trimming re- veals a strong association between the IQGAP1 gene and sole hemorrhage in Holstein cattle
}

\author{
H.H. Swalve ${ }^{* \#}$, C. Floren ${ }^{\S \#}$, M. Wensch-Dorendorf ${ }^{*}$, K. Schöpke $^{*}$, R. Pijl ${ }^{\dagger}$, K. Wimmers ${ }^{\ddagger}$ \\ and B. Brenig ${ }^{\S}$ \\ *Institute of Agricultural and Nutritional Sciences, University of Halle, 06099 Halle, \\ Germany \\ ${ }^{\S}$ Institute of Veterinary Medicine, University of Göttingen, Burckhardtweg 2, 37077 \\ Göttingen, Germany \\ ${ }^{\dagger}$ Fischershäuser 1, 26441 Jever, Germany \\ ${ }^{\ddagger}$ Research Unit of Molecular Biology, Leibniz Institute for Farm Animal Biology, Wil- \\ helm-Stahl-Allee 2, 18196 Dummerstorf, Germany \\ "These authors contributed equally to the work
}

published in

Journal of Dairy Science, 97 (1), 507-519 (2014)

URL: http://www.sciencedirect.com/science/article/pii/S0022030213007509

DOI: $10.3168 / j d s .2013-6997$ 


\section{Abstract}

Feet and leg problems have a major effect on the well-being and lifespan of the dairy cow and thus are economically important to the dairy farmer. Apart from approaches using genetic selection for classical traits from conformation scoring, attempts for genetic improvement can be based either on records of individual disease cases or on records of disorder status at time of hoof trimming. In this study, 1,962 first-lactation cows were subjected to hoof trimming with an assessment of disorder status for sole hemorrhage as a binary trait. Cows were from 7 large commercial herds in Mecklenburg-Western Pomerania (northeastern Germany) that had similar housing with cubicles, slatted flooring, little use of straw for bedding, and total mixed ration feeding. Cows were trimmed and assessed once, focusing on cows in the first half of the lactation. Herds were visited at intervals to enable recording of cohorts at a similar stage of lactation. Each cohort or herd-visit included between 31 and 165 cows. Additional measurements included body weight, back fat thickness, and body condition at time of trimming. Further data on dairy production, conformation scores, and reproductive performance were merged after collection of records had finished. The DNA extracted from blood of 1,183 cows was used for analysis with a custom-made array of 384 single nucleotide polymorphisms (SNP). The SNP were selected according to results from the literature for effects in classical conformation traits, from biochemical pathway analysis, and from comparative analysis of putative candidate genes in cattle, pigs, and sheep. Selection of cohorts of cows for SNP-chip analysis was such that cohorts with extreme frequencies of disorders and cohorts with slightly deviating housing systems were excluded in this first step. The results from a mixed threshold model analysis with genotype included as a fixed effect and accounting for relationships among animals revealed that the intronic SNP rs29017173 (A/G) within the IQ motif-containing GTPase-activating protein 1 (IQGAP1, Bos taurus autosome 21 ) was significantly associated with disorder status. Back-transformed means of disorder status for the 3 genotypes were $0.37(\mathrm{AA}), 0.52(\mathrm{AG})$, and $0.56(\mathrm{GG})$. Using the full data set of 1,962 cows, including the less- suitable cohorts, gave back-transformed means of 0.51 (AA), 0.58 (AG), and 0.62 (GG). As SNP rs29017173 is included on the Illumina BovineSNP50 DNA Analysis BeadChip (Illumina Inc., San Diego, CA), a sample of 2,394 artificial insemina- 
tion sires from the German calibration sample for genomic selection from birth years 1998 to 2003 was studied for possible correlated effects. The A/G polymorphism of SNP rs29017173 studied here was also associated with substantial effects for feet and leg traits from the classical conformation score system. Selection using this polymorphism will be facilitated by the fact that the same allele is favored for all traits with substantial effects. 


\section{Introduction}

The relevance of diseases of the bovine hoof for the economy of dairy production and the welfare of the dairy cow is undisputed. Detailed economic calculations for The Netherlands have been reported by Bruijnis et al. (2010, 2013). Apart from management factors such as feeding, housing, and trimming of claws, genetic factors also contribute to the occurrence of bovine claw diseases as has been shown by, for example, van der Waaij et al. (2005), Koenig et al. (2005), Swalve et al. (2008), and van der Linde et al. (2010). Estimates of heritabilities for bovine claw diseases have been of low to moderate magnitude. This has also been demonstrated by very recent studies (Buch et al., 2011; Gernand et al., 2012; Neuenschwander et al., 2012; Pritchard et al., 2013). Obviously, conducting large field studies suitable for estimating genetic contributions to the incidence of bovine claw diseases has been hampered by the availability of records on those diseases. In Scandinavian countries, systems for the recording of diseases, including claw diseases, exist and the data have been used for genetic analyses (Laursen et al., 2009; Buch et al., 2011; Häggman et al., 2013). However, estimates of heritabilities, even considering the general level of heritability for health traits, have been on the low side because it is difficult to account for environmental effects in large sets of field data with a large number of persons responsible for recording. In producer-recorded data, the inherent problem appears to be that producers only report extreme cases of diseases (Zwald et al., 2004; Neuenschwander et al., 2012; Parker Gaddis et al., 2012). This problem can also be assumed for any data based on veterinary records (Laursen et al., 2009) as only severe cases are likely to be treated by veterinarians. An alternative approach is to use data recorded at time of herd hoof trimming, which has been suggested by van der Waaij et al. (2005), Koenig et al. (2005), and Swalve et al. (2005). Recording of disorders at time of herd trimming has the distinct advantage that complete contemporary groups; that is, healthy and nonhealthy cows, can be included in later analysis. Therefore, several newer studies (Ettema et al., 2007; Sogstad et al., 2007; Cramer et al., 2009; Kujala et al., 2010; Buch et al., 2011; Fjeldaas et al., 2011; Oberbauer et al., 2013) on environmental or genetic factors influencing bovine claw diseases have been conducted on records taken at time of trimming. 
The relevance of direct observations on bovine claw health, in contrast to feet and leg conformation traits only, has been analyzed with selection index approaches (König and Swalve, 2006; van der Linde et al., 2010; Häggman et al., 2013) with the result that recording systems for claw diseases should be implemented. However, implementation of such systems will still be costly and may not even be feasible in some regions and countries. Genomic approaches could help to reduce costs as they could be based on parts of the population, thus resolving the need for nationwide recording systems. For classical conformation traits of feet and legs in dairy cows, several studies have been undertaken based on genome-scan approaches using microsatellites. Results for Danish data also including direct observations on lameness and summarizing the relevant literature at that time, have been given by Buitenhuis et al. (2007). The authors reported 4 QTL for lameness as defined as an index of various claw diseases. Studies using high-density SNP data and phenotypes describing claw health so far are missing. Accordingly, the situation in dairy cattle is different from studies on feet and leg problems in pigs, where first results based on SNP data are available (Fan et al., 2009, 2011; Laenoi et al., 2011). In genomics, the use of SNP data on the DNA level is only one of several approaches. Regarding bovine laminitis, techniques to obtain tissue samples from the corium tissue of the bovine hoof have been established, and the expression of a sample of genes has been analyzed recently (Osorio et al., 2012). Thus, the establishment of such techniques could complement studies on the DNA level in the future. In the present study, phenotypic observations for sole hemorrhage as an indicator for laminitis were used. Laminitis, also called pododermatitis aseptica diffusa, is a noninfectious disease caused by multiple factors (Vermunt and Greenough, 1994). One factor is a dietary carbohydrate overload that also leads to subacute ruminal acidosis (Nocek, 1997; Stone, 2004). Other factors that contribute to the incidence of the disease are problems of bedding and flooring (Nordlund et al., 2004). Although ruminal acidosis and laminitis can exist independently of each other, vasoactive substances can be produced in the gastrointestinal tract in the case of acidosis, and these substances may affect vascular perfusion of the digit (Lean et al., 2013). Laminitis can then manifest as damage to the vascular structures of the corium, the tissue layer between the horn structure and bone of the bovine hoof. In this study, the occurrence of hemorrhages was taken as an indicator of laminitis. 
The objective of the present study was to examine relationships between genotypes for 384 preselected SNP and disorder status for sole hemorrhage based on the experiment as described in Schöpke et al. (2013). The experiment comprised records taken at time of trimming for 1,962 first-lactation Holstein cows from 7 large dairies in northeastern Germany that had comparable environments, including TMR feeding, cubicle housing, and slatted flooring.

\section{Material and Methods}

\section{Study design and data}

In designing the study, our specific aim was to collect records on the status of claw disorders at the time of hoof trimming in commercial herds that had similar housing conditions and feeding. Disorder status for sole hemorrhage as a binary trait was defined according to the existence of hemorrhages visible on the sole and included mild as well as more severe hemorrhages. Herds were selected from the pool of contract herds of the breed association Rinderzucht Mecklenburg-Vorpommern. Selection from contract herds was desirable because these herds had been used for progeny testing and thus, around $50 \%$ of the sires were young bulls that were used in all contract herds. Selection of herds was according to conditions of housing and feeding such that large herds with cubicle housing, slatted flooring, and TMR feeding of a ration based on maize and grass silage were included. Cubicle housing, slatted floors, and TMR feeding can be viewed as standard conditions for larger herds in Germany. Further requirements were that only one unique system per farm was used and that sizeable groups of contemporaries would be available for the study. A contemporary group was defined as first-lactation cows being in a similar stage of lactation. Based on previous knowledge on the prevalence of laminitis in the course of lactation, as outlined in Pijl and Swalve (2006) and Swalve et al. (2011), recording at trimming focused on cows between d 50 and 150 of lactation. The recording consisted of visits to the specific herds by the recording team consisting of a veterinarian, a field technician, and a professional hoof trimmer. Around 30 to 60 cows were trimmed per day and farm. For larger contemporary groups, trimming per farm continued on consecutive days. In this 
way, contemporary groups were defined as herd visits (HV) and therefore represented herd effects as well as time period effects.

The outline of the experiment is described in more detail in Schöpke et al. (2013). In brief, the present study included 1,962 first-lactation cows from 7 herds, that were visited several times each, which resulted in 24 herd visits. Cows were descendants of 274 sires. Average age of calving was $28.3 \pm 3.2$ mo. Approximately $62 \%$ of all trimmings occurred in the first $100 \mathrm{~d}$ of lactation and only $10 \%$ were conducted after $\mathrm{d}$ 200. Additional measurements at time of trimming included BW, back fat thickness via ultrasound scanner, height at sacrum, and BCS. Cows were trimmed once for the experiment such that all trimmings were the second trimming in the life of each cow. In all participating herds, it was standard practice to conduct a first trimming at the time of proven pregnancy of heifers; thus, trimmings in the experiment were the first trimming while lactating.

Table 1 displays the distribution of records per HV, for herds A to $G$ and visits 1 to 5 . The smallest contemporary group contained 31 records, the largest 165 records. Prevalence rate for sole hemorrhage was remarkably different between $\mathrm{HV}$, and on a high level on average. The general level of the prevalence rate is explained by 2 factors: (1) the inclusion of mild as well as more severe cases of hemorrhages, and (2) the focus on the first trimester of lactation for which the highest prevalence rates can be expected. For a genetic study and from a statistical point of view, the ideal situation would be a prevalence rate of around 50\%, which would result in an optimal distribution of prevalence across genetic lines or genotypes for specific genes. In general, this ideal situation was given for most of the HV. However, some HV, notably B_3, G_1, and G_3, exhibited an extreme prevalence of around $90 \%$. For a genetic study, prevalence rates within contemporary groups being close to zero or close to $100 \%$ are essentially non-informative because management effects statistically cannot be separated from genetic effects.

In our study, because of financial restrictions, only about half of the cows could be genotyped using a custom-made 384-SNP array. Hence, cows had to be selected for array genotyping, whereas the remaining cows and their records served as a sample for further analysis and validation. 
Table 1. Distribution of records across study cohorts (herd-visits at hoof trimming) and prevalence rates for subclinical and clinical laminitis for the entire set of observations (data set I) and the reduced set used for array genotyping (data set II)

\begin{tabular}{|c|c|c|c|c|c|c|}
\hline \multirow{2}{*}{$\begin{array}{l}\text { Herd- } \\
\text { Visit }\end{array}$} & \multicolumn{3}{|c|}{$\begin{array}{l}\text { Full data } \\
\text { Data set I }\end{array}$} & \multicolumn{3}{|c|}{$\begin{array}{c}\text { Cows for array } \\
\text { genotyping } \\
\text { Data set II }\end{array}$} \\
\hline & $\mathrm{N}$ & $\begin{array}{l}\text { Proportion of } \\
\text { data set I (\%) }\end{array}$ & $\begin{array}{c}\text { Prevalence } \\
\text { rate }\end{array}$ & $\mathrm{N}$ & $\begin{array}{c}\text { Proportion of } \\
\text { data set II } \\
(\%)\end{array}$ & $\begin{array}{c}\text { Prevalence } \\
\text { rate }\end{array}$ \\
\hline A_1 & 75 & 3.82 & 0.39 & 73 & 6.17 & 0.40 \\
\hline A_2 & 47 & 2.40 & 0.66 & 47 & 3.97 & 0.66 \\
\hline B_1 & 92 & 4.69 & 0.30 & 89 & 7.52 & 0.31 \\
\hline B_2 & 80 & 4.08 & 0.50 & 79 & 6.68 & 0.49 \\
\hline B_3 & 79 & 4.03 & 0.92 & & & \\
\hline B_4 & 69 & 3.52 & 0.71 & & & \\
\hline C_1 & 87 & 4.43 & 0.55 & 39 & 3.30 & 0.62 \\
\hline C_2 & 73 & 3.72 & 0.53 & 73 & 6.17 & 0.53 \\
\hline C_3 & 70 & 3.57 & 0.66 & 69 & 5.83 & 0.65 \\
\hline C_4 & 165 & 8.41 & 0.68 & 164 & 13.86 & 0.68 \\
\hline D_1 & 114 & 5.81 & 0.49 & 104 & 8.79 & 0.48 \\
\hline D_2 & 80 & 4.08 & 0.25 & 80 & 6.76 & 0.25 \\
\hline D_3 & 93 & 4.74 & 0.54 & 91 & 7.69 & 0.54 \\
\hline D_4 & 84 & 4.28 & 0.73 & 49 & 4.14 & 0.71 \\
\hline E_1 & 154 & 7.85 & 0.55 & 149 & 12.60 & 0.54 \\
\hline E_2 & 31 & 1.58 & 0.61 & & & \\
\hline F_1 & 40 & 2.04 & 0.43 & & & \\
\hline F_2 & 82 & 4.18 & 0.35 & & & \\
\hline F_3 & 70 & 3.57 & 0.43 & & & \\
\hline F_4 & 65 & 3.31 & 0.40 & & & \\
\hline F_5 & 82 & 4.18 & 0.70 & & & \\
\hline G_1 & 75 & 3.82 & 0.87 & & & \\
\hline G_2 & 80 & 4.08 & 0.59 & 77 & 6.51 & 0.58 \\
\hline G_3 & 75 & 3.82 & 0.89 & & & \\
\hline
\end{tabular}


One obvious way of selecting a representative sample from a data set would be to sample cows at random. However, this way of sampling would reduce the size of the contemporary groups and hence counteract all efforts to make them as large as possible. Another way of selection in this situation would be to randomly select entire contemporary groups (i.e., HV). This in turn would not exclude the chance to select noninformative HV. Thus, entire HV were selected that exhibited a "normal" range of prevalence rates of between 0.25 and 0.71 . Following this strategy, cohorts B_1, G_1, and G_3 were not considered for initial array genotyping. As the sample for array genotyping had to be reduced further, herd F and cohorts B_4 and E_2 were also excluded. In the case of herd $F$, the argument for exclusion stemmed from the fact that rearing of young females had partly been on deep-straw bedding, whereas housing for cows was similar to that of all other herds. All other herds reared young stock on slatted floors. Exclusion of B_4 and E_2 and of some cows from C_1 and D_4 were random choices. In summary, the assignment of cohorts and cows to a sample for array genotyping and a full sample comprising all observations resulted in a total of 1,962 cows in the full data set (data set I) and in 1,183 cows in data set II (array genotyping for 384 SNP). At time of trimming, data (i.e., claw disorder status, BW, BCS, height at sacrum, and back fat thickness) were collected electronically and stored in a personal digital assistant. Later, these data were merged with additional data provided by the computing center Vereinigte Informationssysteme Tierhaltung w.V. (Verden an der Aller, Germany). Additional data comprised linear conformation scores and conformation component traits ( 25 traits; $n=1,685$ cows), first-lactation milk production ( 3 traits; $n=1,956$ cows), and reproductive performance ( 5 traits; $n=1,858$ cows).

Some of the SNP included in the array genotyping for 384 SNP were also contained on the Illumina BovineSNP50 BeadChip (Illumina Inc., San Diego, CA). Given that virtually all Holstein Al bulls in use today have been genotyped, a further data set consisted of 2,394 Al Holstein sires of German ownership with genotyping results and information on EBV. All sires were born in years 1998 to 2003 and thus represented the core of the German calibration set for genomic selection as all had EBV with high repeatability for a total of 56 EBV for individual traits as well as component traits and (sub)indices. This data set, denoted data set III, served as a basis for analysis of possible correlated effects in relation to effects based on data sets I and II. It should be noted, however, that 
the target trait of the present study, disorder status for sole hemorrhage, has not until now been routinely included in the German genetic evaluation system. Hence, it was not possible to use data set III as a validation sample. Data set III was provided by Vereinigte Informationssysteme Tierhaltung w.V.

\section{DNA Extraction, SNP Selection, and Genotyping}

Blood samples were taken at the time of trimming. Genomic DNA was extracted for all cows in data set I by using a modified protocol according to Miller et al. (1988). Quantification of DNA was then performed using a NanoDrop ND-1000 spectrophotometer (Peqlab, Erlangen, Germany).

Selection of candidate gene SNP for a custom-made chip followed a 4-step-strategy that included compiling lists of published QTL; identifying syntenic chromosomal regions across cattle, pigs, and humans; selecting candidate genes; and selecting and validating SNP. First, an in silico analysis of published QTL associated with conformation traits in cattle (Supplementary Table S1; http://dx.doi.org/10.3168/jds.20136997) and pigs was performed. Published QTL studies in cattle have generally been based on genome scans using microsatellite markers and the granddaughter design in dairy cattle populations (Ashwell et al., 1998a,b, 2001, 2002; Boichard et al., 2003; Buitenhuis et al., 2007; Hiendleder et al., 2003; Schnabel et al., 2005; Schrooten et al., 2000). The individual traits included in the analyses were rear legs side view, rear legs rear view, rear legs set, hock quality, bone quality, quality of feet and legs, feet and leg score (composite index), foot diagonal, foot angle, hocks, heel depth, and lameness.

Because databases on synteny between cattle and pig are not publically available, we used the human genome as a reference to position the conformation trait QTL determined for cattle and pig, respectively. Only QTL regions that were overlapping on human chromosomes for both species were selected for further analysis. The linkage map locations of the bovine microsatellite markers used in the above-mentioned QTL studies were determined from published marker reports or from the US Department of Agriculture's Meat Animal Research Center website (http://www.marc.usda.gov /genome/genome.html). Physical marker positions were determined on the Btau_4.0 genome assembly (National Center for Biotechnology Information, Bethesda, MD). 
Syntenic regions between cattle and humans were deciphered using BlastZ-net alignments (Kent et al., 2003; Schwartz et al., 2003). For each syntenic block, the exact position of the associated microsatellite marker was manually defined. Identified regions associated with the traits in question are given in Supplementary Table S2 (http://dx.doi.org/10.3168/jds.2013-6997).

Third, 74 functional and positional candidate genes were chosen from further studies on traits associated with locomotion and soundness of feet and legs in different livestock species. The Ingenuity Pathway Analysis software (Ingenuity Systems, Redwood City, CA) was used to identify 310 potentially functional candidate genes from approximately 4,800 annotated human genes within the selected regions to complete the 384-SNP-chip. The syntenic regions contained between 2 and 568 genes. A list of 1,035 candidate genes was extracted. The genes were assigned to at least one of the following biological functions: development, function and disease of skeleton, muscles, and connective tissue $(n=820)$; cell signaling $(n=146)$; disorder in vitamin and mineral metabolism ( $n=487)$; or carbohydrate metabolism $(n=33)$.

Finally, SNP conforming best to the following criteria were selected in the 384 genes: (a) validated SNP (according to NCBI or bovine 50k chip), (b) approximately 0.7- to $1 \mathrm{Mb}$ interval between SNP, (c) minor allele frequency (MAF) of $>0.05$, (d) not located in a repeat region, and (e) tested on a Holstein-Friesian population. The SNP codes, locations, and frequencies were obtained from the National Center for Biotechnology Information (www.ncbi.nlm.nih.gov/SNP) or Illumina databases based on the Btau_4.0 genome assembly. The number of SNP was equal to the number of genes (1 SNP per gene). A summary of the SNP on the custom-made chip is given in Table 2. For designing of custom genotyping bead chips, at least $60 \mathrm{bp}$ of sequence of either side of the SNP of interest were submitted to Illumina's online Assay Design Tool (ADT). Oligo pool assays and the Universal-32 BeadChip obtained from Illumina were used to perform GoldenGate genotyping assays of 1,183 cows according to manufacturer's protocols. Finally, the GoldenGate BeadChips were read on an IScan array scanner (Illumina Inc.) and analyzed using the GenomeStudio software (Illumina Inc.).

Because 1 SNP (HapMap54883-rs29017173, G/A) in IQGAP1 (GenelD: 532715) was strongly associated with sole hemorrhage as revealed by genotyping the cows in data set II (see Results and Discussion), all further samples $(n=779)$ were genotyped for this 
Table 2. Syntenic regions between cattle and pig and the number of selected and used SNP (MAF $>0.05$ )

\begin{tabular}{|c|c|c|c|c|c|c|}
\hline BTA & QTL & Start (Mb) & Stop (Mb) & Length & Gen/SNP & MAF $>0.05$ \\
\hline 1 & Rear legs rear view & 81.4 & 88.6 & 7.2 & 12 & 8 \\
\hline 5 & Lameness, Foot angle & 30.5 & 60.8 & 30.3 & 43 & 25 \\
\hline 6 & & 3.3 & 3.5 & 0.2 & 2 & 1 \\
\hline 6 & Foot angle & 55 & 59 & 4 & 6 & 5 \\
\hline 6 & Foot angle, Quality of feet and legs & 65.9 & 98 & 32.1 & 42 & 28 \\
\hline 7 & Feet and leg score & 17.3 & 19.2 & 1.9 & 4 & 2 \\
\hline 7 & Heel depth & 28.3 & 30.2 & 1.9 & 5 & 4 \\
\hline 7 & Foot angle & 70.8 & 87.1 & 16.3 & 19 & 16 \\
\hline 8 & Foot angle, Feet and leg score, Rear legs rear view & 63.6 & 111.8 & 48.2 & 63 & 42 \\
\hline 9 & Foot angle, Rear legs side view, $\mathrm{Cl}$ Feet and Legs & 55.6 & 58 & 2.4 & 5 & 3 \\
\hline 11 & Rear legs side view & 10.5 & 11.8 & 1.3 & 3 & 3 \\
\hline 11 & Hock quality & 25.8 & 29.7 & 3.9 & 7 & 5 \\
\hline 11 & Hocks, Rear legs set rear view & 48.8 & 69.9 & 21.1 & 26 & 13 \\
\hline 13 & Foot angle & 54.3 & 58.8 & 4.5 & 6 & 5 \\
\hline 13 & Rear legs rear view & 71.8 & 77.6 & 5.8 & 15 & 11 \\
\hline 13 & Foot angle & 84.1 & 84.4 & 0.3 & 0 & --- \\
\hline 14 & Rear legs side view & 27.1 & 33.6 & 6.5 & 5 & 4 \\
\hline 14 & Foot angle & 51.1 & 61.4 & 10.3 & 15 & 12 \\
\hline 14 & Rear legs rear view & 72.8 & 75 & 2.2 & 6 & 3 \\
\hline 15 & Heel depth & 39.1 & 41.2 & 2.1 & 8 & 7 \\
\hline 16 & Rear legs rear view & 0 & 3.9 & 3.9 & 6 & 3 \\
\hline 16 & $\mathrm{Cl}$ Feet and legs, Rear legs side view, Foot angle & 60.3 & 62.2 & 1.9 & 11 & 10 \\
\hline 17 & Foot angle & 3.2 & 12.7 & 9.5 & 9 & 7 \\
\hline 17 & Rear legs side view, Foot angle & 35.9 & 37.6 & 1.7 & 4 & 3 \\
\hline 18 & Heel depth & 46.2 & 47.4 & 1.2 & 4 & 1 \\
\hline
\end{tabular}




\begin{tabular}{lllllll}
\hline BTA & QTL & Start (Mb) & Stop (Mb) & Length & Gen/SNP & MAF >0.05 \\
\hline 21 & Foot angle, Hocks, Rear leg set rear view & 0 & 0,2 & 0,2 & 0 & -- \\
21 & Foot angle, Hocks, Rear leg set rear view & 7 & 11.9 & 4.9 & 5 & 2 \\
21 & Foot angle, Hocks, Rear leg set rear view & 20.2 & 22 & 1.8 & 6 & 4 \\
22 & Lameness & 4.7 & 12.1 & 7.4 & 9 & 7 \\
22 & Foot angle, Feet and leg score, Cl Feet and legs & 32.5 & 33.7 & 1.2 & 5 & 2 \\
23 & Rear legs rear view & 7.3 & 7.6 & 0.3 & 4 & 1 \\
23 & Rear legs rear view & 26.2 & 27.9 & 1.7 & 5 & 4 \\
23 & Quality of feet and legs, Foot angle & 46.5 & 48.6 & 2.1 & 0 & -- \\
26 & Lameness, Bone quality & 41.1 & 45.9 & 4.8 & 7 & 5 \\
27 & Hock quality, Bone quality & 39.6 & 46.1 & 6.5 & 6 & 4 \\
28 & Rear legs rear view & 34.6 & 42.8 & 8.2 & 11 & 9 \\
\hline Total & & & $259.8 \mathrm{Mb}$ & 384 SNP & 259 SNP \\
\hline
\end{tabular}

$\stackrel{\infty}{\sim}$ 
SNP by a fluorescence resonance energy transfer assay (Förster, 1946). Primers were designed corresponding to the IQGAP1 genomic DNA sequence (NCBI; NW_003104533.1) using the Primer3 program (http:// frodo.wi.mit.edu/primer3/); probes were designed with Meltcalc (http://www.meltcalc.com). Primers and probes were synthesized by Sigma-Aldrich (Taufkirchen, Germany). A 143-bp fragment was amplified with the PCR primers BT_IQGAP1_SNP_F (5'-GAATCTGGCAGTCCAACAAA-3') and BT_IQGAP1_SNP_R (5'-AATCCCCAGCCCTTTATCTT- $\left.3^{\prime}\right)$. The sensor probe BT_IQGAP1_Probe (5'-CCCCACTTAATCAGAACAGAAAT-3'), labeled at the $5^{\prime}$ end with LightCycler red fluorophore LC610 and phosphorylated at the $3^{\prime}$ end, was designed to hybridize at the SNP site (polymorphic position is underlined). The anchor probe BT_IQGAP1_Anchor (5'-AGTACTGAGCTATGGAACACCTTGCC-3') was labeled with fluorescein at the $3^{\prime}$ end. The PCR reactions were performed in a Light-Cycler 480 instrument (Roche Diagnostics, Mannheim, Germany) and carried out with the following setup: $40 \mathrm{ng}$ of DNA, $200 \mu \mathrm{mol}$ of each dNTP, $0.4 \mu \mathrm{mol}$ of each primer, $0.4 \mu \mathrm{mol}$ of hybridization probes (probe and anchor), and $1.5 \mathrm{U}$ of Fast-Start Taq-polymerase in $1 \times$ buffer as recommended by the manufacturer (Roche Diagnostics) in a total reaction volume of $25 \mu \mathrm{L}$. The PCR cycling program consisted of an initial denaturation step at $95^{\circ} \mathrm{C}$ for $10 \mathrm{~min}$, followed by 33 cycles of $30 \mathrm{~s}$ at $95^{\circ} \mathrm{C}, 30 \mathrm{~s}$ at $51^{\circ} \mathrm{C}$, and $30 \mathrm{~s}$ at $72^{\circ} \mathrm{C}$. After a denaturation step of $95^{\circ} \mathrm{C}$ for $30 \mathrm{~s}$, the melting curves were obtained from $40^{\circ} \mathrm{C}$ to $65^{\circ} \mathrm{C}$, with a temperature ramp rate of $0.11^{\circ} \mathrm{C} / \mathrm{s}$. The melting points are defined as maxima of the negative first derivative of the measured fluorescence over temperature. The melting temperature of the wild-type (GG) was $58^{\circ} \mathrm{C}$ and for the SNP variant (AA) was $50^{\circ} \mathrm{C}$. Each fluorescence resonance energy transfer assay included animals representing the 3 genotypes as controls. If the aberrance of melting temperature of the samples and the controls was less than $0.5^{\circ} \mathrm{C}$, the results were accepted.

\section{Statistical Analyses}

Possible associations between disorder status for sole hemorrhage and SNP were tested applying the following methods. First, the genotypic association between individual SNP and binary disorder status was analyzed with a $\chi 2$ test as included in the FREQ 
procedure of the SAS package (SAS Institute Inc., Cary, NC). Second, the GLIMMIX procedure of SAS was used, employing a threshold model with fixed effects to account for environmental effects. All SAS procedures were run employing self-written macro language subprograms to enable easy repetitions for all SNP. In the GLIMMIX analyses, inclusion of fixed effects was based on the models as described by Schöpke et al. (2013) and defined as follows:

$\operatorname{PR}_{L A M}\left(Y_{i j k l}=1\right)=\theta\left[\mu+G T_{i}+H V_{j}+L S_{k}+b_{1}(B W)+e_{i j k l}\right]$

where PR is the probability of occurrence of the disorder, $y_{i j k l}$ is the disorder score $(1=$ positive finding), $\theta$ is the probit link function, $\mu$ is the overall mean, $\mathrm{GT}_{\mathrm{i}}$ is the SNP genotype $(i=1,2,3), H V_{j}$ is the fixed effect of herd-visit $(j=1, \ldots, 24$ for data set $I ; j=1, \ldots$, 14 for data set II), $L S_{k}$ is the fixed effect of stage of lactation as grouped into classes ( $k$ $=1, \ldots, 5$ for DIM: $<50,50-99,100-149,150-149, \geq 150)$, and $b_{1}(B W)$ is the regression coefficient for BW, and $\mathrm{e}_{\mathrm{ijk}}$ is the residual effect. The $P$-values for the genotype effect were subjected to the Bonferroni correction to account for multiple comparisons. Associations between genotype and disorder status were also tested using the PLINK software (Purcell et al., 2007). Results for individual SNP were compared using the allelic $\chi 2$ test. For all analyses with GLIMMIX and PLINK, 259 SNP with MAF $>0.05$ could be used.

A further analysis, run for all SNP in data set II and for 1 SNP genotype available for all cows in data set I, comprised a full mixed threshold model including relationships between animals applying the ASREML software (Gilmour et al., 2009). For this analysis, the model given above was augmented by a random animal effect.

\section{Results and Discussion}

\section{Selection of SNP for the Custom-Made Chip}

The selection of SNP for the custom-made 384-SNP-chip was based on the general assumption that significant genetic correlations between leg conformation traits and claw disorders exist as was shown by van der Waaij et al. (2005). The in silico analyses revealed 91 QTL associated with 12 feet and leg conformation traits as shown in Sup- 
plementary Table S1 (http://dx.doi. org/10.3168/jds.2013-6997). Identified QTL were spread across all bovine autosomes with the exception of BTA4, 10, and 20. Chromosomes BTA6, 9, 11-13, 15-17, 21-24, and 26-28 harbor QTL affecting 2 or 3 different traits. Before our study, no published QTL for laminitis or sole hemorrhage were available and, to our knowledge, this is still the case because there is no information on QTL for this disease in CattleQTLdb (www.animalgenome.org; last accession date: December 2012) or in PubMed.

For 51 of the 91 trait-associated bovine QTL, syntenic regions on human chromosomes HSA1-6, 8-12, 17-20, and 22 have been determined (Supplementary Table S2; http://dx.doi.org/10.3168/jds.2013-6997). Similar to the studies in cattle, QTL for conformation traits in pigs were also evaluated. Sixty-eight QTL in pigs were positioned on human chromosomes 1-11 and 13-17. Performing comparative genomics, 52 corresponding regions (Supplementary Table S3; http:// dx.doi.org/10.3168/jds.2013-6997) between cattle, pig, and human were identified on human chromosomes (HSA1-6, 8$12,15,19-20)$. Based on the bovine genome, the conserved syntenic regions were located on BTA1, 5-9, 11, 13-18, 21-23, and 26-28, covering an overall range of 259.8 $\mathrm{Mb}$ (Table 2). The average QTL interval was $7.41 \mathrm{Mb}$ and ranged from $0.2 \mathrm{Mb}$ (BTA21) to $48.2 \mathrm{Mb}$ (BTA8) on individual chromosomes.

A 4-step strategy was implemented to select 384 candidate genes with the purpose of designing a custom SNP-chip with 1 SNP per candidate gene, but no SNP could be determined for the syntenic regions on BTA13 (84.1-84.4 Mb), BTA21 (0-0.2 Mb), or BTA23 (46.5-48.6 Mb; Table 2). The average physical distance between 2 neighboring SNP was $0.7 \mathrm{Mb}$, ranging from $8.9 \mathrm{~kb}$ to $17.8 \mathrm{Mb}$. In an initial in silico screen, $85 \%$ of the SNP were confirmed (GenCall score $\geq 0.6$ ). The $15 \%$ of failed markers (GenCall score $<0.6)$ were replaced by alternative SNP that were located within the same genes. The genomic positions of the SNP based on Btau 4.1 can be summarized as follows: 39 coding SNP (10.2\%), two 5'-untranslated regions (UTR) upstream SNP (0.5\%), fourteen 3'UTR downstream SNP (3.6\%), 278 intronic SNP (72.4\%), and 51 intergenic SNP (13.3\%). Because 125 SNP (32.5\%) had a MAF <0.05, only 259 SNP (67.4\%) were used for the association analysis with data set II and the Illumina Golden-Gate Genotyping Assay. A list of all SNP included in this analysis is given in Supplementary File B (Excel; http://dx.doi.org/10.3168/jds.2013-6997). 
A recently published genome-wide association analysis in US Holstein cows (Cole et al., 2011) identified various polymorphisms associated with 4 locomotion traits: foot angle (FA), rear legs side view (RLSV), rear legs rear view (RLR), and feet/legs score (FL). This confirmed our selection of genes even though different SNP within the genes had been chosen by Cole et al. (2011). Several of their top 100 most significant SNP effects (rounded cutoff for P-value: FA $P \geq 10-20$, RLS $P \geq 10-15$, RLR $P \geq 10-17$, FL $P \geq 10-17$ ) for each trait are located in or near $( \pm 5 \mathrm{Mb})$ our identified syntenic regions. Among the 20 most significant SNP effects, for FA 10 SNP (BTA14, 17, 18, 26), for RLSV 8 SNP (BTA1, 16, 18, 27), for RLR 4 SNP (BTA11, 26), and for FL 7 SNP (BTA5, 14, 26) were located in the same region or close to our studied bovine QTL regions. In a further genome-wide association analysis in pigs, applying the PorcineSNP60 BeadChip, candidate SNP and genes for several body conformation and feet and leg structure soundness traits have been identified (Fan et al., 2011). The genes GABRG2, AKAP2, ISOC1, ADAMTS19, MGMT, WISP2, WFDC5, and STK4 were also selected for our SNP-chip compilation. Additionally, more than 25 of our selected genes represent the same gene families (i.e., transcription factors, collagen proteoglycans, transforming growth factor- $\beta$, calcium channels, fibroblast growth factors, and metalloproteases). Although the molecular background of bovine laminitis is largely unknown, an increasing number of studies have been conducted on the physiology and genetics of equine laminitis, indicating the relevance of metalloproteinases for this disease: MMP-2 and MMP-9 are reported to be elevated during the acute phase of carbohydrate laminitis in horses (Johnson et al., 1998; Kyaw-Tanner and Pollitt, 2004; Kyaw-Tanner et al., 2008). A recent study (Visser and Pollitt, 2012) has, however, postulated that these proteases apparently do not initiate the pathogenesis of laminitis. Furthermore, the equine ADAMTS-4 was found to be upregulated in naturally occurring as well as in druginduced laminitis (Budak et al., 2009; Coyne et al., 2009).

\section{Analysis of Experimental Data}

Analysis by PLINK of 259 SNP with MAF $>0.05$ using data set II revealed one highly significant association between disorder status for sole hemorrhage and the SNP (Hap- 
Map54883-rs29017173, A/G) in IQGAP1 (GenelD: 532715, BTA21). The $\chi^{2}$ value was 15.182, and the P-value was 0.0000976. The genotypic $\chi^{2}$ test in the FREQ procedure of SAS yielded a test statistic of 17.6813 with a P-value of 0.0001411 , equivalent to 0.0365 after Bonferroni correction. No other SNP showed significant associations after this correction.

After the remaining cows missing in data set II but available in the full data set I had been genotyped for SNP rs29017173, tests were repeated for this SNP. In total, 1,957 cows out of 1,962 cows with sufficient call rates for this SNP could be used. This resulted in $\chi 2$ values of 9.397 with a P-value of 0.00217313 from PLINK employing the allelic $\chi 2$ test, and a respective $\chi 2$ value of 9.9281 with a P-value of 0.007 from the genotypic $\chi 2$ test (Bonferroni correction not applicable). A summary of the distribution of disorder status across genotypes is given in Table 3.

Table 3. Distribution of cows (absolute frequencies) for disorder status (0/1) for laminitis across genotypes for the SNP (rs29017173)

\begin{tabular}{lcccccc}
\hline \multirow{2}{*}{ Genotype } & \multicolumn{3}{c}{ Data set I } & \multicolumn{3}{c}{ Data set II } \\
& 0 & 1 & Total & 0 & 1 & Total \\
\hline AA & 197 & 208 & 405 & 134 & 94 & 228 \\
AG & 429 & 579 & 1008 & 282 & 330 & 612 \\
GG & 209 & 335 & 544 & 137 & 197 & 334 \\
\hline Total & 835 & 1122 & 1957 & 553 & 621 & 1174 \\
\hline
\end{tabular}

For both data sets, the frequency of the A allele of SNP rs29017173 was 0.46 . Also, in both data sets, allelic frequencies were in equilibrium. Considering disorder status, distributions were shifted toward increased frequencies for GG and disorder status $=1$. In data set II (the array analysis), the GLIMMIX analysis applying a completely fixed model resulted in back-transformed means of the disorder status of 0.35 (AA), 0.49 $(A G)$, and $0.54(G G)$, thus equal to a reduction of 0.19 when comparing both homozygous genotypes. For the full data set, data set $\mathrm{I}$, the corresponding values were 0.50 (AA), $0.56(A G)$, and $0.60(G G)$. Similar results were obtained from the mixed threshold model analysis when applying ASREML. Means back-transformed to the original scale from least square means of the ASREML analysis are given in Table 4. For the sake of comparison, the 2 left columns display the results when considering fixed effects, in- 
cluding the SNP effect, a random animal effect, and relationships between animals, whereas the 2 right columns show parameters as estimated from a model in which the effect of SNP rs29017173 was considered random instead of being treated as fixed. When $\sigma_{G}^{2}$ is the total additive genetic variance, $\sigma_{a}^{2}$ is the additive genetic (polygenic)

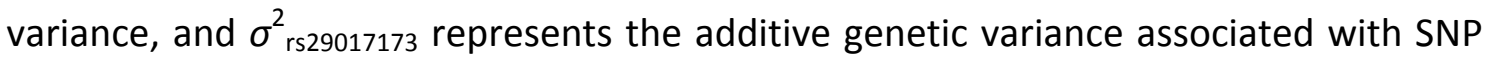

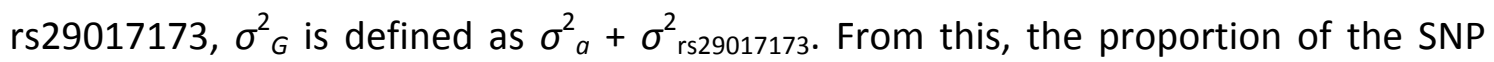
variance relative to $\sigma_{G}^{2}$ was estimated as $15.3 \%$ (data set I) and $35.2 \%$ (data set II).

The effect of the allele substitution can be visualized when breeding values were estimated using the mixed threshold model, with the effect of SNP rs29017173 treated as fixed, as shown in Figure 1. As can be seen when inspecting back-transformed means (Table 4), the $G$ allele exhibited a dominant nature. Animals with the AA genotype could be readily separated from the other 2 genotypes.

Table 4: Estimates of parameters from the mixed threshold model (ASREML analysis) when considering the genotype for SNP (rs29017173) as fixed or random in data sets I (all cows) and II (cows included in SNP array analysis)

\begin{tabular}{|c|c|c|c|c|}
\hline \multirow[b]{2}{*}{ Estimated parameter } & \multicolumn{4}{|c|}{ Genotype (SNP (rs29017173)) in model as } \\
\hline & Data set I & Data set II & Data set I & Data set II \\
\hline $\mathrm{Se}_{\mathrm{e}}^{2}$ & 1 & 1 & 1 & 1 \\
\hline $\mathrm{s}_{\mathrm{a}}{ }^{2}$ & 0.0817923 & 0.107057 & 0.0793387 & 0.102769 \\
\hline $\mathrm{s}^{2}(\mathrm{rs} 29017173)$ & - & - & 0.014348 & 0.0557341 \\
\hline$s_{p}^{2}$ & 1.0817923 & 1.107057 & 1.093687 & 1.1585031 \\
\hline$h^{2}$ & 0.0756 & 0.0967 & 0.0857 & 0.1368 \\
\hline $\mathrm{s}^{2}(\mathrm{rs} 29017173)$ in $\%$ of $\mathrm{s}_{\mathrm{G}}{ }^{2}$ & - & - & 15.31 & 35.16 \\
\hline$s^{2}(r s 29017173)$ in $\%$ of $s_{p}^{2}$ & & & 1.32 & 8.88 \\
\hline$P(y=1 \mid A A)^{1,2}$ & $0.506^{\mathrm{a}}$ & $0.369^{a}$ & $0.521^{\mathrm{a}}$ & $0.383^{a}$ \\
\hline$P(y=1 \mid A G)^{1,2}$ & $0.578^{b^{*}}$ & $0.519^{b * * *}$ & $0.576^{\mathrm{ab}}$ & $0.516^{\mathrm{b} * * *}$ \\
\hline$P(y=1 \mid G G)^{1,2}$ & $0.615^{b^{* *}}$ & $0.559^{b * * *}$ & $0.605^{b^{* *}}$ & $0.551^{\mathrm{b} * * *}$ \\
\hline Difference $P(G G)$ - $P(A A)$ & $10.9^{* *}$ & $19.0 * * *$ & $8.4^{* *}$ & $16.8^{* * *}$ \\
\hline
\end{tabular}

1) Probability of disorder status $=1$ (= back-transformed mean of disorder status on the original scale)

2) Different superscripts denote significant differences between back-transformed means. Levels of significance are ${ }^{*}=\mathrm{P}<0.05,{ }^{* *}=\mathrm{P}<0.01, * * * \mathrm{P}=<0.001$

Genotypes in data set II ( $n=1,183$ cows; $n=259$ SNP, after exclusion of MAF <0.05) were also examined using GLIMMIX for a possible association with the supplementary traits recorded at time of trimming; that is, BW, BCS at time of trimming, and back fat 
thickness, as well as with other data available for this sample-linear conformation scores, conformation component traits, first-lactation milk production data, and reproductive performance. Fixed effects in the models used were adapted to the respective traits. As the target trait in this study was sole hemorrhage as an indicator for laminitis and the SNP-chip was tailored toward the target trait, and as all "standard" traits in general are of lesser importance because they are already included in the estimation of genomic breeding values in many countries, the results of this part of our study will only be summarized briefly.

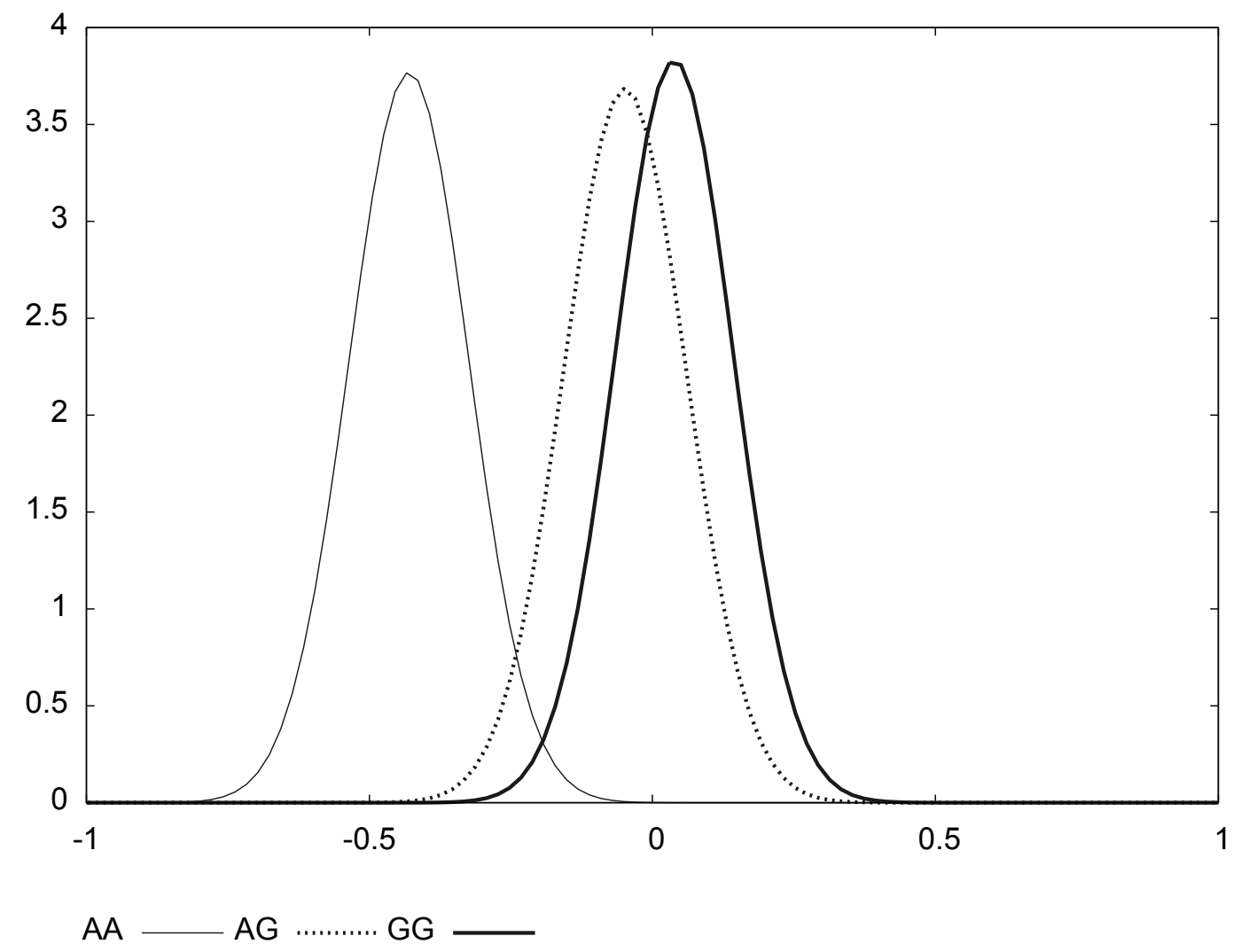

Figure 1: Distribution of estimated breeding values for disorder status of laminitis from a mixed threshold model analysis when treating SNP ( $r$ 29017173) as fixed using data set II by genotype for SNP (rs29017173)

Highly significant associations, after Bonferroni correction, were found for dairy character (genes ACVR1B, ITGA5, XPOT, all on BTA 5), for rump angle (genes SLC26a2, HMGXB3, both on BTA 7), for udder depth (genes LPHN3, IGFBP7, both on BTA 6), for 
rear teat placement (ITGA5, on BTA 5), and for BCS at time of classification (ADAMTS20, on BTA 5).

In data sets I and II, all 38 traits of the above-mentioned trait groups were examined for possible associations with SNP rs29017173. No other trait except disorder status for sole hemorrhage showed a significant association.

\section{Testing Associations Using a Sample of Al Bulls}

Data set III, consisting of Al sires genotyped with the Illumina 54K array and originating from birth years 1998 to 2003 ( $n=2,394$ ), served as a basis for analysis of possible effects of SNP rs29017173 on traits other than sole hemorrhage disorder. Numbers of sires per genotype were $630(A A), 1,197(A G)$, and 567 (GG). Thus, the frequency of the A allele $[P(A)]$ is 0.51 , slightly higher than in the cow population of data set I. As all sires had progeny proofs with high accuracies for a total of 56 EBV of individual traits, component traits, and indices of trait groups, this sample of sires was highly suitable for this type of analysis. Results were obtained by applying a simple fixed model with genotype as the only fixed effect. Results for the most significant EBV and traits are shown in Table 5 and ordered by F-value of the genotype effect in the ANOVA. All EBV displayed in Table 5 exhibited P-values of $<0.0001$ for the effect of genotype. The EBV shown are not independent of each other because feet and legs total is an index from the respective subjectively scored or linearly scored trait. Rear legs rear view is included in the feet and legs index with a weight of 0.20 , equal to the 4 other feet and leg traits available.

In Germany, all traits in the genetic evaluation scheme are expressed on a scale with the mean of base animals equal to 100 and an SD of true breeding values of 12 . For traits with low heritability and comparatively little information, the SD of EBV can be considerably lower than the SD of the true breeding values. This is the case for temperament, whereas for feet and legs (total and index), the amount of information as well as the heritability is sufficient to reach a SD near the value for true breeding values. All sires had proofs for conformation with a reliability of $>60 \%$ and, for most of the sires, reliabilities were $>75 \%$. All associations are in favor of the A allele and are of substantial size compared with the SD (EBV) and relative to the fact that only half of the 
difference in the cow population can be estimated among sires. Slightly larger Pvalues, but again favoring the A-allele, were obtained for yield of fat and protein.

Table 5: Least Square means of SNP (rs29017173) genotypes for the eight most significant trait associations. Traits are estimated breeding values (EBV) for A.I. sires ( $n=$ 2,371 for temperament, $n=2,394$ for all other traits)

\begin{tabular}{|c|c|c|c|c|c|c|c|c|}
\hline \multirow{3}{*}{ EBV } & \multirow{3}{*}{$\begin{array}{l}\text { S.D. (EBV) } \\
\text { - all sires - }\end{array}$} & \multirow{3}{*}{$\begin{array}{l}\text { F- } \\
\text { value }^{4)}\end{array}$} & \multicolumn{6}{|c|}{ SNP (rs29017173) genotype } \\
\hline & & & \multicolumn{2}{|c|}{ AA } & \multicolumn{2}{|c|}{ AG } & \multicolumn{2}{|l|}{ GG } \\
\hline & & & LSM & s.e. & LSM & s.e. & LSM & s.e. \\
\hline Feet \& legs total ${ }^{1)}$ & 10.2 & 11.49 & 100.49 & 0.40 & 100.07 & 0.29 & 97.91 & 0.43 \\
\hline $\begin{array}{l}\text { Feet \& legs } \\
\text { score }^{2)}\end{array}$ & 7.8 & 11.29 & 100.41 & 0.31 & 99.99 & 0.22 & 98.40 & 0.33 \\
\hline Body depth & 9.3 & 10.95 & 100.89 & 0.37 & 99.61 & 0.27 & 98.39 & 0.39 \\
\hline Temperament & 5.0 & 10.70 & 100.55 & 0.20 & 100.01 & 0.14 & 99.22 & 0.21 \\
\hline $\begin{array}{l}\text { Feet \& legs in- } \\
\text { dex }^{3)}\end{array}$ & 10.6 & 10.62 & 100.44 & 0.42 & 100.20 & 0.31 & 97.95 & 0.45 \\
\hline $\begin{array}{l}\text { Rear legs rear } \\
\text { view }\end{array}$ & 8.0 & 10.41 & 100.55 & 0.32 & 100.05 & 0.23 & 98.54 & 0.34 \\
\hline \multicolumn{9}{|c|}{${ }^{1)}$ Feet \& legs total $=0.5$ (Feet \& legs score) +0.5 (Feet \& legs index $)$} \\
\hline \multicolumn{9}{|c|}{${ }^{2)}$ Feet $\&$ legs score $=$ subjectively scored } \\
\hline \multicolumn{9}{|c|}{ 3) Feet $\&$ legs index $=$ index from all feet $\&$ legs traits as scored linearly } \\
\hline
\end{tabular}

As no corrections or deregressions of sire proofs were applied for data set III, we hypothesized that the reliability of EBV could influence the magnitude of the contrast when comparing the 2 homozygous genotypes. Setting higher requirements on the reliability of EBV for feet and legs total resulted in increasing magnitudes for the contrast. The entire data set III showed a contrast of 2.58 (see Table 5), requiring $78 \%$ gave 2.93 ( $n=2,247$ sires) and limiting the analysis to sires with $>81 \%$ reliability resulted in a difference between the 2 homozygous genotypes of 3.1 ( $n=1,779$ sires). Higher requirements more than halved the size of the data set and thus were considered impractical.

Based on the results for SNP rs29017173 from the cow data (data sets I and II), it can be hypothesized for the feet and leg conformation traits that cows receive higher scores when they are able to move in a "healthy" way. Without any speculation and given the results from all data sets, no harmful side effects would result from selection favoring the A allele. 
Figure 2 shows the frequency distribution of EBV for feet and legs total by genotype. What is visualized when comparing homozygous genotypes is a decrease of the number of $A A$ sires for low EBV and an even larger increase of the number of $A A$ sires for high EBV.

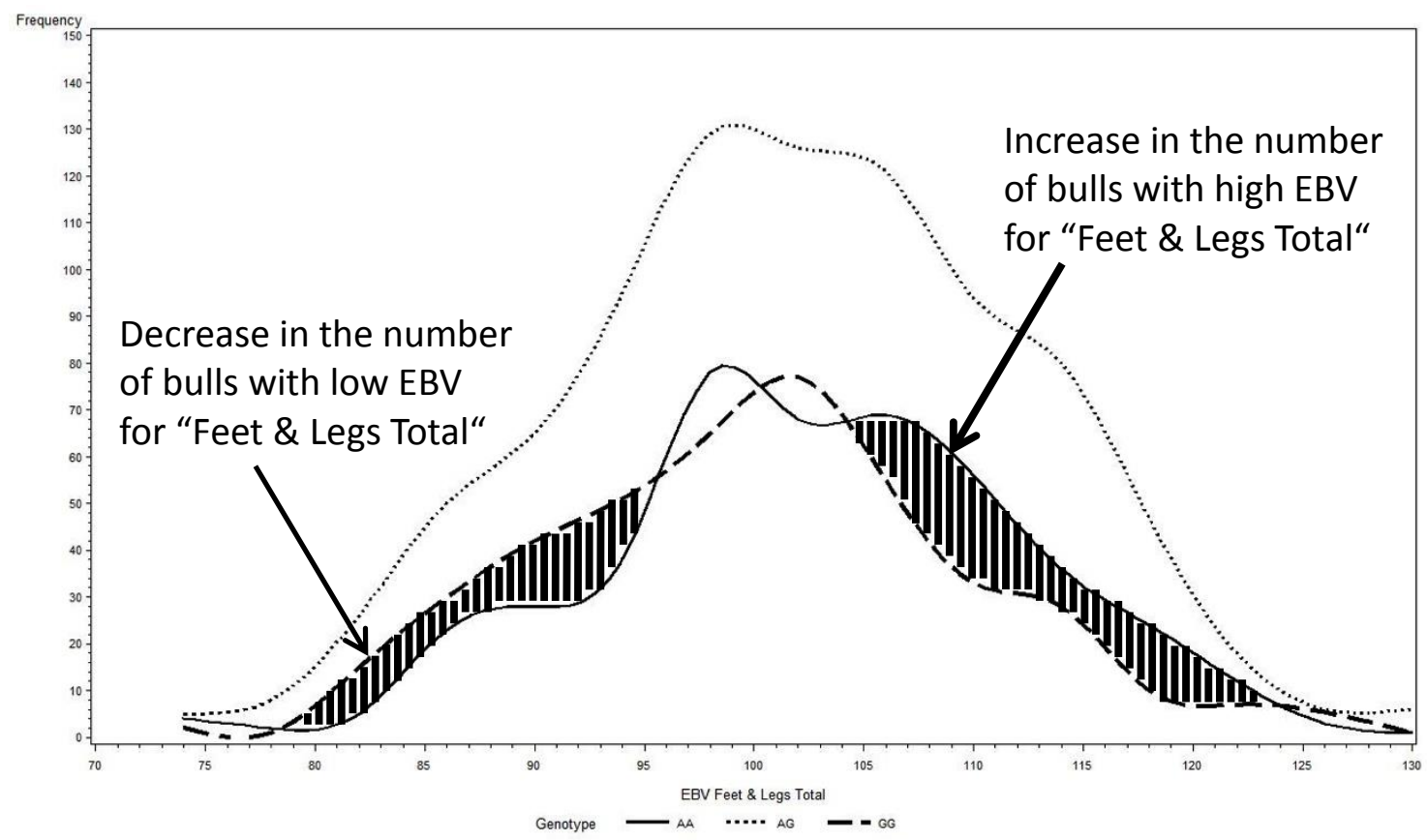

Figure 2: Distribution of estimated breeding values for Feet \& Legs Total of A.I. bulls from the official national evaluation (data set III, $n=2,394$ ) by genotype for SNP (rs29017173)

\section{IQGAP1 as a Candidate Gene}

Based on the results from this study, IQGAP1 is a promising candidate gene for the pathogenesis of sole hemorrhage in cattle. The associated SNP rs29017173 is located in intron 15 of the IQGAP1 gene on BTA21 at position 22,562,920 (UMD_3.1). The SNP was selected for the chip because it met all criteria described in the Materials and Methods section: it fulfilled the criterion of a $0.5-\mathrm{Mb}$ interval between the adjacent SNP and it has been validated in a Holstein-Friesian population with allele frequency of $A=0.6$ and $G=0.4$, and genotype frequency of $A G=0.4, A A=0.4$, and $G G=0.2$ (http://www.ncbi.nlm.nih.gov/projects/SNP/snp_ss.cgi?subsnp_id = 38333464). 
The IQGAP1 gene codes for a ubiquitously expressed scaffolding protein that contains several protein-interacting domains (White et al., 2009). It binds to a variety of targets and modulates fundamental cellular activities, including cytoskeletal architecture, cellcell adhesion, transcription, and diverse signaling pathways (Ren et al., 2007). Urao et al. (2010) demonstrated a critical role of IQGAP1 in postischemic neovascularization and tissue repair by regulating endothelial cell-mediated angiogenesis and reactive oxygen species production in ischemic tissues and inflammatory cell infiltration. Moreover, IQGAP1-/- mice show reduced capillary density, limb blood recovery, and $\alpha$ actin positive arterioles. In mice lacking IQGAP1 and subjected to a femoral artery ligation, tissue damage increased, characterized by nail bed degeneration, toe edema, and, to a certain degree, necrosis. Based on these reports, it is conceivable that IQGAP1 could be causative for the development of sole hemorrhage in cattle or be critically involved in the repair of damaged vascular tissue. The role of IQGAP1 as a gene interacting with vascular endothelial growth factors has also been pointed out by Kowanetz and Ferrara (2006).

In another respect, IQGAP1 could be viewed as a candidate gene: Gao et al. (2011) identified IQGAP1 as a key regulator of dendritic spine number with a specific role in cognitive but not emotional or motivational processes. In a series of experiments with wild-type mice and IQGAP1 knockout mice, these authors were able to show the impaired behavior of mice with respect to context-dependent fear conditioning, tonedependent fear conditioning, freezing to context after a shock, and object discrimination. Thus, these findings indicate the need to further explore the behavior of cows of different IQGAP1 genotypes, as indications on behavioral aspects are given by our results from sire EBV for temperament in data set III.

\section{General Aspects}

Health traits in general are often characterized by low degrees of heritability and very dominant environmental effects. This is partly due to the difficulty of precisely defining "healthy" or "diseased" states; that is, phenotyping for health appears to be very difficult. Furthermore, the large dependency on environmental factors gives rise to the 
occurrence of genotype by environmental interaction. With respect to health status, genotypes may differ in one environment but not in another. The aforementioned principles were the basis of the planning of this study. For phenotyping of cows, we attempted to standardize the environment to the most common one in Germany: slatted flooring, little use of straw, feeding a TMR, and hoof trimming in the first half of the first lactation. Additional efforts toward standardization consisted of visiting a few large herds $(n=7)$ only and having all trimming work and health status appraisal done by only one person. Because of financial restrictions, only $60 \%$ of all samples could be used for genotyping with the custom-made 384-SNP array. Hence, parts of the samples had to be selected. First, herd-visit cohorts with extreme frequencies for the disorder were excluded. Second, one herd in which the rearing of animals differed from the system in other herds was excluded. Obviously, these choices had to be made before genotyping started. After inspection of the results for both the reduced and the full data sets, our expectations were confirmed: cohorts with extreme disease frequencies or deviant environmental systems can greatly influence the results. However, the association between the IQGAP1 gene and the prevalence of mild as well as more severe cases of hemorrhage as an indicator for laminitis is still detectable, even when less suitable data are analyzed.

\section{Conclusions}

Diseases and disorders of the hoof are important factors influencing the well-being and milk production of the dairy cow. In this study, the IQGAP1 gene on BTA21 was identified, for which indications of its major role in the etiology and course of sole hemorrhage are overwhelming. Polymorphism of the intronic SNP used here was associated with substantial effects when considering sole hemorrhage but also with effects for feet and leg traits from the classical conformation score system. Fortunately, selection using this polymorphism will be facilitated by the fact that the same allele is favored for all traits with substantial effects. This study demonstrates the difficulties encountered when trying to separate genetic effects or individual gene effects from environmental factors in studies of disease. Even when a substantial genetic background 
exists, the etiology of a disease is highly dependent on the environment, and genetic factors may not be detectable in some environments but are readily separated in other environments.

\section{Acknowledgements}

The authors acknowledge the financial support from the German Federal Ministry of Education and Research under the FUGATO-plus program through the grant GENE-FL. The support and interest of the participating dairy farms and the cattle breeding organization RMV (Rinderzucht Mecklenburg-Vorpommern GmbH, Woldegk, Germany) is gratefully acknowledged. The authors thank F. Rosner and S. Weidling (University of Halle, Germany) for their technical assistance with data collection in the field. The expert technical assistance of I. Wiedemann and S. Pach (University of Goettingen, Germany) as well as $\mathrm{H}$. Tychsen (Leibniz Institute for Farm Animal Biology, Dummerstorf, Germany) is highly appreciated. Diana Sorg (University of Halle) is thanked for help in preparing the manuscript. 


\section{Supplementary data}

Table S1: Results of the in-silico QTL analysis for conformation traits in cattle

\begin{tabular}{|c|c|c|c|c|}
\hline Chromosome & Trait & Marker & Position (1) & Study (2) \\
\hline BTA 1 & Rear legs side view & BMS4017-BMS4000 & 36.2 & A \\
\hline BTA 1 & Rear legs rear view & BMS4008-BM8246 & 72.2 & A \\
\hline BTA 2 & Rear legs side view & BMS1866-BMS1987 & 88 & A \\
\hline BTA 3 & Rear legs side view & BM7225-BM2924 & 110 & A \\
\hline BTA 3 & Foot angle & BM4301-HUJI177 & 65 & D \\
\hline BTA 5 & Lameness1 & BMC1009-RM500 & 44.2 & A \\
\hline BTA 5 & Foot angle & Lysmic-ETH10 & 72 & B \\
\hline BTA 5 & Quality of feet and legs & RM029-BMS1248 & 101 & B \\
\hline BTA 6 & Foot angle & ILSTS097-BP7 & 88 & B \\
\hline BTA 6 & Quality of feet and legs & ILSTS097-BP7 & 89 & B \\
\hline BTA 6 & Foot angle & BM4322-BMS470 & 67 & D \\
\hline BTA 6 & Rear leg set & BP7 & 85 & G \\
\hline BTA 7 & Rear legs side view & OARAE129-ILSTS006 & 104 & A \\
\hline BTA 7 & Heel depth & BM741 & 32 & C \\
\hline BTA 7 & Foot angle & BB719-BM9065 & 83 & D \\
\hline BTA 7 & Feet and leg score & BM2607 & NA & $\mathrm{E}$ \\
\hline BTA 8 & Foot angle & MCM64-CSSM047 & 92 & A \\
\hline BTA 8 & Feet leg score & BMS2072-IDVGA-52 & 86 & I \\
\hline BTA 8 & Rear legs rear view & BM711-CSSM047 & 109 & I \\
\hline BTA 9 & Heel depth & BM2504 & 32 & C \\
\hline BTA 9 & Rear legs side view & URB024-TGLA73 & 61 & D \\
\hline BTA 9 & Foot angle & BM4204 & NA & $\mathrm{F}$ \\
\hline BTA 9 & Rear legs side view & BM4204 & NA & $\mathrm{F}$ \\
\hline BTA 9 & $\mathrm{Cl}$ Feet and legs & BM4204 & NA & $\mathrm{F}$ \\
\hline BTA11 & Hock quality & INRA177_2-RM096 & 30 & A \\
\hline BTA11 & Rear legs side view & BM716-BMS2569 & 8 & A \\
\hline BTA11 & Hocks & BM6445-INRA108 & 61 & B \\
\hline BTA11 & Rear leg set rear view & BM6445-INRA108 & 61 & B \\
\hline BTA12 & Hock quality & BMS975-BMS1316 & 98 & A \\
\hline BTA12 & Feet and leg composite index & BM6404-BMS975 & 41 & D \\
\hline BTA12 & Feet and leg score & BM6404-BMS975 & 41 & D \\
\hline BTA12 & Rear legs rear view & BM6404-BMS975 & 41 & D \\
\hline BTA12 & Foot angle & BM6404 & 56 & $\mathrm{H}$ \\
\hline BTA12 & Feet and leg composite & BM6404 & 56 & $\mathrm{H}$ \\
\hline BTA12 & Rear legs rear view & BM6404 & 56 & $\mathrm{H}$ \\
\hline BTA 13 & Rear legs rear view & BL1071-AGLA232 & 76 & A \\
\hline BTA 13 & Hocks & MILSTS077-KIEL_E1 & 53 & B \\
\hline BTA 13 & Rear leg set rear view & MILSTS077-KIEL_E1 & 53 & B \\
\hline BTA 13 & Foot angle & UWCA25-BL42 & 54 & D \\
\hline BTA 14 & Rear legs side view & RM011-BM302 & 30 & A \\
\hline
\end{tabular}




\begin{tabular}{|c|c|c|c|c|}
\hline Chromosome & Trait & Marker & Position (1) & Study (2) \\
\hline BTA 14 & Foot angle & BMS1899-BM4513 & 54 & $\mathrm{D}$ \\
\hline BTA 14 & Rear legs side view & BM6425 & NA & $E$ \\
\hline BTA 15 & Hock quality & BMS2076-BMS820 & 78 & $A$ \\
\hline BTA 15 & Bone quality & BMS2076-BMS820 & 78 & $A$ \\
\hline BTA 15 & Heel depth & BMS2684 & NA & $\mathrm{C}$ \\
\hline BTA 16 & Rear legs rear view & TGLA245-HUJ614 & 8 & $A$ \\
\hline BTA 16 & Rear leg rear view & Centro-BM6430 & 0 & $\mathrm{D}$ \\
\hline BTA 16 & Feet and legs $\mathrm{Cl}$ & BM719 & NA & $E$ \\
\hline BTA 16 & Rear legs side view & BM719 & NA & $E$ \\
\hline BTA 16 & Foot angle & BM719 & NA & $E$ \\
\hline BTA 17 & Bone quality & CSSM9-OARFCB48 & 32 & $A$ \\
\hline BTA 17 & Foot angle & RM156-BMS2220 & 5 & B \\
\hline BTA 17 & Quality of feet and legs & BMS941-OARFCB48 & 34 & B \\
\hline BTA 17 & Rear legs side view & BM8125 & NA & $E$ \\
\hline BTA 17 & Foot angle & BM8125 & NA & $E$ \\
\hline BTA 18 & Heel depth & ILSTSO02 & 74 & $\mathrm{C}$ \\
\hline BTA 18 & Rear legs rear view & BM2078 & NA & $\mathrm{F}$ \\
\hline BTA 18 & Foot angle & BMS929-BM6507 & 90 & 1 \\
\hline BTA 19 & Lameness2 & BM9202-BMS745 & 12.1 & $A$ \\
\hline BTA 19 & Rear leg set & BM17132 & 76 & G \\
\hline BTA 21 & Rear legs side view & INRA103-BMS2815 & 14 & $A$ \\
\hline BTA 21 & Foot angle & BM8115-HEL5 & 6 & B \\
\hline BTA 21 & Hocks & HEL5 & 12 & B \\
\hline BTA 21 & Rear leg set rear view & HEL5 & 12 & B \\
\hline BTA 22 & Lameness2 & INRA026-BM1558 & 8.1 & $A$ \\
\hline BTA 22 & Foot angle & ВM3628 & NA & $F$ \\
\hline BTA 22 & Feet and leg score & BM3628 & NA & $\mathrm{F}$ \\
\hline BTA 22 & $\mathrm{Cl}$ Feet and legs & BM3628 & NA & $\mathrm{F}$ \\
\hline BTA 23 & Quality of feet and legs & BM1905-BM1443 & 84 & B \\
\hline BTA 23 & Foot angle & BM1905-BM1443 & 84 & B \\
\hline BTA 23 & Foot angle & BM1905 & NA & $\mathrm{F}$ \\
\hline BTA 23 & Rear legs rear view & CYP21 & NA & $\mathrm{F}$ \\
\hline BTA 23 & Rear legs side view & BB705 & 36.7 & $\mathrm{H}$ \\
\hline BTA 24 & Rear leg set & AGLA269 & 17 & G \\
\hline BTA 24 & Foot diagonal & AGLA269 & 17 & G \\
\hline BTA 24 & Feet and legs & CSSM31-AGLA269 & 15 & G \\
\hline BTA 25 & Feet and leg composite index & BM4005-URB036 & 7 & $\mathrm{D}$ \\
\hline BTA 25 & Foot angle & BMS1353-BM1864 & 39 & $\mathrm{D}$ \\
\hline BTA 26 & Lameness1 & BMS882-BM804 & 56.1 & $A$ \\
\hline BTA 26 & Bone quality & BMS882-BM804 & 52 & $A$ \\
\hline BTA 27 & Hock quality & HUJI13-BM203 & 62 & $A$ \\
\hline BTA 27 & Bone quality & HUJI13-BM203 & 62 & A \\
\hline BTA 27 & Feet and legs $\mathrm{Cl}$ & BM3507 & NA & $\mathrm{E}$ \\
\hline
\end{tabular}




\begin{tabular}{lllll}
\hline Chromosome & Trait & Marker & Position (1) & Study (2) \\
\hline BTA 27 & Rear legs side view & BM3507 & NA & E \\
BTA 28 & Rear legs rear view & BMS1714-BMC2208 & 50 & A \\
BTA 28 & Rear leg rear view & BL25-BM6466 & 26 & D \\
BTA 28 & Feet and leg composite index & BM6466-BM2515 & 48 & D \\
BTA 28 & Foot angle & BM6466-BM2515 & 48 & D \\
BTA 29 & Rear legs rear view & BM4602-BMS1857 & 0.1 & A \\
BTA 29 & Foot angle & BMS3224-BMC6004 & 34 & D \\
BTA 29 & Feet and leg score & BMS1600-BMC3224 & 32 & D \\
\hline
\end{tabular}

(1) $=\mathrm{CM}$ position of the marker map used in the listed studies

(2) A= Buitenhuis et al. (2007) J Dairy Sci 90:472-481;

B = Hiendleder et al. (2003) J Hered 94 (6): 496-506;

C = Boichard et al. (2003) Genet Sel Evol 35: 77-101;

$\mathrm{D}=$ Ashwell et al. (2005) J Dairy Sci 88: 4111-4119;

$E=$ Ashwell et al. (1998b) J Dairy Sci 81: 3309-3314;

$\mathrm{F}=$ Ashwell et al. (1998a) J Dairy Sci 81: 1120-1125;

G = Schrooten et al. (2000) J Dairy Sci 83: 795-806;

$\mathrm{H}=$ Ashwell et al. (2001) J Dairy Sci 84: 2535-2542;

I = Schnabel et al. (2005) Anim Genet 36: 408-416. 
Table S2: Selected QTL from different studies and the syntenic regions between BTA and HSA associated with conformation traits in cattle

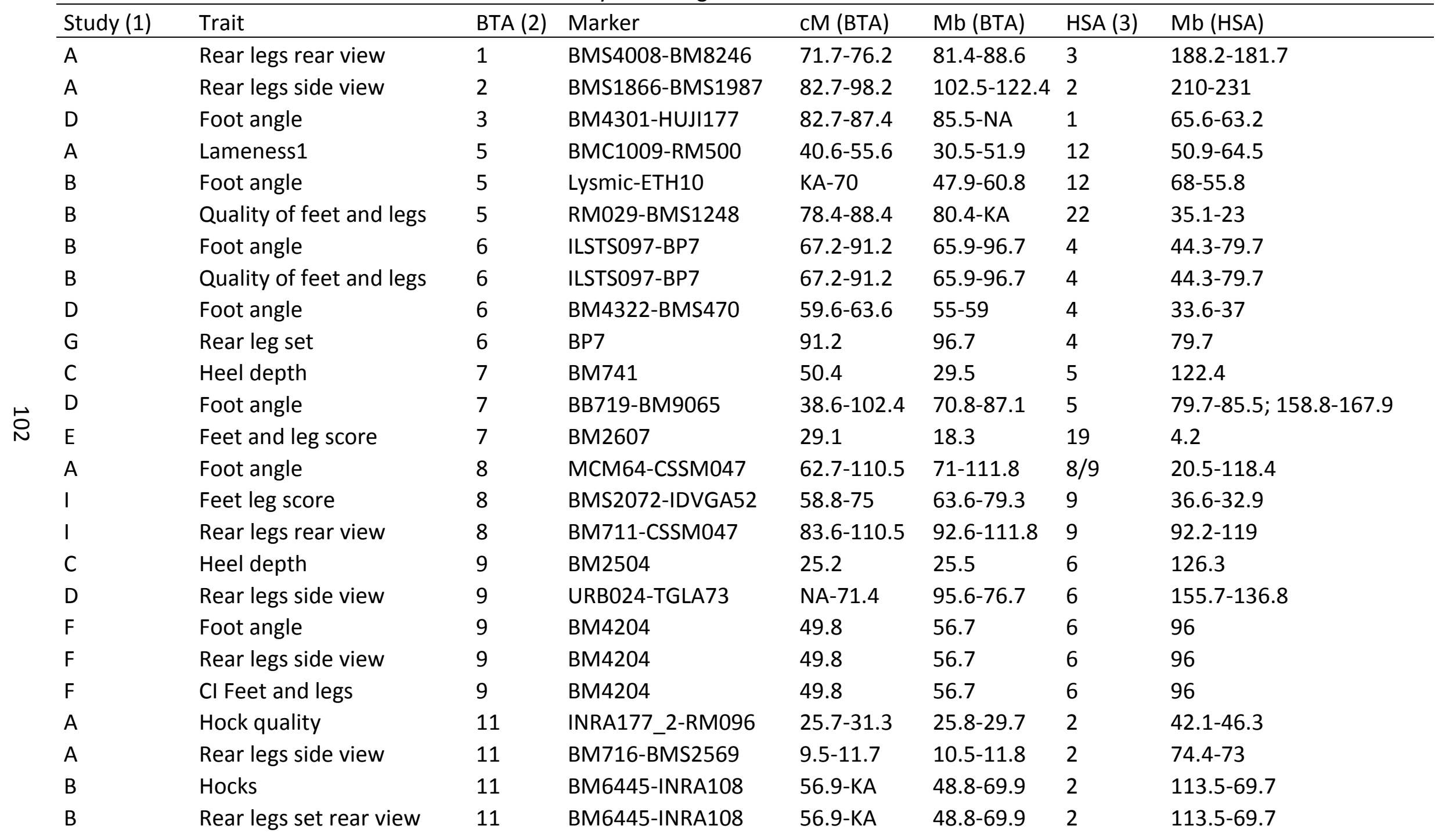




\begin{tabular}{|c|c|c|c|c|c|c|c|}
\hline Study (1) & Trait & BTA (2) & Marker & $\mathrm{cM}$ (BTA) & $\mathrm{Mb}(\mathrm{BTA})$ & HSA (3) & $\mathrm{Mb}(\mathrm{HSA})$ \\
\hline A & Rear legs rear view & 13 & BL1071-AGLA232 & $68.6-79.5$ & $71.8-77.6$ & 20 & $40.5-46.5$ \\
\hline B & Rear leg set rear view & 13 & MILSTS077-KIEL_E1 & $32-38.6$ & $28.4-35.5$ & 10 & $14.3-29.7$ \\
\hline$A$ & Rear legs side view & 14 & RM011-BM302 & $27.7-36.9$ & 27.1-33.6 & 8 & $62.8-70.6$ \\
\hline D & Foot angle & 14 & BMS1899-BM4513 & $52-62.5$ & $51.1-61.4$ & 8 & $112.5-102.3$ \\
\hline$E$ & Rear legs side view & 14 & BM6425 & 85.7 & 73.8 & 8 & 88.8 \\
\hline$A$ & Rear legs rear view & 16 & TGLA245-HUJ614 & $6.5-11.5$ & $0.02-3.9$ & 1 & 201.1-205.3 \\
\hline D & Rear leg rear view & 16 & Centro-BM6430 & $0-22$ & $0-2.2$ & 1 & 201.5-203.6 \\
\hline$E$ & Feet and legs $\mathrm{Cl}$ & 16 & BM719 & 78 & 63.1 & 1 & 182.5 \\
\hline$E$ & Rear legs side view & 16 & BM719 & 78 & 63.1 & 1 & 182.5 \\
\hline$E$ & Foot angle & 16 & BM719 & 78 & 63.1 & 1 & 182.5 \\
\hline B & Foot angle & 17 & RM156-BMS2220 & $0-16.2$ & $3.2-12.7$ & 4 & $155.7-147.5$ \\
\hline $\mathrm{F}$ & Rear legs rear view & 18 & BM2078 & 77.8 & 62 & 19 & 59.2 \\
\hline । & Foot angle & 18 & BMS929-BM6507 & $63.3-78.9$ & $49.8-63$ & 19 & $46-59.8$ \\
\hline$A$ & Lameness2 & 19 & BM9202-BMS745 & $0-15.9$ & $0.7-11.8$ & 17 & $48-55.5$ \\
\hline G & Rear leg set & 19 & BM17132 & 58.6 & 39 & 17 & 44 \\
\hline B & Foot angle & 21 & BM8115-HEL5 & $0-13$ & 2.1-9.3 & 15 & $23.5-94.5$ \\
\hline B & Hocks & 21 & BM8115-HEL5 & $0-13$ & $2.1-9.3$ & 15 & $23.5-94.5$ \\
\hline B & Rear leg set rear view & 21 & BM8115-HEL5 & $0-13$ & 2.1-9.3 & 15 & $23.5-94.5$ \\
\hline$A$ & Lameness2 & 22 & INRA026-BM1558 & $0-17.3$ & $4.7-12.1$ & 3 & $30.3-38.6$ \\
\hline
\end{tabular}




\begin{tabular}{llllllll}
\hline Study (1) & Trait & BTA (2) & Marker & CM (BTA) & Mb (BTA) & HSA (3) & Mb (HSA) \\
\hline F & Foot angle & 22 & BM3628 & 44.5 & 32.6 & 3 & 69 \\
F & Feet and leg score & 22 & BM3628 & 44.5 & 32.6 & 3 & 69 \\
F & Cl Feet and legs & 22 & BM3628 & 44.5 & 32.6 & 3 & 69 \\
B & Quality of feet and legs & 23 & BM1905-BM1443 & $64.3-67.1$ & $46.5-48.6$ & $6 / 1$ & $9.7-173.2$ \\
B & Foot angle & 23 & BM1905-BM1443 & $64.3-67.1$ & $46.5-48.6$ & $6 / 1$ & $9.7-173.2$ \\
F & Foot angle & 23 & BM1905 & 64.3 & 46.5 & 6 & 9.7 \\
F & Rear legs rear view & 23 & CYP21 & 36 & 27.1 & 6 & 32.1 \\
G & Rear leg set & 24 & AGLA269 & 27.6 & 25.8 & 18 & 28 \\
G & Foot diagonal & 24 & AGLA269 & 27.6 & 25.8 & 18 & 28 \\
G & Feet and legs & 24 & CSSM31-AGLA269 & $25.2-27.6$ & $23.4-25.8$ & 18 & $30.5-28$ \\
A & Lameness1 & 26 & BMS882-BM804 & $51-59.6$ & $41.1-45.9$ & 10 & $122.2-127.2$ \\
A & Bone quality & 26 & BMS882-BM804 & $51-59.6$ & $41.1-45.9$ & 10 & $122.2-127.2$ \\
A & Hock quality & 27 & HUJ13-BM203 & $56.6-64.1$ & $39.6-46.1$ & $8 / 3$ & $42.3-23.8$ \\
A & Bone quality & 27 & HUJ13-BM203 & $56.6-64.1$ & $39.6-46.1$ & $8 / 3$ & $42.3-23.8$ \\
E & Feet and legs Cl & 27 & BM3507 & 0 & 5.1 & 8 & 5.7 \\
E & Rear legs side view & 27 & BM3507 & 0 & 5.1 & 8 & 5.7 \\
A & Rear legs rear view & 28 & BMS1714-BMC2208 & $42.1-52.4$ & $34.6-42.8$ & 10 & $81.8-49.5$ \\
A & Rear legs rear view & 29 & BM4602-BMS1857 & $0-0.9$ & $2-2.6$ & 11 & $92.1-91.5$ \\
\hline
\end{tabular}

(1) A= Buitenhuis et al. (2007) J Dairy Sci 90:472-481;

$B=$ Hiendleder et al. (2003) J Hered 94 (6): 496-506;

C = Boichard et al. (2003) Genet Sel Evol 35: 77-101;

D = Ashwell et al. (2005) J Dairy Sci 88: 4111-4119;

$\mathrm{E}=$ Ashwell et al. (1998b) J Dairy Sci 81: 3309-3314;

$\mathrm{F}=$ Ashwell et al. (1998a) J Dairy Sci 81: 1120-1125;

$\mathrm{G}=$ Schrooten et al. (2000) J Dairy Sci 83: 795-806; 


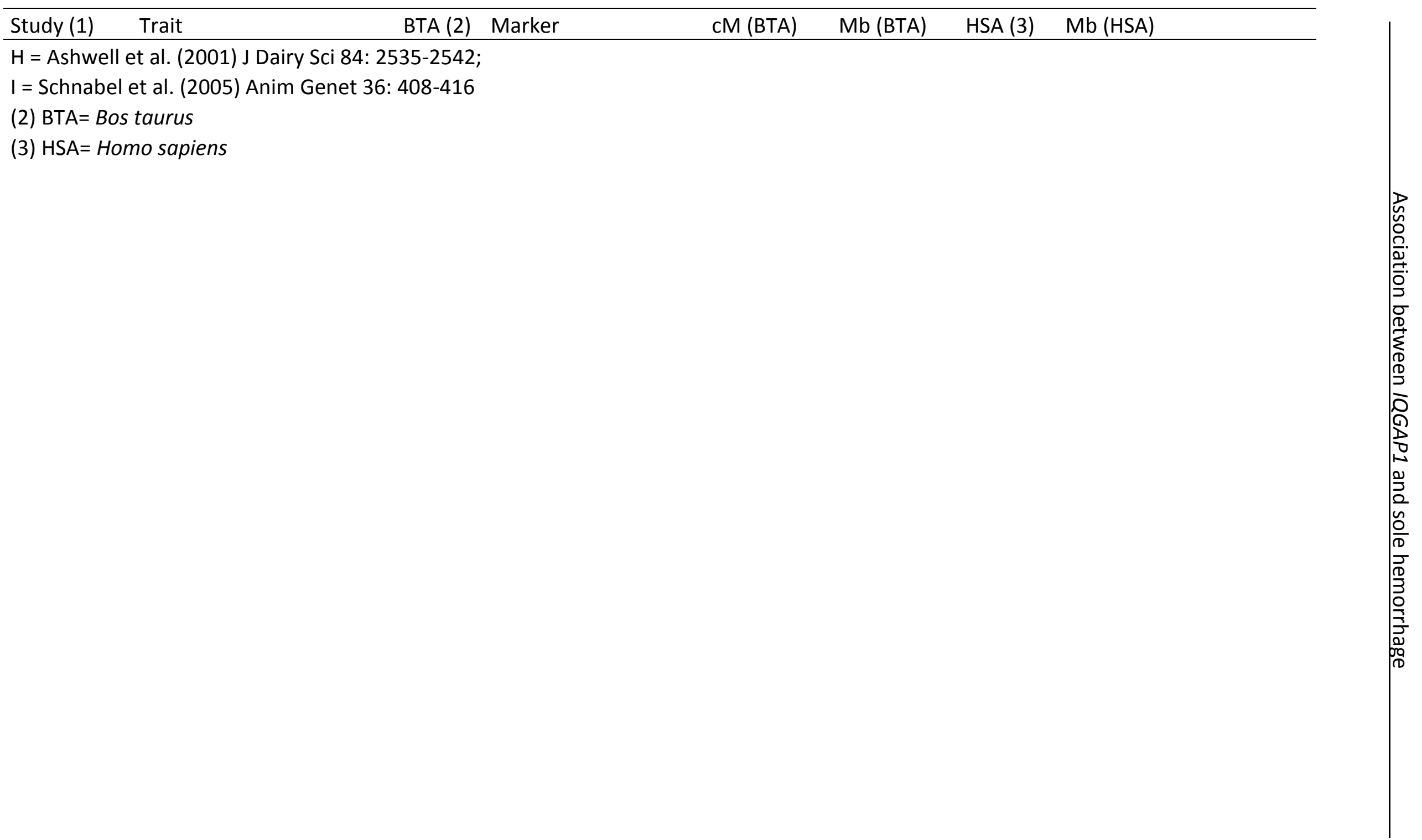


Table S3: Syntenic chromosomes between BTA, SSC and HSA and the consensus regions for conformation traits on HSA

\begin{tabular}{|c|c|c|c|}
\hline Bos taurus & Sus scrofa & Homo sapiens & Konsensusregionen HSA (Mb) \\
\hline BTA1 & SSC13 & HSA3 & $181.7-188.2$ \\
\hline BTA5 & SSC3/SSC5 & HSA12 & $50.9-64.5$ \\
\hline BTA5 & SSC3/SSC5 & HSA12 & $55.8-68$ \\
\hline BTA5 & SSC14 & HSA22 & 23-30 \\
\hline BTA6 & SSC8 & HSA4 & $44.3-79.7$ \\
\hline BTA6 & SSC8 & HSA4 & $33.6-37$ \\
\hline BTA6 & SSC8 & HSA4 & $74-84$ \\
\hline BTA7 & $\mathrm{SSC} 2 / \mathrm{SSC} 16$ & HSA5 & $117-127$ \\
\hline BTA7 & $\mathrm{SSC} 2 / \mathrm{SSC} 16$ & HSA5 & 79.7-85.5; 158.8-167.9 \\
\hline BTA7 & $\mathrm{SSC} 2 / \mathrm{SSC} 6$ & HSA19 & $0-9$ \\
\hline BTA8 & SSC4/SSC1 & HSA8/HSA9 & $20.5-27.5 / 32.9-34.8 ; 84.8-98.5 ; 102.2-118.4$ \\
\hline BTA8 & SSC1/SSC4 & HSA8/HSA9 & 33.8-38.5; 99.1-102.2; 65.6-65.7/19.8-27.5 \\
\hline BTA8 & SSC1 & HSA9 & $92.1-119$ \\
\hline BTA9 & SSC1 & HSA6 & $91-101$ \\
\hline BTA11 & SSC3/SSC15 & HSA2 & 42.1-46.3 \\
\hline BTA11 & SSC15 & HSA2 & $73-74.4$ \\
\hline BTA11 & SSC15 & HSA2 & 61.2-69.7; 76.7-86.9; 88.1-89.7;112.9-113.9 \\
\hline BTA13 & SSC17 & HSA2O & $40.5-46.5$ \\
\hline BTA13 & SSC17 & HSA2O & $54.2-56.6$ \\
\hline BTA14 & SSC4 & HSA8 & $62.8-70.6$ \\
\hline BTA14 & SSC4 & HSA8 & $102.3-112.5$ \\
\hline BTA14 & SSC4 & HSA8 & $83-93$ \\
\hline BTA15 & SSC2/SSC9 & HSA11 & $5-15$ \\
\hline BTA16 & SSC4/SSC10 & HSA1 & 201.1-205.3 \\
\hline BTA16 & $\mathrm{SSC} 4 / \mathrm{SSC} 10$ & HSA1 & $201.5-203.6$ \\
\hline BTA16 & SSC4 & HSA1 & $177-187$ \\
\hline BTA17 & SSC8 & HSA4 & $147.5-155.7$ \\
\hline BTA17 & SSC8 & HSA4 & $118-128$ \\
\hline BTA18 & SSC6 & HSA19 & $33-43$ \\
\hline BTA21 & SSC1 & HSA15 & $25-25.5 ; 89.4-94.5$ \\
\hline BTA22 & SSC13 & HSA3 & $30.3-38.6$ \\
\hline BTA22 & SSC13 & HSA3 & $64-74$ \\
\hline BTA23 & SSC4 & HSA1 & $173-173.5$ \\
\hline BTA23 & SSC1/SSC7 & HSA6 & $27-37$ \\
\hline BTA26 & SSC14 & HSA10 & $122.2-127.2$ \\
\hline BTA27 & SSC4/SSC13/SSC14 & HSA3/HSA8 & 26.1-27.1; 20.5-23.5/ 18.3-19.8; 42.3-43.2 \\
\hline BTA28 & SSC14 & HSA10 & $43.4-49.5 ; 81.8-89$ \\
\hline
\end{tabular}




\section{References}

Ashwell, M. S., Y. Da, C. P. Van Tassell, P. M. Vanraden, R. H. Miller, and C. E. Rexroad Jr. 1998a. Detection of putative loci affecting milk production and composition, health, and type traits in a United States Holstein population. J. Dairy Sci. 81:3309-3314.

Ashwell, M. S., Y. Da, P. M. VanRaden, C. E. Rexroad Jr., and R. H. Miller. 1998b. Detection of putative loci affecting conformational type traits in an elite population of United States Holsteins using microsatellite markers. J. Dairy Sci. 81:1120-1125.

Ashwell, M. S., D. W. Heyen, J. I. Weller, M. Ron, T. S. Sonstegard, C. P. Van Tassell, and H. A. Lewin. 2005. Detection of quantitative trait loci influencing conformation traits and calving ease in Holstein-Friesian cattle. J. Dairy Sci. 88:4111-4119.

Ashwell, M. S., C. P. Van Tassell, and T. S. Sonstegard. 2001. A genome scan to identify quantitative trait loci affecting economically important traits in a US Holstein population. J. Dairy Sci. 84:2535-2542.

Boichard, D., C. Grohs, F. Bourgeois, F. Cerqueira, R. Faugeras, A. Neau, R. Rupp, Y. Amigues, M. Y. Boscher, and H. Leveziel. 2003. Detection of genes influencing economic traits in three French dairy cattle breeds. Genet. Sel. Evol. 35:77-101.

Bruijnis, M. R. N., H. Hogeveen, and E. N. Stassen. 2010. Assessing economic consequences of foot disorders in dairy cattle using a dynamic stochastic simulation model. J. Dairy Sci. 93:2419-2432.

Bruijnis, M. R. N., H. Hoogeveen, and E. N. Stassen. 2013. Measures to improve dairy cow foot health: Consequences for farmer income and dairy cow welfare. Animal 7:167-175. http://dx.doi. org/10.1017/S1751731112001383.

Buch, L. H., A. C. Sørensen, J. Lassen, P. Berg, J.-Å. Eriksson, J. H. Jakobsen, and M. K. Sørensen. 2011. Hygiene-related and feed-related hoof diseases show different patterns of genetic correlations to clinical mastitis and female fertility. J. Dairy Sci. 94:1540- 1551. http://dx.doi.org/10.3168/jds.2010-3137.

Budak, M. T., J. A. Orsini, C. C. Pollitt, and N. A. Rubinstein. 2009. Gene expression in the lamellar dermis-epidermis during the developmental phase of carbohydrate overload-induced laminitis in the horse. Vet. Immunol. Immunopathol. 131:86-96.

Buitenhuis, A. J., M. S. Lund, J. R. Thomasen, B. Thomsen, V. Hunnicke Nielsen, C. Bendixen, and B. Guldbrandtsen. 2007. Detection of quantitative trait loci affecting lameness and leg conformation traits in Danish Holstein cattle. J. Dairy Sci. 90:472-481.

Cole, J. B., G. R. Wiggans, L. Ma, T. S. Sonstegard, T. J. Lawlor Jr., B. A. Crooker, C. P. Van Tassell, J. Yang, S. Wang, L. K. Matukumalli, and Y. Da. 2011. Genome-wide association analysis of thirty one production, health, reproduction and body conformation traits in contemporary U.S. Holstein cows. BMC Genomics 12:408.

Coyne, M. J., H. Cousin, J. P. Loftus, P. J. Johnson, J. K. Belknap, C. M. Gradil, S. J. Black, and D. Alfandari. 2009. Cloning and expression of ADAM-related metalloproteases in equine laminitis. Vet. Immunol. Immunopathol. 129:231-241. 
Cramer, G., K. D. Lissemore, C. L. Guard, K. E. Leslie, and D. F. Kelton. 2009. Herd-level risk factors for seven different foot lesions in Ontario Holstein cattle housed in tie stalls or free stalls. J. Dairy Sci. 92:1404-1411. http://dx.doi.org/10.3168/jds.2008-1134.

Ettema, J. F., N. Capion, and A. E. Hill. 2007. The association of hoof lesions at claw trimming with test-day milk yield in Danish Holsteins. Prev. Vet. Med. 79:224-243.

Fan, B., S. K. Onteru, Z. Q. Du, D. J. Garrick, K. J. Stalder, and M. F. Rothschild. 2011. Genome-wide association study identifies loci for body composition and structural soundness traits in pigs. PLoS ONE 6:e14726.

Fan, B., S. K. Onteru, B. E. Mote, T. Serenius, K. J. Stalder, and M. F. Rothschild. 2009. Large-scale association study for structural soundness and leg locomotion traits in the pig. Genet. Sel. Evol. 41:14.

Fjeldaas, T., A. M. Sogstad, and O. Østerås. 2011. Locomotion and claw disorders in Norwegian dairy cows housed in freestalls with slatted concrete, solid concrete, or solid rubber flooring in the alleys. J. Dairy Sci. 94:1243-1255. http://dx.doi.org/10.3168/ jds.2010-3173.

Förster, T. 1946. Energiewanderung und Fluoreszenz. Naturwissenschaften 33:166175.

Gao, C., S. F. Frausto, A. L. Guedea, N. C. Tronson, V. Jovasevic, K. Leaderbrand, K. A. Corcoran, Y. F. Guzmán, G. T. Swanson, and J. Radulovic. 2011. IQGAP1 regulates NR2A signaling, spine density, and cognitive processes. J. Neurosci. 31:8533-8542. http:// dx.doi.org/10.1523/JNEUROSCI.1300-11.2011.

Gernand, E., P. Rehbein, U. v. Borstel, and S. König. 2012. Incidences of and genetic parameters for mastitis, claw disorders and common health traits recorded in dairy cattle contract herds. J. Dairy Sci. 95:2144-2156. http://dx.doi.org/10.3168/jds.20114812.

Gilmour, A. R., B. J. Gogel, B. R. Cullis, and R. Thompson. 2009. ASREML User Guide. VSN International Ltd., Hemel Hempstead, UK.

Häggman, J., J. Juga, M. J. Sillanpää, and R. Thompson. 2013. Genetic parameters for claw health and feet and leg conformation traits in Finnish Ayrshire cows. J. Anim. Breed. Genet. 130:89- 97. http://dx.doi.org/10.1111/j.1439-0388.2012.01007.x.

Hiendleder, S., H. Thomsen, N. Reinsch, J. Bennewitz, B. Leyhe-Horn, C. Looft, N. Xu, I. Medjugorac, I. Russ, C. Kuhn, G. A. Brockmann, J. Blumel, B. Brenig, F. Reinhardt, R. Reents, G. Averdunk, M. Schwerin, M. Forster, E. Kalm, and G. Erhardt. 2003. Mapping of QTL for body conformation and behavior in cattle. J. Hered. 94:496-506.

Johnson, P. J., S. C. Tyagi, L. C. Katwa, V. K. Ganjam, L. A. Moore, J. M. Kreeger, and N. T. Messer. 1998. Activation of extracellular matrix metalloproteinases in equine laminitis. Vet. Rec. 142:392-396. 
Kent, W. J., R. Baertsch, A. Hinrichs, W. Miller, and D. Haussler. 2003. Evolution's cauldron: Duplication, deletion, and rearrangement in the mouse and human genomes. Proc. Natl. Acad. Sci. USA 100:11484-11489.

Koenig, S., A. R. Sharifi, H. Wentrot, D. Landmann, M. Eise, and H. Simianer. 2005. Genetic parameters of claw and foot disorders estimated with logistic models. J. Dairy Sci. 88:3316-3325.

König, S., and H. H. Swalve. 2006. A model calculation on the prospects of an improvement of claw health in dairy cattle via genetic selection. Zuchtungskunde 78:345356.

Kowanetz, M., and N. Ferrara. 2006. Vascular endothelial growth factor signaling pathways: Therapeutic perspective. Clin. Cancer Res. 12:5018-5022. http://dx.doi.org/10.1158/1078-0432.CCR- 06-1520.

Kujala, M., I. R. Dohoo, and T. Soveri. 2010. White-line disease and haemorrhages in hooves of Finnish dairy cattle. Prev. Vet. Med. 94:18-27.

Kyaw-Tanner, M., and C. C. Pollitt. 2004. Equine laminitis: Increased transcription of matrix metalloproteinase-2 (MMP-2) occurs during the developmental phase. Equine Vet. J. 36:221-225.

Kyaw-Tanner, M. T., O. Wattle, A. W. van Eps, and C. C. Pollitt. 2008. Equine laminitis: Membrane type matrix metalloproteinase-1 (MMP-14) is involved in acute phase onset. Equine Vet. J. 40:482-487.

Laenoi, W., M. J. Uddin, M. U. Cinar, C. Große-Brinkhaus, D. Tesfaye, E. Jonas, A. M. Scholz, E. Tholen, C. Looft, K. Wimmers, C. Phatsara, H. Juengst, H. Sauerwein, M. Mielenz, and K. Schellander. 2011. Quantitative trait loci analysis for leg weakness related traits in a Duroc $\times$ Pietrain crossbred population. Genet. Sel. Evol. 43:13. http://dx.doi.org/10.1186/1297-9686-43-13.

Laursen, M. V., D. Boelling, and T. Mark. 2009. Genetic parameters for claw and leg health, foot and leg conformation, and locomotion in Danish Holsteins. J. Dairy Sci. 92:1770-1777. http://dx.doi. org/10.3168/jds.2008-1388.

Lean, I. J., C. T. Westwood, H. M. Golder, and J. J. Vermunt. 2013. Impact of nutrition on lameness and claw health in cattle. Livest. Sci. 156:71-87. http://dx.doi.org/10.1016/j.livsci.2013.06.006.

Miller, S. A., D. D. Dykes, and H. F. Polesky. 1988. A simple salting out procedure for extracting DNA from human nucleated cells. Nucleic Acids Res. 16:1215.

Neuenschwander, T. F.-O., F. Miglior, J. Jamrozik, O. Berke, D. F. Kelton, and L. R. Schaeffer. 2012. Genetic parameters for producer-recorded health data in Canadian Holstein cattle. Animal 6:571-578.

Nocek, J. E. 1997. Bovine acidosis: Implications on laminitis. J. Dairy Sci. 80:1005-1028. 
Nordlund, K. V., N. B. Cook, and G. R. Oetzel. 2004. Investigation strategies for laminitis problem herds. J. Dairy Sci. 87(E. Suppl.):E27-E35.

Oberbauer, A. M., S. L. Berry, J. M. Belanger, R. M. McGoldrick, J. M. Pinos-Rodriquez, and T. R. Famula. 2013. Determining the heritable component of dairy cattle foot lesions. J. Dairy Sci. 96:605-613. http://dx.doi.org/10.3168/jds.2012-5485.

Osorio, J. S., B. C. Fraser, D. E. Graugnard, S. S. Singh, J. K. Drackley, E. F. Garret, and J. J. Loor. 2012. Corium tissue expression of genes associated with inflammation, oxidative stress, and keratin formation in relation to lameness in dairy cows. J. Dairy Sci. 95:6388-6396. http://dx.doi.org/10.3168/jds.2011-5143.

Parker Gaddis, K. L., J. B. Cole, J. S. Clay, and C. Maltecca. 2012. Incidence validation and relationship analysis of producer-recorded health event data from on-farm computer systems in the United States. J. Dairy Sci. 95:5422-5435. http://dx.doi.org/10.3168/ jds.2012-5572.

Pijl, R., and H. H. Swalve. 2006. An analysis of claw disorders diagnosed at claw trimming. Pages 34-36 in Proc. 14th Symp. 6th Conf. Lameness in Ruminants, Uruguay. http://www.ivis.org/proceedings/rumlameness/toc.asp.

Pritchard, T., M. Coffey, R. Mrode, and E. Wall. 2013. Genetic parameters for production, health, fertility and longevity traits in dairy cows. Animal 7:34-46. http://dx.doi.org/10.1017/ S1751731112001401.

Purcell, S., B. Neale, K. Todd-Brown, L. Thomas, M. A. R. Ferreira, D. Bender, J. Maller, P. Sklar, P. I. W. de Bakker, M. J. Daly, and P. C. Sham. 2007. PLINK: A toolset for wholegenome association and population-based linkage analysis. Am. J. Hum. Genet. 81:559-575.

Ren, J. G., Z. Li, and D. B. Sacks. 2007. IQGAP1 modulates activation of B-Raf. Proc. Natl. Acad. Sci. USA 104:10465-10469.

Schnabel, R. D., T. S. Sonstegard, J. F. Taylor, and M. S. Ashwell. 2005. Whole-genome scan to detect QTL for milk production, conformation, fertility and functional traits in two US Holstein families. Anim. Genet. 36:408-416.

Schöpke, K., S. Weidling, R. Pijl, and H. H. Swalve. 2013. Relationships between bovine hoof disorders, body condition traits, and test-day yields. J. Dairy Sci. 96:679-689. http://dx.doi. org/10.3168/jds.2012-5728.

Schrooten, C., H. Bovenhuis, W. Coppieters, and J. A. Van Arendonk. 2000. Whole genome scan to detect quantitative trait loci for conformation and functional traits in dairy cattle. J. Dairy Sci. 83:795-806.

Schwartz, S., W. J. Kent, A. Smit, Z. Zhang, R. Baertsch, R. C. Hardison, D. Haussler, and W. Miller. 2003. Human-mouse alignments with BLASTZ. Genome Res. 13:103-107.

Sogstad, Å. M., O. Østerås, T. Fjeldaas, and A. O. Refsdal. 2007. Bovine claw and limb disorders at claw trimming related to milk yield. J. Dairy Sci. 90:749-759. 
Stone, W.C. 2004. Nutritional approaches to minimize subacute ruminal acidosis and laminitis in dairy cattle. J. Dairy Sci. 87(E. Suppl.):E13-E26.

Swalve, H. H., H. Alkhoder, and R. Pijl. 2008. Estimates of breeding values for sires based on diagnoses recorded at hoof trimming: Relationships with EBV for conformation traits. Interbull Bull. 38:87-90.

Swalve, H. H., H. Alkhoder, and R. Pijl. 2011: Genetic background of disorders of the bovine hoof from data collected at hoof trimming. 16th Symposium and 8th Conference on Lameness in Ruminants, Rotorua, New Zealand. http://www.ivis.org/proceedings/rumlameness/toc.asp.

Swalve, H. H., R. Pijl, M. Bethge, F. Rosner, and M. Wensch-Dorendorf. 2005. Analysis of genetic and environmental effects on claw disorders diagnosed at hoof trimming. Page 29 in Book of Abstracts for 56th Annual Meeting of the EAAP, Uppsala, Sweden. EAAP, Rome, Italy

Urao, N., M. Razvi, J. Oshikawa, R. D. McKinney, R. Chavda, W. F. Bahou, T. Fukai, and M. Ushio-Fukai. 2010. IQGAP1 is involved in post-ischemic neovascularization by regulating angiogenesis and macrophage infiltration. PLOS ONE 5:e13440. http://dx.doi. org/10.1371/journal.pone.0013440.

van der Linde, C. G. de Jong, E. P. C. Koenen, and H. Eding. 2010. Claw health index for Dutch dairy cattle based on claw trimming and conformation data. J. Dairy Sci. 93:4883-4891.

van der Waaij, E. H. M. Holzhauer, E. Ellen, C. Kamphuis, and G. de Jong. 2005. Genetic parameters for claw disorders in Dutch dairy cattle and correlations with conformation traits. J. Dairy Sci. 88:3672-3678.

Vermunt, J. J., and P. R. Greenough. 1994. Review: Predisposing factors of laminitis in cattle. Br. Vet. J. 150:151-164.

Visser, M. B., and C. C. Pollitt. 2012. The timeline of metalloprotease events during oligofructose induced equine laminitis development. Equine Vet. J. 44:88-93.

White, C. D., M. D. Brown, and D. B. Sacks. 2009. IQGAPs in cancer: A family of scaffold proteins underlying tumorigenesis. FEBS Lett. 583:1817-1824.

Zwald, N. R., K. A. Weigel, Y. M. Chang, R. D. Welper, and J. S. Clay. 2004. Genetic selection for health traits using producer- recorded data. I. Incidence rates, heritability estimates and sire breeding values. J. Dairy Sci. 87:4287-4294. 


\title{
Molecular genetics of coat colour variations in White Galloway and White Park cattle
}

\author{
B. Brenig ${ }^{*}$, J. Beck ${ }^{\dagger}$, C. Floren ${ }^{*}$, K. Bornemann-Kolatzki ${ }^{\dagger}$, I. Wiedemann ${ }^{*}$, S. Hennecke ${ }^{*}$, \\ H. Swalve ${ }^{\ddagger}$ and E. Schütz ${ }^{* \dagger}$
}

* Institute of Veterinary Medicine, Burckhardtweg 2, D-37077, Göttingen, Germany

${ }^{\dagger}$ Chronix Biomedical GmbH, Goetheallee 8, D-37073, Göttingen, Germany

${ }^{\ddagger}$ Institute of Agricultural and Nutritional Sciences, Martin-Luther-University HalleWittenberg, Theodor-Lieser-Str. 11, D-06120, Halle/Saale, Germany

\author{
published in \\ Animal Genetics, 44 (4), 450-453 (2013) \\ URL: http://onlinelibrary.wiley.com/doi/10.1111/age.12029/full \\ DOI: 10.1111/age.12029
}




\section{Summary}

White Galloway cattle exhibit three different white coat colour phenotypes, that is, well marked, strongly marked and mismarked. However, mating of individuals with the preferred well or strongly marked phenotype also results in offspring with the undesired mismarked and/or even fully black coat colour. To elucidate the genetic background of the coat colour variations in White Galloway cattle, we analysed four coat colour relevant genes: mast/stem cell growth factor receptor (KIT), KIT ligand (KITLG), melanocortin 1 receptor (MC1R) and tyrosinase (TYR). Here, we show that the coat colour variations in White Galloway cattle and White Park cattle are caused by a KIT gene (chromosome 6) duplication and aberrant insertion on chromosome 29 (Cs29) as recently described for colour-sided Belgian Blue. Homozygous (Cs29/Cs29) White Galloway cattle and White Park cattle exhibit the mismarked phenotype, whereas heterozygous (Cs29/wt29) individuals are either well or strongly marked. In contrast, fully black individuals are characterised by the wild-type chromosome 29. As known for other cattle breeds, mutations in the MC1R gene determine the red colouring. Our data suggest that the white coat colour variations in White Galloway cattle and White Park cattle are caused by a dose-dependent effect based on the ploidy of aberrant insertions and inheritance of the KIT gene on chromosome 29.

White Galloway cattle are robust, polled and docile cattle originating from south-west Scotland. The exact phylogenetic origin of White Galloway cattle is unknown; however, it has been shown that they genetically cluster together with English Longhorn and White Park cattle showing a comparable coat colour phenotype (Decker et al. 2009). White Galloway cattle have long guard hair and fine bottom hair and therefore are optimally adapted to the harsh climate in Scotland. Until today, White Galloway cattle are regarded as a coat colour variation and are not considered as an individual Galloway breed. Three different white coat colour variations have been described, called well marked (black ears, muzzle, eyes and feet; 'colour pointed'; preferred coat colour phenotype), strongly marked (black ears, muzzle, feet and black markings of varying size at additional body parts; similar to well marked with additional pigmentation at 
the torso; second preferred coat colour phenotype) and mismarked (almost no black markings, especially no black markings of the feet; undesired coat colour phenotype) (Fig. 1). As with most cattle breeds, instead of black, markings also can be red coloured or diluted (Schmutz \& Dreger 2012). As the potential causative genes for the white colour variations have not been identified so far, breeding with White Galloway cattle and White Park cattle was puzzling because the exact phenotypical outcome of the progeny was difficult to predict. Especially, the mating of well-marked or strongly marked animals resulted in a certain percentage in completely black animals, which were referred to as 'fully black' White Galloway cattle.

Hitherto, it is known that coat colour in cattle is controlled mainly by at least eight different genes and their corresponding alleles, that is, ASIP (agouti), TYR (albinism), TYRP1 (brown), KIT (colour sided, dominant white), KITLG (roan), PMEL (dilution), MC1R (extension) and MITF (white spotting) (Charlier et al. 1996; Nonneman et al. 1996; Reinsch et al. 1999; Seitz et al. 1999; Berryere et al. 2003; Guibert et al. 2004; Schmutz et al. 2004; Mohanty et al. 2008; Fontanesi et al. 2010, 2012; Philipp et al. 2011; Albrecht et al. 2012; Schmutz \& Dreger 2012).

Recently, it has been shown that a duplication of the KIT gene located on chromosome 6 and its aberrant insertion on chromosome 29 (Cs29) results in the white coat colour phenotype 'colour sided' in Belgian Blue and other cattle breeds (Durkin et al. 2012). A secondary re-insertion event of the duplicated KIT on chromosome 6 (Cs6) is responsible for the similar phenotype in Brown Swiss (Durkin et al. 2012). In this study, it has also been shown that Cs6/Cs6 homozygous animals differ in the extent of pigmentation compared to heterozygous Cs6/wt6 animals.

To elucidate the origin of coat colour variations of White Galloway cattle, we analysed four of the potentially involved genes, that is, KIT, KITLG, TYR and MC1R. The coding regions, including splice acceptor and donor sites, were amplified and sequenced. Several SNPs were detected; however, none of the variants showed an association with the White Galloway cattle coat colours with the exception of the previously described MC1R mutations resulting in red coat colour (Rouzaud et al. 2000; Kriegesmann et al. 2001). As shown in Table S1, the majority of the 184 animals genotyped for MC1R alleles harboured the e2/e2, ED/ED alleles in combination with the heterozygous BTA29 
(Cs29/ wt29) ( $n=105$; well or strongly marked), followed by animals with the homozygous Cs29/Cs29 ( $n=38$; mismarked) or wt29/wt29 ( $n=23$; fully black) genotypes.

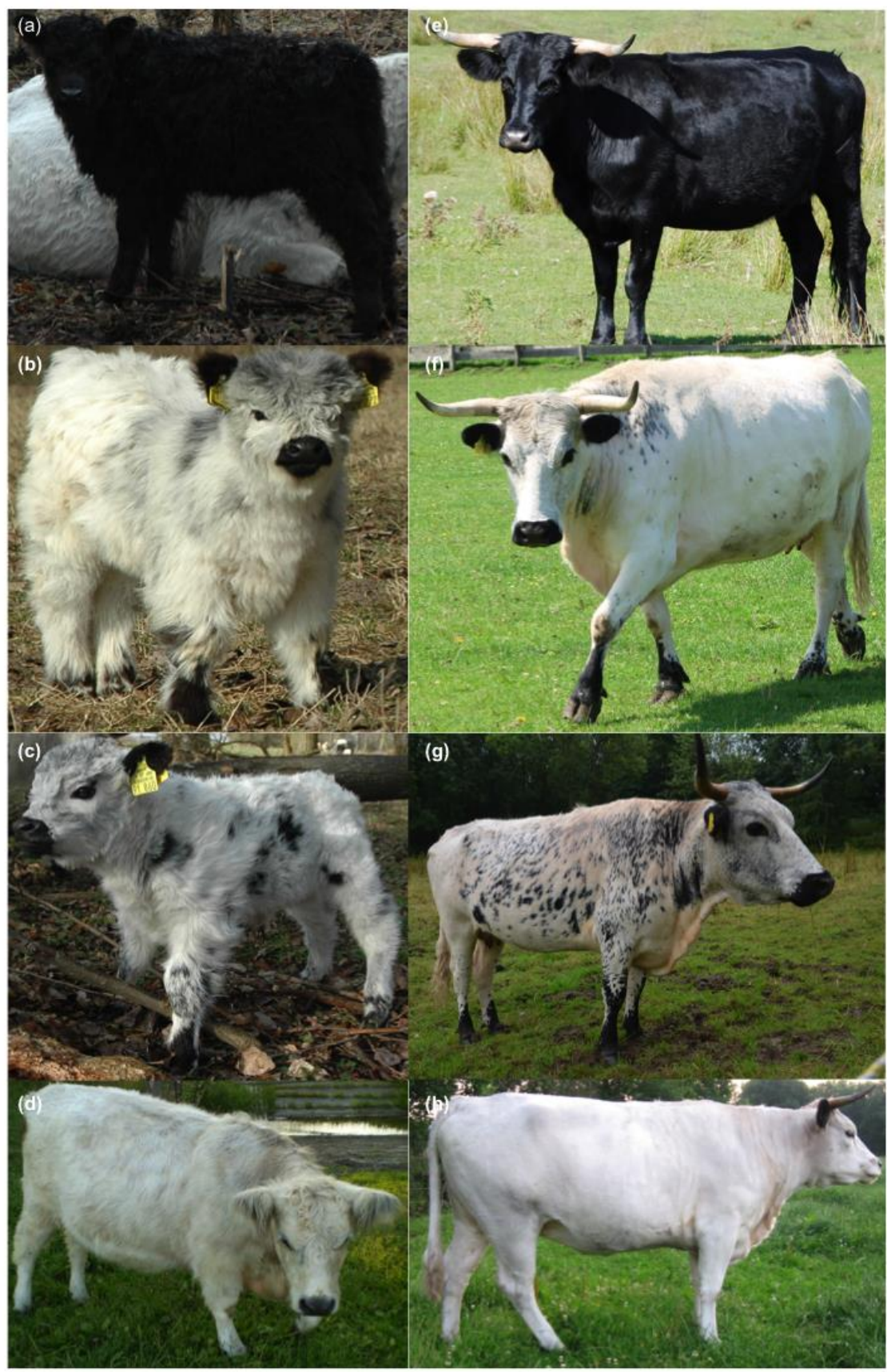

Fig. 1 White Galloway cattle and White Park cattle KIT genotypes and corresponding coat colours. a-d) White Galloway cattle: a) fully black calf ( $\left.w t_{29} / w_{29}\right)$; b) well marked calf $\left(\mathrm{Cs}_{29} / \mathrm{wt}_{29}\right) ; \mathrm{c}$ ) strongly marked calf $\left(\mathrm{Cs}_{29} / \mathrm{wt}_{29}\right)$; d) mismarked cow $\left(\mathrm{Cs}_{29} / \mathrm{Cs}_{29}\right)$; e-h) White Park cattle: e) fully black cow ( $\left.w t_{29} / w t_{29}\right)$; f) well marked cow $\left(\mathrm{Cs}_{29} / \mathrm{wt}_{29}\right)$; g) strongly marked cow $\left.\left(\mathrm{Cs}_{29} / \mathrm{wt}_{29}\right) ; \mathrm{h}\right)$ mismarked cow $\left(\mathrm{Cs}_{29} / \mathrm{Cs}_{29}\right)$. 
Two animals were homozygous for the E+ allele and therefore showed a red coat colour.

As none of the SNPs detected in the potential causative genes were associated with the white coat colour phenotypes, the recently described KIT gene duplication and aberrant insertion on BTA29 and/or re-insertion on BTA6 were analysed by FISH (fluorescence in situ hybridisation), whole-genome sequencing and PCR-based genotyping of the insertion break points (Durkin et al. 2012).

Here, we show that the white coat colour variations of White Galloway cattle and White Park cattle can be explained by the recently described duplication and aberrant insertion of the KIT gene on chromosome 29 (Durkin et al. 2012). Well-marked and strongly marked animals are heterozygous Cs29/wt29, whereas mismarked animals are homozygous Cs29/Cs29. Further, single nucleotide variations did not show any association with the different white phenotypes. As shown in Fig. S1, KIT gene signals were detected on both chromosomes BTA6 and BTA29 in White Galloway cattle by FISH analysis. The KIT-BAC clone also generated weaker signals on BTA3, which were visible in both phenotypes used for FISH analysis, that is, fully black and well marked. End sequencing showed that the BAC clone was not chimeric (data not shown). The additional signals on BTA3 might be due to unspecific cross-hybridisation of the BAC. However, we cannot explain the exact reason for these signals currently.

The duplication of the region BTA6 (72.6M-73.1M) was confirmed in the White Galloway cattle sample, compared to a Black Galloway control using the whole-genome sequencing approach. The result of the copy number variation seeking using CNV-Seq for the suggested region on BTA6 is shown in Fig. S2. The data were inspected for the translocation break points on BTA6 and BTA29. The paired end reads showed one insertion at the upstream insertion point, whereas read pairs spanning the downstream insertion were not detected due to a low local coverage at the suggested region. The above-mentioned insertion is shown in the INTEGRATIVE GENOMICS VIEWER (IGV) picture (Fig. S3) (Robinson et al. 2011; Thorvaldsdottir et al. 2012).

The aberrant KIT gene insertion on BTA29 and re-insertion on BTA6 were genotyped in 178 animals. As outlined in Table1 and Table S2, mismarked White Galloway cattle are homozygous for the KIT gene insertion on BTA29 (Cs29/Cs29), whereas well-marked and strongly marked White Galloway cattle are heterozygous (Cs29/ wt29). Fully black 
White Galloway cattle exhibit the wild-type BTA29 chromosomes. None of the White Galloway cattle carried the Cs6 alleles as shown in Table S2. The molecular cause for the differences in the extent of black markings in well-marked and strongly marked White Galloway cattle cannot be explained at the moment. These differences might be due to the influence of additional genes or incomplete penetrance. However, the differences between well-marked or strongly marked and mismarked animals seem to be the result of a dose-dependent effect of the KIT gene copy number in the genome.

Table 1 KIT gene alleles and resulting marking patterns of White Galloway cattle ${ }^{\text {a) }}$

\begin{tabular}{lllllll}
\hline & \multicolumn{5}{c}{$\begin{array}{l}\text { BTA29 } \\
(\mathrm{wt})\end{array}$} & \multicolumn{2}{l}{$\mathrm{BTA29}\left(\mathrm{Cs}_{29}\right)$} & & $\mathrm{BTA6}\left(\mathrm{Cs}_{6}\right)$ \\
\cline { 2 - 7 } Marking patterns & $\mathrm{n}$ & $\mathrm{ab} \mathrm{b}^{\mathrm{b})}$ & $\mathrm{aD}^{\mathrm{b})}$ & $\mathrm{AE}^{\mathrm{b})}$ & $\mathrm{Cb}^{\mathrm{b})}$ & $\mathrm{gB}^{\mathrm{b})}$ \\
\hline fully black & 27 & 27 & 0 & 0 & 0 & 0 \\
well marked & 104 & 104 & 104 & 104 & 104 & 0 \\
strongly marked & 10 & 10 & 10 & 10 & 10 & 0 \\
mismarked & 37 & 0 & 37 & 37 & 37 & 0 \\
\hline
\end{tabular}

a) The marking pattern of one animal could not be determined accurately, and therefore, this animal was omitted from further analyses. $\mathrm{Cs}_{29}$ : abberant insertion of KIT gene on BTA29. $\mathrm{wt}_{29}$ : wild-type BTA29.

The Cs29 and Cs6 break points were also analysed in Charolais, Chianina, Hereford, Blonde d'Aquitaine, Limousin, Highland cattle, German Angus, Braunvieh, Glan cattle, Simmental, Aberdeen Angus, Gelbvieh, Angeln cattle, Welsh Black, Piedmontese, Holstein Friesian and Aubrac. All analysed individuals showed the homozygous wild-type chromosome 29. We also analysed 64 White Park cattle. In these animals, we detected the same three different genotypes that were present in White Galloway cattle, that is, $n=13$ wt29/wt29, $n=20$ Cs29/wt29 and $n=31$ Cs29/Cs29. As shown in Fig. 1, all corresponding coat colour phenotypes (well marked, strongly marked, mismarked and fully black) can be distinguished and are phenotypically almost identical between both breeds.

In summary, in White Galloway cattle and White Park cattle, the four different coat colour phenotypes can be clearly attributed to the duplicated and aberrantly inserted KIT gene on BTA29. The extent of black marking is thereby dependent on a dose effect based on the number of duplicated and inserted KIT gene alleles. 


\section{Acknowledgments}

The authors are grateful to M. Bening, S. Beny, G. Bernasconi and all other White Galloway cattle breeders for providing blood samples. Our thanks are extended to W. Wemheuer for taking blood samples from White Galloway cattle at different farms. M. Scharfenstein, S. Loos, L. Jüttner, J. Lindemann and S. Pach are thanked for expert technical assistance. J. Wienberg (Chronobios) is thanked for the FISH analysis. Wildpark Schorfheide, E. Fandrey (Arche Warder), S. von Hedemann-Heespen (Gut Deutsch-Nienhof), Family Derjong, H. Kindel, A. Gallun and U.G.W. Hesse (Zuchtgemeinschaft Müller-Hesse) are acknowledged for providing pictures of White Galloway cattle or White Park cattle.

\section{References}

Albrecht E., Komolka K., Kuzinski J. \& Maak S. (2012) Agouti revisited: transcript quantification of the ASIP gene in bovine tissues related to protein expression and localization. PLOS ONE 7, e35282.

Berryere T.G., Schmutz S.M., Schimpf R.J., Cowan C.M. \& Potter J. (2003) TYRP1 is associated with dun coat colour in Dexter cattle or how now brown cow? Animal genetics 34, 169-75.

Charlier C., Denys B., Belanche J.I., Coppieters W., Grobet L., Mni M., Womack J., Hanset R. \& Georges M. (1996) Microsatellite mapping of the bovine roan locus: a major determinant of White Heifer disease. Mammalian Genome 7, 138-42.

Decker J.E., Pires J.C., Conant G.C. et al. (2009) Resolving the evolution of extant and extinct ruminants with high-throughput phylogenomics. Proceedings of the National Academy of Sciences of the United States of America 106, 18644-9.

Durkin K., Coppieters W., Drogemuller C. et al. (2012) Serial translocation by means of circular intermediates underlies colour sidedness in cattle. Nature 482, 81-4.

Fontanesi L., Tazzoli M., Russo V. \& Beever J. (2010) Genetic heterogeneity at the bovine KIT gene in cattle breeds carrying different putative alleles at the spotting locus. Animal Genetics 41, 295-303.

Fontanesi L., Scotti E. \& Russo V. (2012) Haplotype variability in the bovine MITF gene and association with piebaldism in Holstein and Simmental cattle breeds. Animal Genetics $43,250-6$. 
Guibert S., Girardot M., Leveziel H., Julien R. \& Oulmouden A. (2004) Pheomelanin coat colour dilution in French cattle breeds is not correlated with the TYR, TYRP1 and DCT transcription levels. Pigment Cell Research 17, 337-45.

Kriegesmann B., Dierkes B., Leeb T., Jansen S. \& Brenig B. (2001) Two breed-specific bovine MC1-R alleles in Brown Swiss and Saler breeds. Journal of Dairy Science 84, 1768-71.

Mohanty T.R., Seo K.S., Park K.M., Choi T.J., Choe H.S., Baik D.H. \& Hwang I.H. (2008) Molecular variation in pigmentation genes contributing to coat colour in native Korean Hanwoo cattle. Animal Genetics 39, 550-3.

Nonneman D., Shibuya H. \& Johnson G.S. (1996) A BstUI PCR/ RFLP in the bovine tyrosinase-related protein-1 (TYRP1) gene. Animal Genetics 27, 218-9.

Philipp U., Lupp B., Momke S., Stein V., Tipold A., Eule J.C., Rehage J. \& Distl O. (2011) A MITF mutation associated with a dominant white phenotype and bilateral deafness in German Fleckvieh cattle. PLoS ONE 6, e28857.

Reinsch N., Thomsen H., Xu N. et al. (1999) A QTL for the degree of spotting in cattle shows synteny with the KIT locus on chromosome 6. The Journal of Heredity 90, 62934.

Robinson J.T., Thorvaldsdottir H., Winckler W., Guttman M., Lander E.S., Getz G. \& Mesirov J.P. (2011) INTEGRATIVE GENOMICS VIEWER. Nature Biotechnology 29, 24-6.

Rouzaud F., Martin J., Gallet P.F., Delourme D., Goulemot-Leger V., Amigues Y., Menissier F., Leveziel H., Julien R. \& Oulmouden A. (2000) A first genotyping assay of French cattle breeds based on a new allele of the extension gene encoding the melanocortin-1 receptor (MC1R). Genetics, Selection, Evolution: GSE 32, 511-20.

Schmutz S.M. \& Dreger D.L. (2012) Interaction of MC1R and PMEL alleles on solid coat colors in Highland cattle. Animal Genetics 44, 9-13.

Schmutz S.M., Berryere T.G., Ciobanu D.C., Mileham A.J., Schmidtz B.H. \& Fredholm M. (2004) A form of albinism in cattle is caused by a tyrosinase frameshift mutation. Mammalian Genome 15, 62-7.

Seitz J.J., Schmutz S.M., Thue T.D. \& Buchanan F.C. (1999) A missense mutation in the bovine MGF gene is associated with the roan phenotype in Belgian Blue and Shorthorn cattle. Mammalian Genome 10, 710-2.

Thorvaldsdottir H., Robinson J.T. \& Mesirov J.P. (2012) INTEGRATIVE GENOMICS VIEWER (IGV): high-performance genomics data visualization and exploration. Briefings in Bioinformatics, DOI: 10.1093/ bib/bbs017. 


\section{Supporting information}

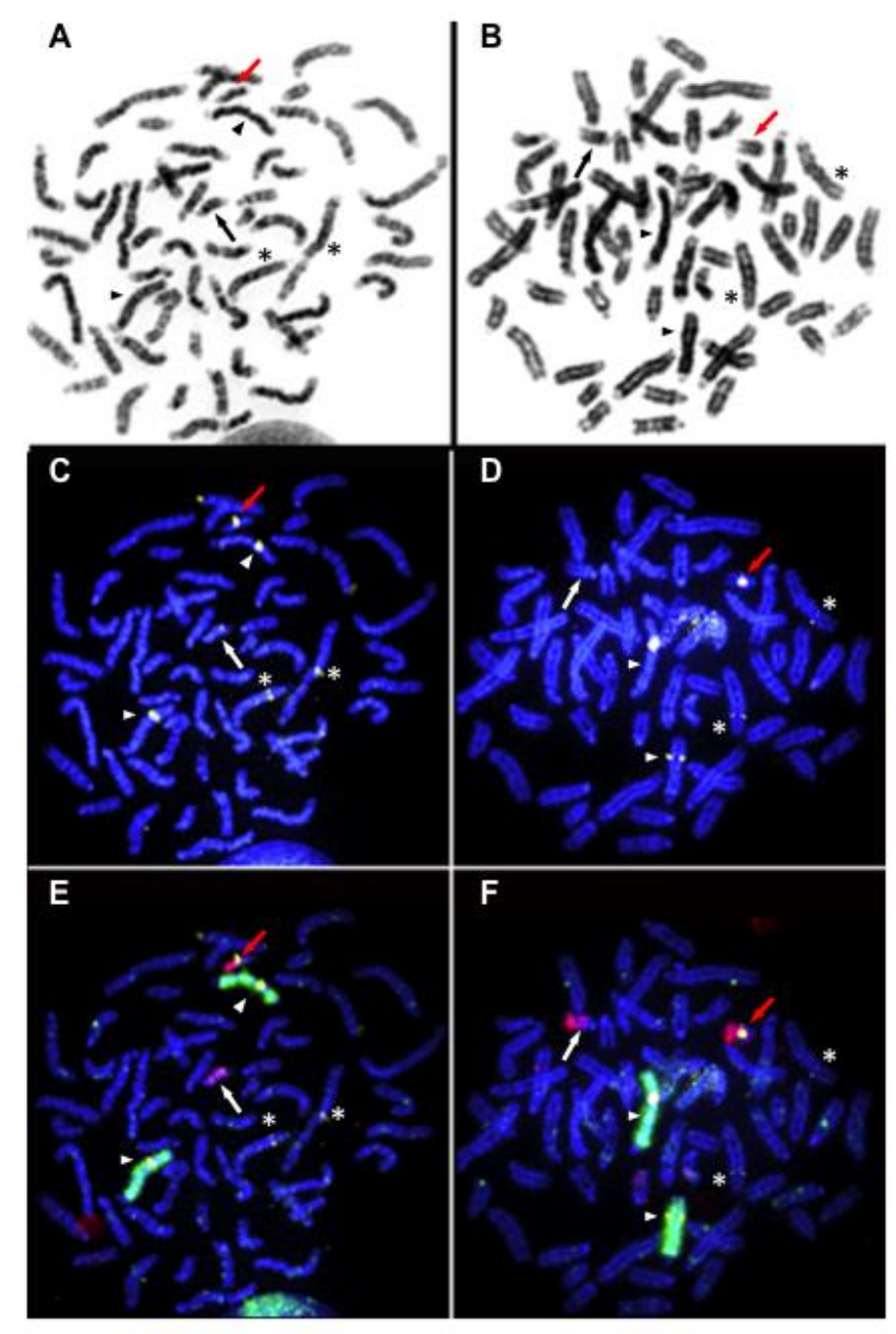

Figure S1 FISH analysis of a well marked White Galloway cattle using KIT gene BAC clone $\mathrm{CH} 240-63 \mathrm{G} 14$

Chromosome preparations were made from standard PHA stimulated blood cultures. Blood cultures were incubated for 48 and $72 \mathrm{~h}$, respectively. Chromosome preparations were made according to standard cytogenetic techniques. About $30 \mu \mathrm{l}$ of cell suspensions were dropped on a glass slide, air dried and baked at $50^{\circ} \mathrm{C}$ for several hours.

BAC clone CH240-63G14 (CHORI-240, bovine (male) BAC library) harbouring the bovine KIT gene (exons 1-21, NW_001495197) and cloned in pTARBAC1.3, was used as probe (http://bacpac.chori.org/home.htm). BAC DNA was prepared using the Qiagen Plasmid Maxi kit according to the manufacturer's instructions. $1 \mu \mathrm{l}$ of the BAC DNA (about 3.6 $\mu \mathrm{g})$ was labelled by a standard nick translation procedure $\left(90 \mathrm{~min}, 15^{\circ} \mathrm{C}\right)$. Digoxigenin (Roche Diagnostics) was used as labelled dUTP at the concentration of $20 \mu \mathrm{M}$. Probe 
length was analysed on a $1 \%$ agarose gel. The probe showed the optimal average length of about $300 \mathrm{bp}$ after nick translation.

About 10 ng BAC DNA were combined with the hybridisation buffer (50\% formamide, 2xSSC, $10 \%$ Dextransulfate), applied to the chromosome slides, mounted with a cover slip and sealed with rubber cement. Slide and probe were denatured together on a hot plate at $72^{\circ} \mathrm{C}$ for 3 minutes. Hybridisation was done over night at $37^{\circ} \mathrm{C}$ in a humid chamber.

After hybridization the cover slip was carefully removed and the slide was washed in $2 x S S C$ for $8 \mathrm{~min}$. Slides were then incubated at $70^{\circ} \mathrm{C}$ in $0.4 x S S C / 0.1 \%$ Tween for $1 \mathrm{~min}$. The slide was then washed shortly in $4 \times \mathrm{SSC} / 0.1 \% \mathrm{~T}$ ween/5\%BSA at room temperature. Probe detection used an anti-Digoxigenin antibody coupled with rhodamin (Roche). Detection with the antibody was for $30 \mathrm{~min}$ at $37^{\circ} \mathrm{C}$ in $4 \times \mathrm{xSC} / 0.1 \% \mathrm{~T}$ ween/5\%BSA followed by washes in $4 \times S S C / 0.1 \%$ Tween two times for $10 \mathrm{~min}$. Slides were then stained in DAPI (4',6-Diamidino-2-phenylindole) for $10 \mathrm{~min}$. For microscopy the slide was mounted in antifade solution (Vectashield).

Chromosome paints specific for BTA6 (labelled Biotin, detected with Avidin Cy5), BTA29 (labelled TAMRA), and BTA1/3 (labelled with Biotin) were used. All probes were derived from the sheep homologs: BTA3-OAR6, BTA6-OAR6, BTA29-OAR21. Note: OAR paint1 paints BTA chromosomes 3 and 1. Painting probes for chromosomes BTA6 and 29 and BAC probe were hybridized together in a first experiment. The painting probe for BTA3 was hybridized in a second experiment on the same slide.

Slide and probe were denatured together on a hot plate at $72^{\circ} \mathrm{C}$ for 3 minutes. Hybridization was done over night at $37^{\circ} \mathrm{C}$ in a humid chamber. Washing steps were the same as for the BAC hybridization.

The in situ hybridisation signals were analysed on a Zeiss Axioplan II microscope. Each image plain was recorded separately with a b/w CCD camera (SenSys, Photometrics). Chromosomes and FISH signals were then displayed in false colours and images were merged on the computer. Camera control, image capture and merging were done with SmartCaptureX software (Digital Scientific, Cambridge, UK).

The figure shows two of 20 representative metaphases that were analysed. Panels A), C), E), and B), D), F) show the same metaphases, respectively. Panels a) and b) depict chromosome banding. In panels c) and d) signals after FISH using $\mathrm{CH} 240-63 \mathrm{G} 14$ can be seen. Panels $\mathrm{E}$ ) and F) show signals after hybridization with heterologous paint probes, i.e. BTA 6 (green) and BTA29 (red). Arrow heads indicate the location on BTA6. The white arrow indicates the wild type and the red arrow the mutant BTA29. Asterisks indicate the cross-hybridization with BTA3. 


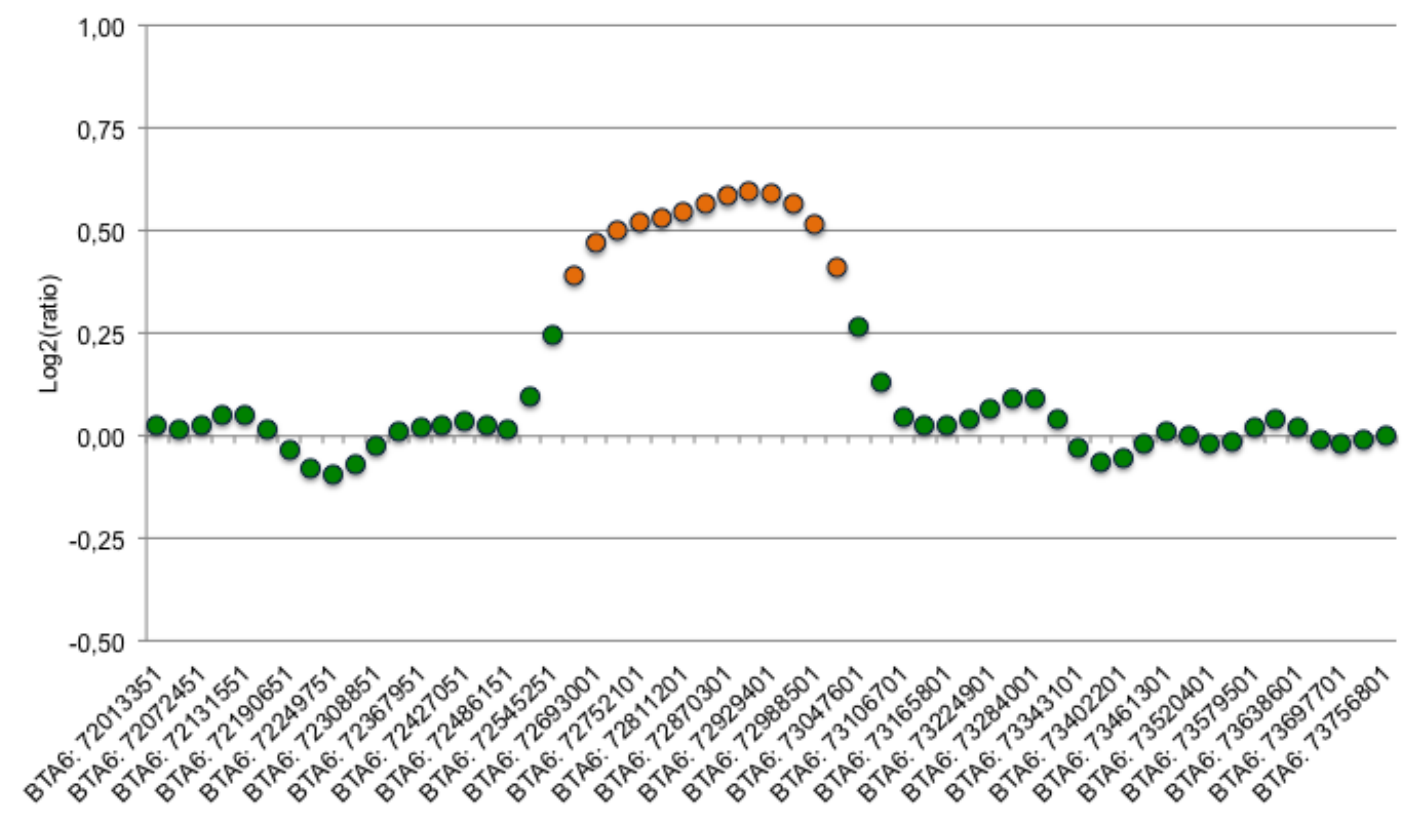

Figure S2 Log(2)ratio of suggested region on BTA6

DNA from a Black Galloway (control) and White Galloway cattle (well marked) was subjected to whole genome sequencing. Briefly, $1 \mu \mathrm{g}$ DNA was used for ultrasonic shearing to an average of $500 \mathrm{nt}$ in length, using a Covaris sonicator (Model S220). The resulting fragments were end-repaired and the Illumina sequencing adaptors (TruSeqV2) were end-ligated according to the manufactures recommendations. The resulting fragment libraries were then used for paired-end sequencing on an Illumina HiSeq system. About 71 million paired reads were matched to the bovine genome database for the White Galloway cattle and about 65 million for the Black Galloway control.

The yielded reads were aligned to the bovine genome (Btau 4.0) using the Casava software suite (Illumina) and default parameters. To evaluate the suspected structural difference, the binary alignment maps were used as input for CNV-Seq, a R-program written to detect copy number variations between two samples by depth of coverage analysis (Xie \& Tammi, 2009). The resulting output data consisting of $\log (2)$ transformed globally normalized ratios of read counts per bins (approx. 60k nt with 30k sliding window), was cleaned for low coverage and subsequently subjected to a ParzenRosenblatt smoothing (Rosenblatt, 1956; Parzen, 1962). The significance of the ratio for each bin was estimated by Z-transformation according to (Hinkley, 1969; Hayya et al., 1975) for correlated data and calculated from Gaussian distribution. Any as such calculated $p$-value was corrected for each chromosome by the method for controlling the false discovery rate as suggested by Benjamini and Hochberg (Ferreira \& Zwinderman, 2006), based on a 99\% value. Orange filled circles depict values with significant deviations from zero. 


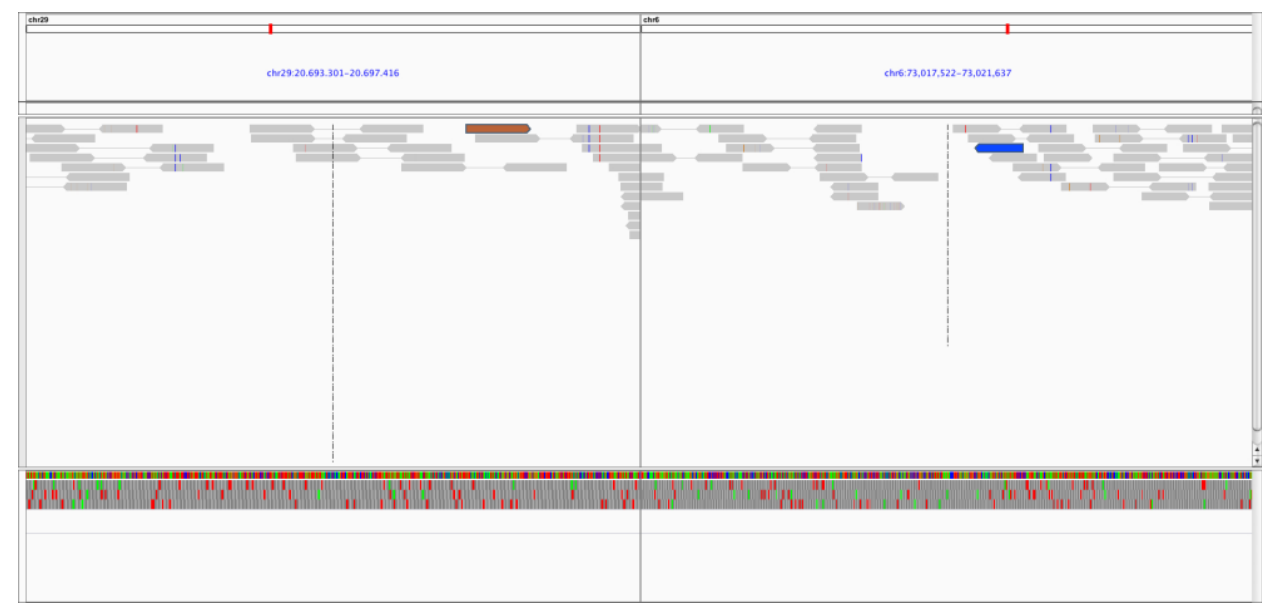

Figure S3 IGV display of the mapped paired-end reads around the insertion site BTA6 > BTA29

The aberrantly mapping read pair that spans the ?D breakpoint between BTA29 and BTA6 is highlighted in brown and blue.

Table S1: Detection of MC1R and KIT alleles in White Galloway cattle

\begin{tabular}{|c|c|c|c|}
\hline Coat colour & MC1R genotype & BTA29 & Number \\
\hline \multirow[t]{12}{*}{ black } & $\mathrm{e}^{2} / \mathrm{e}^{2}, \mathrm{E}^{\mathrm{D}} / \mathrm{E}^{\mathrm{D}}$ & $w t_{29} / w t_{29}$ & 23 \\
\hline & & $\mathrm{Cs}_{29} / \mathrm{wt}_{29}$ & 105 \\
\hline & & $\mathrm{Cs}_{29} / \mathrm{Cs}_{29}$ & 38 \\
\hline & $\mathrm{e}^{1} / \mathrm{e}^{2}, \mathrm{E}^{\mathrm{D}} / \mathrm{E}^{\mathrm{D}}$ & $w t_{29} / w t_{29}$ & 2 \\
\hline & & $\mathrm{Cs}_{29} / \mathrm{wt}_{29}$ & 5 \\
\hline & & $\mathrm{Cs}_{29} / \mathrm{Cs}_{29}$ & 0 \\
\hline & $e^{1} / e^{2}, E^{D} / E^{+}$ & $w t_{29} / w t_{29}$ & 2 \\
\hline & & $\mathrm{Cs}_{29} / \mathrm{wt}_{29}$ & 3 \\
\hline & & $\mathrm{Cs}_{29} / \mathrm{Cs}_{29}$ & 1 \\
\hline & $\mathrm{e}^{2} / \mathrm{e}^{2}, \mathrm{E}^{\mathrm{D}} / \mathrm{E}^{+}$ & $w t_{29} / w t_{29}$ & 1 \\
\hline & & $\mathrm{Cs}_{29} / \mathrm{wt}_{29}$ & 1 \\
\hline & & $\mathrm{Cs}_{29} / \mathrm{Cs}_{29}$ & 1 \\
\hline \multirow[t]{2}{*}{ red } & $e^{1} / e^{1}, E^{+} / E^{+}$ & $w t_{29} / w t_{29}$ & 1 \\
\hline & $e^{1} / e^{2}, E^{+} / E^{+}$ & $w t_{29} / w t_{29}$ & 1 \\
\hline
\end{tabular}

a) genotypes according to (Adalsteinsson et al., 1995; Joerg et al., 1996; Rouzaud et al., 2000; Kriegesmann et al., 2001) 
Table S2: KIT gene alleles and resulting marking patterns of White Galloway cattle ${ }^{\text {a) }}$

\begin{tabular}{|c|c|c|c|c|c|c|}
\hline \multirow[b]{2}{*}{ Marking patterns } & \multirow[b]{2}{*}{$\mathrm{n}$} & \multirow{2}{*}{$\begin{array}{l}\text { BTA29 } \\
\text { (wt) } \\
\alpha \beta^{\text {b) }}\end{array}$} & \multicolumn{3}{|c|}{ BTA29 (Cs 29$)$} & \multirow{2}{*}{$\begin{array}{c}\text { BTA6 }\left(\mathrm{Cs}_{6}\right) \\
\gamma \mathrm{B}^{\mathrm{b})}\end{array}$} \\
\hline & & & $\alpha D^{b)}$ & $A E^{b)}$ & $C \beta^{\mathrm{b})}$ & \\
\hline fully black & 27 & 27 & 0 & 0 & 0 & 0 \\
\hline well marked & 104 & 104 & 104 & 104 & 104 & 0 \\
\hline strongly marked & 10 & 10 & 10 & 10 & 10 & 0 \\
\hline mismarked & 37 & 0 & 37 & 37 & 37 & 0 \\
\hline
\end{tabular}

a) The phenotype of one animal could not be determined accurately and therefore this animal was omitted from further analyses. b) Breakpoints were determined according to (Durkin et al., 2012). 


\title{
Species identification and quantification in meat and meat products using Droplet Digital PCR (ddPCR)
}

\author{
C. Floren ${ }^{a}$, I. Wiedemann ${ }^{a}$, B. Brenig ${ }^{a}$, E. Schütz ${ }^{a, b}$ and J. Beck ${ }^{b}$ \\ a Institute of Veterinary Medicine, University of Göttingen, Burckhardtweg 2, 37077 \\ Göttingen, Germany

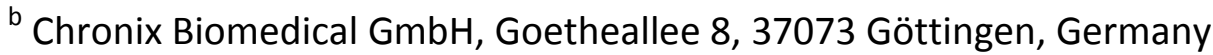

submitted to

Food Chemistry 


\begin{abstract}
Species fraud and product mislabeling in processed food, albeit not being a direct health issue, often results in consumer distrust. Therefore methods for quantification of undeclared species are needed. Targeting mitochondrial DNA, e.g. CYTB gene, for species quantification is unsuitable, due to a five-fold inter-tissue variation in mtDNA content per cell resulting in either an under- $(-70 \%)$ or overestimation $(+160 \%)$ of species DNA contents. Here, we describe a reliable two-step droplet digital PCR (ddPCR) assay targeting the nuclear F2 gene for precise quantification of cattle, horse, and pig meat in processed foods. The ddPCR assay is advantageous over qPCR showing a limit of quantification (LOQ) and detection (LOD) in different meat products of $0.01 \%$ and $0.001 \%$, respectively. No cross-reactivity was detected in 14 different species. Hence, determining F2 in food by ddPCR can be recommended for quality assurance and control in production systems.
\end{abstract}

